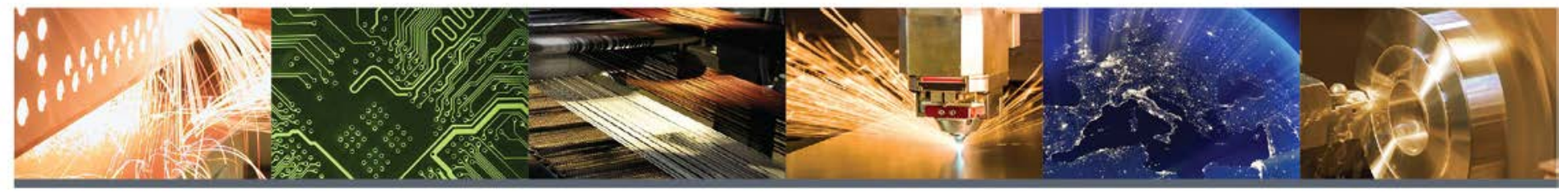

\title{
Refrigerants: Market Trends and Supply Chain Assessment
}

Chuck Booten, Scott Nicholson, Margaret Mann National Renewable Energy Laboratory

Omar Abdelaziz

Oak Ridge National Laboratory

CEMAC is operated by the Joint Institute for Strategic Energy Analysis for the U.S. Department of Energy's Clean Energy Manufacturing Initiative.

\section{Technical Report}

NREL/TP-5500-70207

February 2020

Contract No. DE-AC36-08GO28308 


\section{Refrigerants: Market Trends and Supply Chain Assessment}

Chuck Booten, Scott Nicholson, Margaret Mann National Renewable Energy Laboratory

Omar Abdelaziz

Oak Ridge National Laboratory

Clean Energy Manufacturing Analysis Center

15013 Denver West Parkway

Golden, CO 80401

$303-275-3000$
CEMAC is operated by the Joint Institute for Strategic Energy Analysis for the U.S. Department of Energy's Clean Energy Manufacturing Initiative.

\section{Technical Report}

NREL/TP-5500-70207

February 2020

Contract No. DE-AC36-08G028308 


\section{NOTICE}

This work was authored in part by the National Renewable Energy Laboratory, operated by Alliance for Sustainable Energy, LLC, for the U.S. Department of Energy (DOE) under Contract No. DE-AC3608G028308. Funding provided by the U.S. Department of Energy Office of Energy Efficiency and Renewable Energy Building Technologies Office. The views expressed herein do not necessarily represent the views of the DOE or the U.S. Government.

Available electronically at SciTech Connect: http:/www.osti.gov/scitech

Available for a processing fee to U.S. Department of Energy and its contractors, in paper, from:

U.S. Department of Energy

Office of Scientific and Technical Information

P.O. Box 62

Oak Ridge, TN 37831-0062

OSTI http://www.osti.gov

Phone: 865.576.8401

Fax: 865.576.5728

Email: reports@osti.gov

Available for sale to the public, in paper, from:

U.S. Department of Commerce

National Technical Information Service

5301 Shawnee Road

Alexandria, VA 22312

NTIS http://www.ntis.gov

Phone: 800.553 .6847 or 703.605 .6000

Fax: 703.605.6900

Email: orders@ntis.gov

Cover Photos: (left to right) iStock 2225189; iStock 16687273; Oak Ridge National Laboratory; iStock 24304597; iStock 26005993; iStock 2069560

NREL prints on paper that contains recycled content. 


\section{Acknowledgments}

This work was funded through the U.S. Department of Energy Building Technologies Office. The authors would like to thank Karma Sawyer, Antonio Bouza, and Sven Mumme for their support of this project. 


\section{Nomenclature and Acronyms}

BSRIA

CFC

CEMAC

ECHA

EPA

GWP

HCFC

HF

HFC

HFO

HVAC

IGSD

kton

MAC

$\mathrm{MMT} \mathrm{CO}_{2} \mathrm{e}$

NREL

PTFE

ODS

OECD

$R \& D$

REACH

U.S. ITC

WTO

XPS
Building Services Research and Information Association

chlorofluorocarbon

Clean Energy Manufacturing Analysis Center

European Chemical Agency

U.S. Environmental Protection Agency

global warming potential

hydrochlorofluorocarbon

hydrofluoric acid

hydrofluorocarbon

hydrofluoroolefin

heating, ventilating, and air conditioning

Institute for Governance and Sustainable Development

one thousand metric tons

mobile air conditioning

million metric tons of carbon dioxide equivalent

National Renewable Energy Laboratory

polytetrafluoroethylene

ozone-depleting substance

Organization of Economic Coordination and Development

research and development

Registration, Evaluation, Authorization and Restriction of Chemicals

U.S. International Trade Commission

World Trade Organization

extruded polystyrene 


\section{Executive Summary}

The National Renewable Energy Laboratory (NREL), in partnership with Oak Ridge National Laboratory, under the Clean Energy Manufacturing Analysis Center (CEMAC ) ${ }^{1}$ umbrella, assessed the current state of existing and low-global-warming-potential (GWP) refrigerants for major end-use applications, including heating, ventilating, and air conditioning (HVAC) and those outside of the HVAC industry. The project incorporated a market overview and supply chain assessment to determine the production, distribution, consumption, costs, and potential operating efficiency impacts of new and alternative refrigerants entering the market. Market trends and ongoing research are also documented. This work supplements other U.S. Department of Energy efforts to support research activities on refrigerants and their applications, including a refrigerant research and development roadmap (Goetzler et al. 2014) and an outlook into global air-conditioning markets (Goetzler et al. 2016).

\section{Key Objectives of This Report:}

- Document existing refrigerant global supply chain, including production and distribution, usage, and intellectual property.

- Analyze major current end uses of refrigerants. Forward-looking estimates will have an emphasis on low-GWP refrigerant applications and the implications of scaling-up production and usage of the refrigerants.

- Estimate and document production and development of alternative refrigerants.

- Support U.S. Department of Energy's Building Technologies Office goals of increasing the deployment of energy efficiency technologies through evaluation of market and cost barriers.

The global refrigerants market is large and is projected to grow rapidly as developing countries in warmer areas of the globe continue to grow, become more affluent, and consume more and more air conditioning, refrigeration (Goetzler et al. 2016), foam, and aerosol products and services (Grand View Research 2017). Innovation in this global refrigerants market is often led by major U.S. companies; however, the markets for their products are global. Understanding this global market landscape is a critical component for maintaining U.S. leadership in innovation and manufacturing in a strategically important industry.

"The U.S. chemical industry is the major innovator in creating the replacements [for hydrofluorocarbons]. This is a matter of industrial policy for the United States so our manufacturers have access to these huge growing export markets." (E\&E News 2017).

\footnotetext{
${ }^{1}$ www.manufacturingcleanenergy.org
} 


\section{Key Findings From This Report:}

- Refrigerant markets are global and growing rapidly.

o 2010-2050: 4.5x increase in air conditioning for non-Organization of Economic Coordination and Development (OECD) countries, and 1.3x increase for OECD countries.

o Regional, national, and international commitments will create large market opportunities for innovative refrigerants and products that use them.

- U.S.-based companies are leaders in intellectual property and production of advanced refrigerants.

- China has aggressively expanded production of conventional refrigerants for domestic use as well as export.

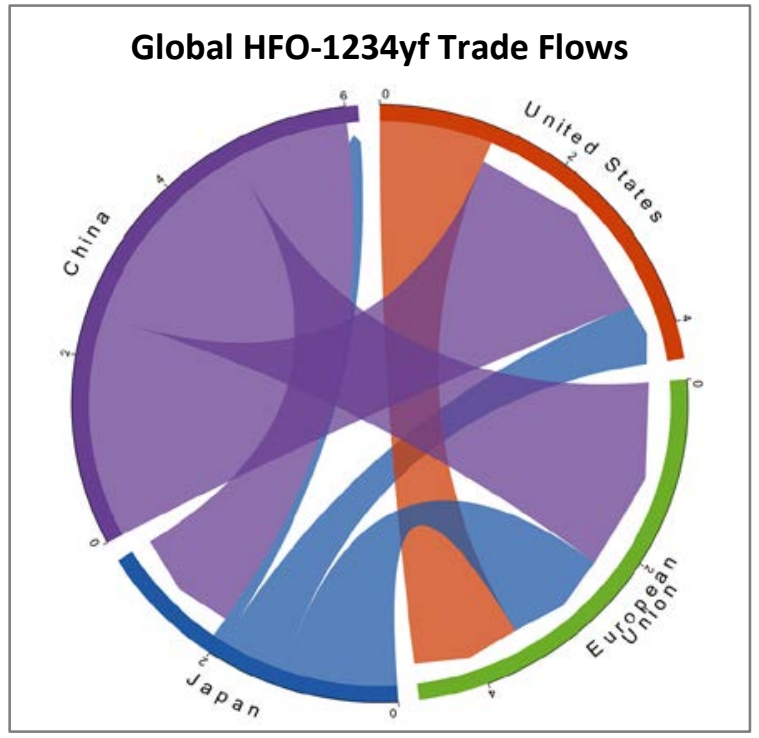

Figure ES-1. Global HFO-1234yf trade flows in 2015 (ktons)

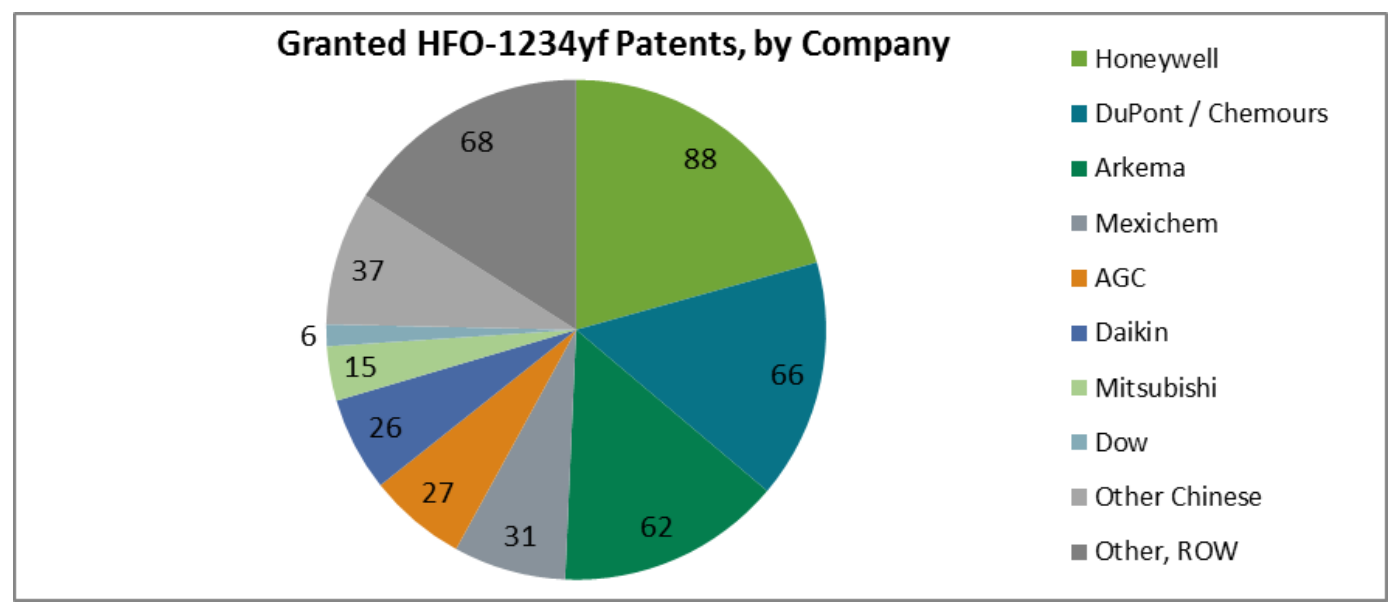

Figure ES-2. Granted patents related to HFO-1234yf 
- Refrigerants are used in large quantities for more than just cooling.

- Foam production, aerosols, fire suppression, and chemical production are important end uses for these materials.

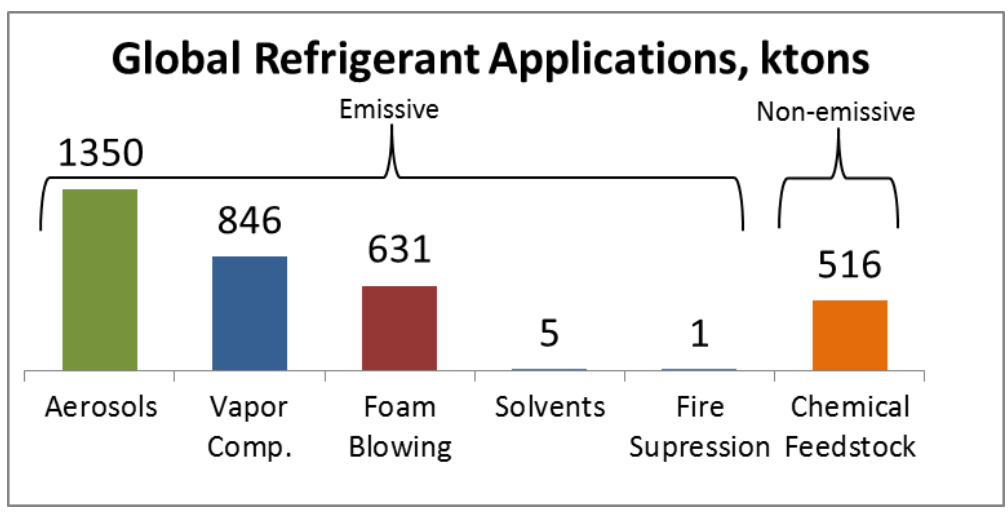

Figure ES-3. Global refrigerant usage, by application

- Vapor compression systems primarily use fluorocarbon refrigerants.

o This is the most difficult and impactful area for refrigerant innovation.

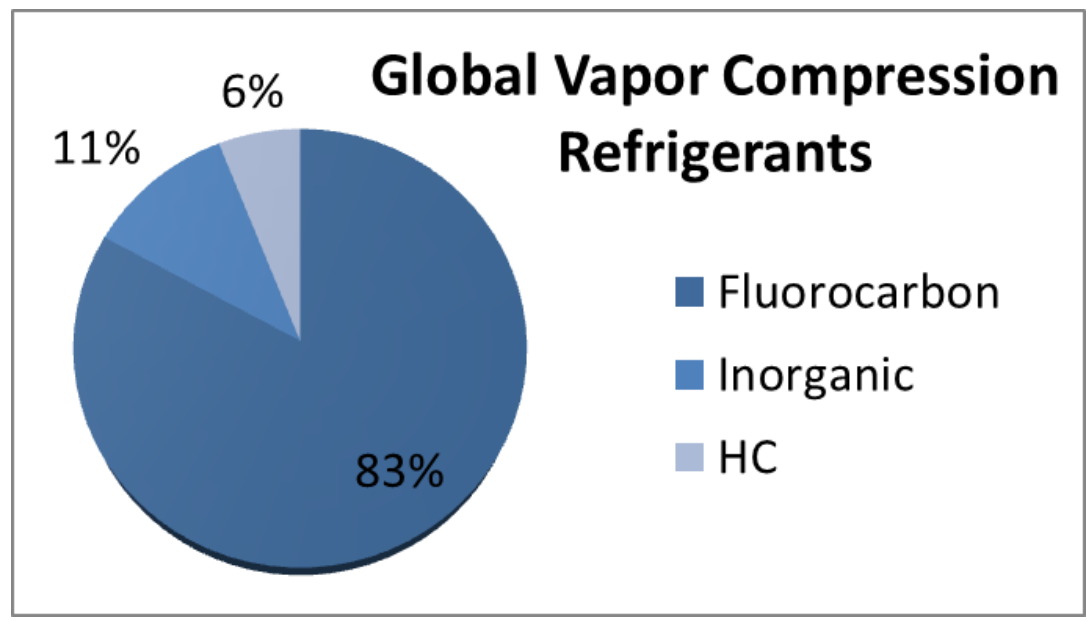

Figure ES-4. Global vapor compression refrigerant types

- Alternative refrigerants to fluorocarbons are well established.

o The refrigerant market is defined as all materials used in applications where fluorocarbons are used: vapor compression, foam blowing, aerosols, chemical feedstock, fire suppression, and solvents.

- Alternative refrigerants comprise more than $50 \%$ of the total market as it exists today.

- Common natural/hydrocarbon refrigerants include ammonia, pentane, carbon dioxide, propane, and butane.

o They have substantially lower global warming potential than most fluorocarbons.

- Nonfluorinated refrigerants may provide comparable or superior performance to fluorocarbons in some end uses. 


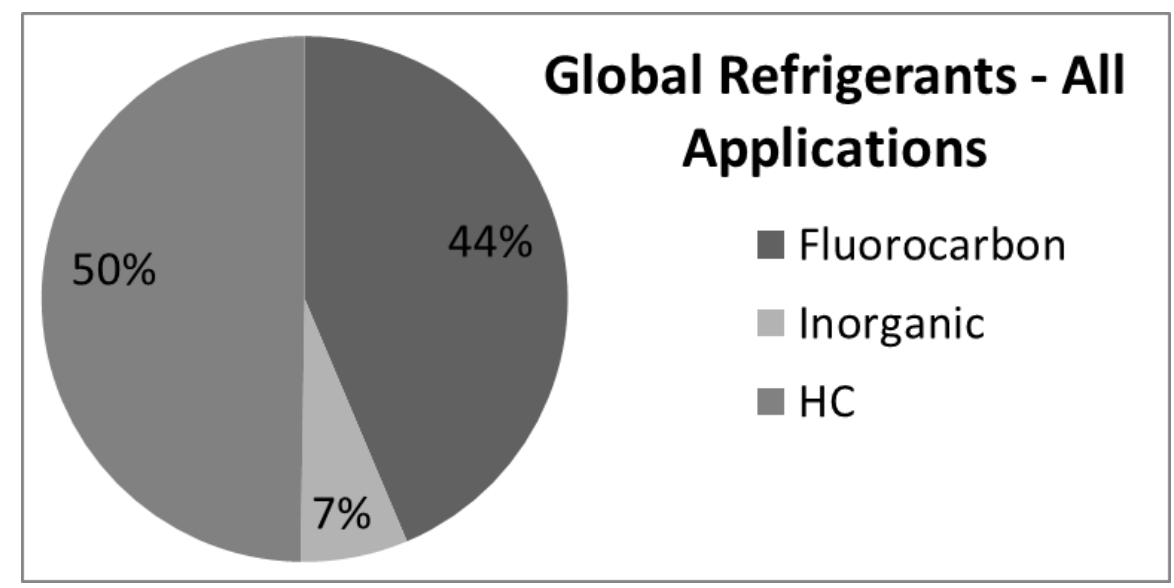

Figure ES-5. Global refrigerants for all applications

- Advanced fluorocarbon refrigerants are commercially available that reduce environmental impact while maintaining or potentially improving performance.

o One size doesn't fit all-some common applications are more difficult to solve than others; this necessitates ongoing research and development.

o U.S. companies are currently at the forefront of this innovation.

o The hydrochlorofluorocarbon phaseout is nearing completion in developed countries; attention has formally turned to the phasedown of high GWP hydrofluorocarbons with the passage of the Kigali Amendment in 2016. Significant global adoption of advanced fluorocarbon refrigerants and hydrocarbon alternatives will be instrumental to the success of this imminent HFC phasedown.

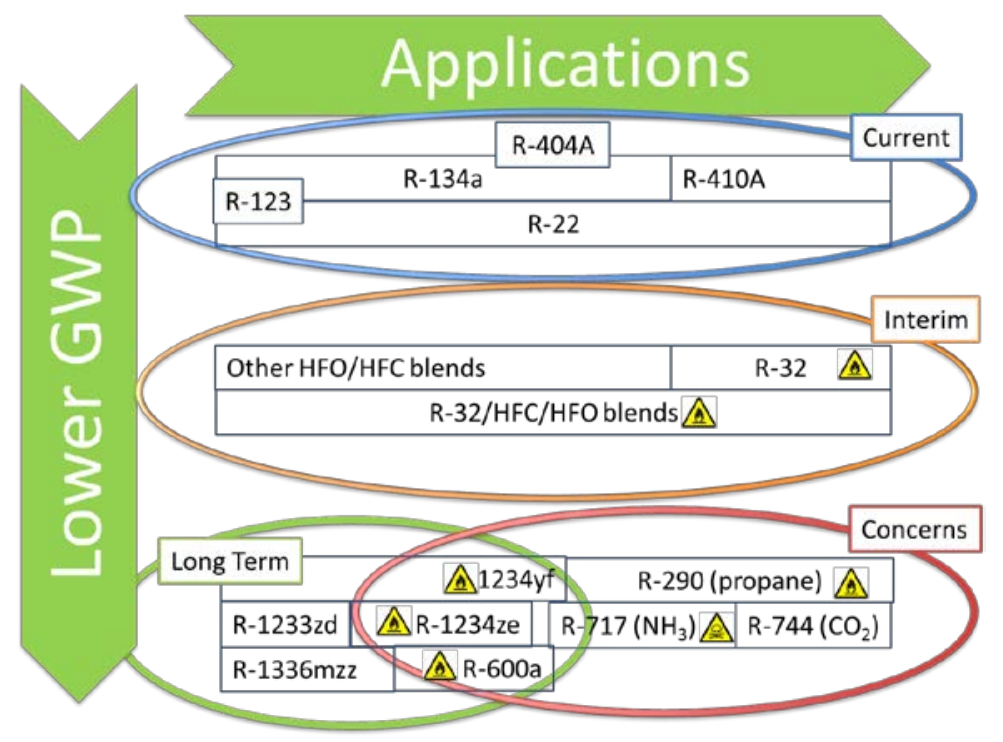

Figure ES-6. Groupings of refrigerants by GWP 
- Refrigerant manufacturing locations are primarily guided by:

o Proximity to fluorspar, hydrofluoric acid, or other chemical feedstock

- Existing refrigerant manufacturing capital and experienced labor force

- Availability of cheap energy and labor

o Financial incentives from local governments or development authorities.

- The United States is positioned to be a major production center for advanced refrigerants, including hydrofluoroolefins (HFOs) and their blends.

- Market share of production is likely to be larger if there is a substantial U.S. market for advanced refrigerants.

- Fluorspar will remain in demand as manufacturers transition to producing HFOs, and the U.S. fluorspar supply is stable. Demand is now supplied mainly by Mexico, whereas historically, China had been the leading supplier.

o U.S. companies, such as Honeywell and Chemours, own much of the intellectual property associated with the production and usage of HFOs.

- Antidumping lawsuits regarding Chinese imports have played a major role in shaping this industry. Decisions on HFC imports have generally been in favor of U.S. companies, setting an important precedent for any future HFO-related trade disputes.

- Recently constructed HFO production capacity in Louisiana serves as an example of the effect that financial incentives from development authorities can have on manufacturers' plant location decisions. 


\section{Table of Contents}

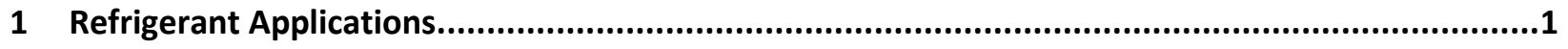

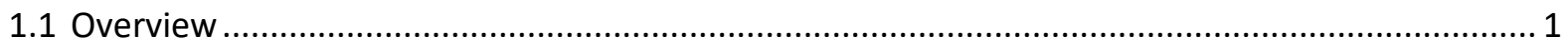

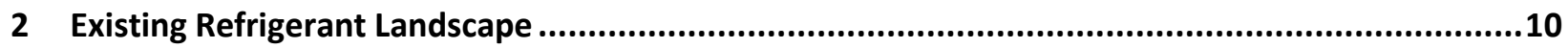

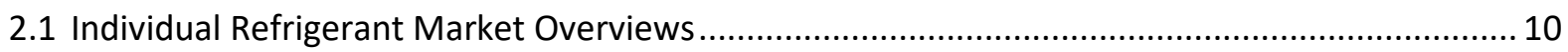

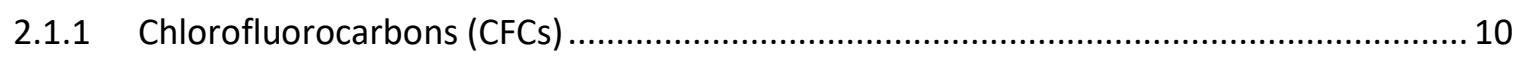

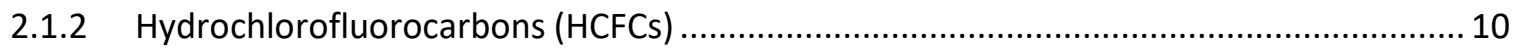

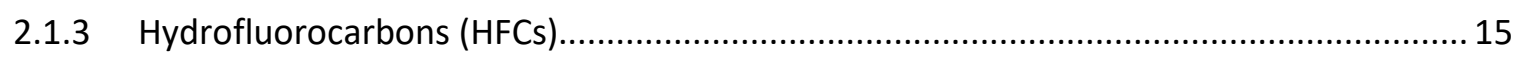

2.2 Supply Chain Considerations: Fluorspar and Hydrofluoric Acid ............................................... 20

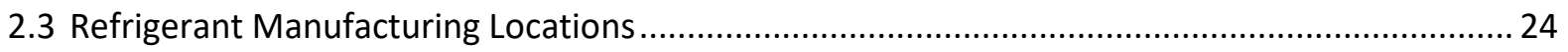

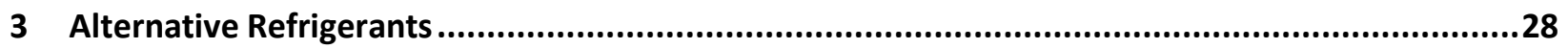

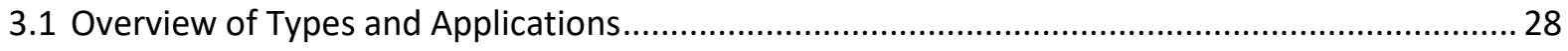

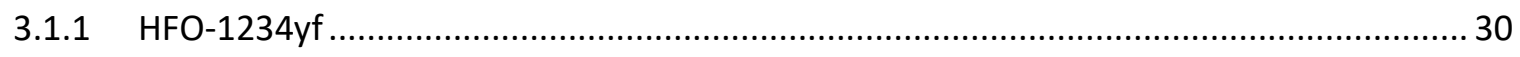

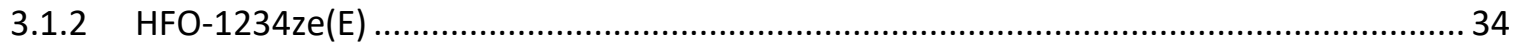

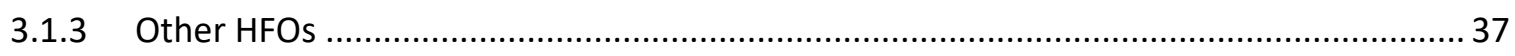

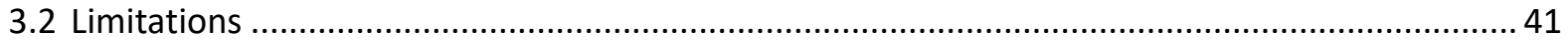

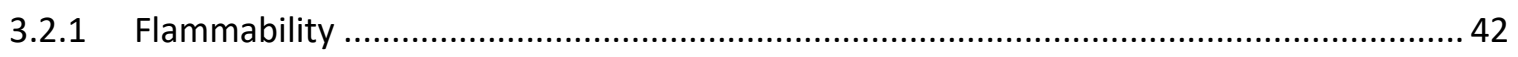

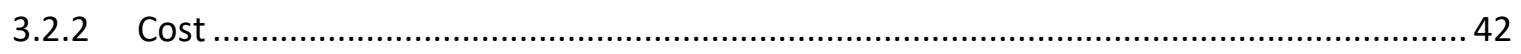

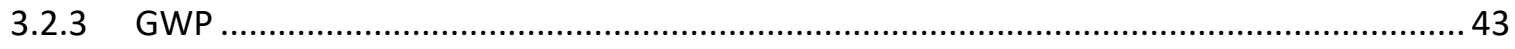

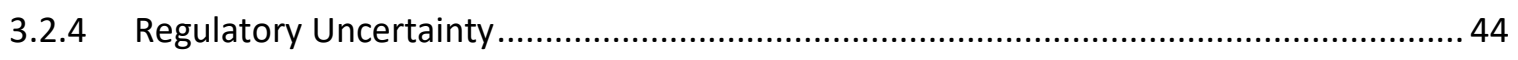

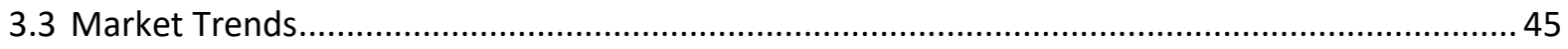

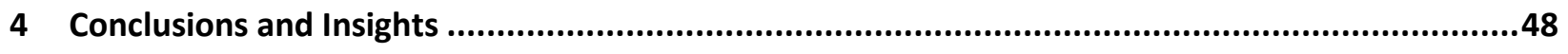

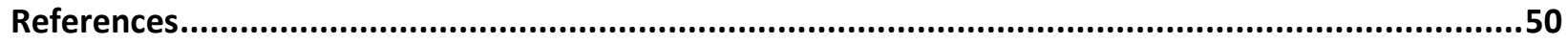




\section{List of Figures}

Figure 1. Total global refrigerants market for all classes of refrigerants .1

Figure 2. Foam blowing agent use by refrigerant type. As existing fluorocarbon refrigerants are phased out, many of those uses will transition to hydrocarbons, while others may transition to newer fluorocarbons (HFOs).

Figure 3. Aerosol use by refrigerant type. The dominance of hydrocarbons in this market is not likely to change substantially with the development of new fluorocarbon refrigerants. .3

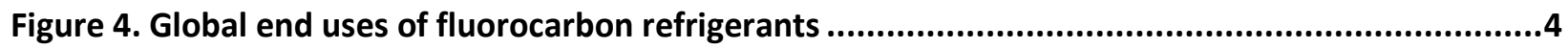

Figure 5. Global vapor compression use of refrigerant, in ktons....................................................4

Figure 6. Global refrigerant consumption by refrigeration application (excluding HVAC), in ktons ........5

Figure 7. Major refrigerants used globally for refrigeration (excluding HVAC), in ktons ......................5

Figure 8. Global refrigerants used in HVAC (excluding refrigeration) applications, in ktons.................6

Figure 9. Major refrigerants used in HVAC (excluding refrigeration) applications globally, in ktons.......6

Figure 10. Simplified flow diagram of U.S. HCFC-22 supply chain, as of 2014. HFC-23 is a byproduct of HCFC-22 production, and most HFC-23 is now intentionally destroyed to avoid emitting it to the atmosphere, because it has a high global warming potential (GWP) of 12,400.

Figure 11. Metric tons of annual HCFC and HFC production for emissive use, by region (2000-2016).

China is now the world's largest producer of both HCFCs and HFCs.

Figure 12. Unit values and quantities for U.S. imports of HFC-134a from China, July 2009-July 2017. The vertical lines represent the dates of final decisions issued by the U.S. International Trade Commission in the two antidumping lawsuits concerning HFC-134a imports from China. The recent spike in unit values is indicative of the antidumping duties going into effect.

Figure 13. Global mined quantities of acid-grade fluorspar (“acidspar"), 1993-2016

Figure 14. Annual U.S. import quantities of acid-grade fluorspar ("acidspar"), 1993-2016. Mexico, China, and South Africa are the major countries of origin for acidspar. Other countries that have imported significant quantities of fluorspar to the United States include Vietnam, Spain, the United Kingdom, and Mongolia.

Figure 15. Nominal prices of acid-grade fluorspar ("acidspar") imported into the U.S. market, by country of origin, 1993-2016.

Figure 16. U.S. imports of hydrofluoric acid, 1993-2016 .23 
Figure 17. Locations and estimated capacities of HCFC manufacturing plants as of 2016. HCFC capacity is concentrated in China, with significant additional capacity in the United States, Europe, and Japan. Lesser capacities are scattered across various other countries.

Figure 18. Locations and estimated capacities of HFC manufacturing plants as of 2016. HFC capacity is concentrated in China, with significant additional capacity in the United States and Japan. Lesser capacities are scattered across various other countries.

Figure 19. Locations and estimated capacities of HFO manufacturing plants, projected for 2018. By 2018, the major HFO capacity is expected to be relatively evenly spread between the United States and China, followed by Japan and India. Note: capacities for HFO plants are not typically disclosed and may vary widely from the estimates shown here.

Figure 20. 2016 trade flows of HFO-1234yf in ktons. Trade flows not involving the European Union, which reports import and export data specifically for HFO-1234yf, should only be viewed as rough estimates. The "Other" category includes all other countries listed as receiving HFO-1234yf imports from Europe, most notably Turkey and South Africa. It is anticipated that U.S. production (and exports) will increase significantly in $\mathbf{2 0 1 7}$ with the opening of Honeywell's Louisiana plant, and this growth in U.S. market share will continue when the Chemours plant in Texas begins operation in 2018.

Figure 21. Fluorocarbon-related patents, by grant year. On an annual basis, the rate patents are being granted for technologies and applications relating to HFO-1234yf is unprecedented in the history of the fluorocarbon industry.

Figure 22. Granted HFO-1234yf patent count, by company. Of the many companies involved in refrigerant research and development, U.S. companies Honeywell and DuPont/Chemours have been granted the highest and second-highest number of patents related to HFO-1234yf, respectively.

Figure 23. Granted HFO-1234ze patent count, by company. U.S.-based Honeywell holds the highest number of patents related to HFO-1234ze, followed by Japanese company Central Glass Co., U.S.based Chemours, and the French company Arkema.

Figure 24. HFO-related granted patents, by grant year, 1992-2016.

Figure 25. Granted HFO-1233zd patent count, by company, though 2016

Figure 26. Granted HFO-1336mzz patent count, by company, through 2016

Figure 27. Price estimates for a generic HFC/HFO blended refrigerant with $75 \% \mathrm{HFC}$ and $25 \% \mathrm{HFO}$. The

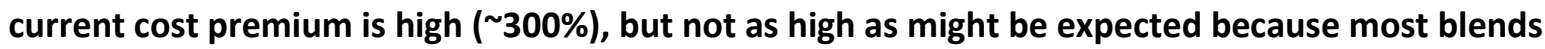
are predominantly HFC. Long-term cost premiums are small ( $25 \%)$. Because refrigerant costs are $1 \%$ or less of total system costs for most systems the high-volume price premium of a system using an HFC/HFO blend will be $0.25 \%$. 
Figure 28. Vapor compression refrigerant applications and direct GWP. Long-term solutions exist for lower operating pressure systems. At higher operating pressures, alternatives are often highly flammable (hydrocarbons), have intermediate GWP (150-700), or have potential efficiency or toxicity constraints $\left(\mathrm{CO}_{2}, \mathrm{NH}_{3}\right)$.

Figure 29. International HFC trade flows in 2000 (a) and 2015 (b), in ktons. There is a clear trend of reduced exports from the United States and EU and increasing exports from Asia, mostly China. 47

\section{List of Tables}

Table 1. Global Annual End Uses of Major Refrigerants in ktons

Table 2. Dominant Installed Refrigerants for Vapor Compression Applications ..................................8

Table 3. Typical End Uses of Refrigerant HFC and HFC/HFO Blends and What Refrigerant(s) They Replace.

Table 4. Common Alternative Refrigerants

Table 5. HFO Production Locations 


\section{Refrigerant Applications}

The current global refrigerant market is $\$ 14$ billion/year (Markets and Markets 2017) and covers a variety of applications, which often comprise a range of products. An overview of this market will be provided in this report, with an emphasis on understanding the breadth of applications, international trade flows, supply chain, and regulatory factors that impact the market.

Despite its maturity, the refrigerant industry is rapidly changing. Historically, much of the change in this industry has been driven by international cooperation to avoid the ozonedepleting characteristics of an early class of refrigerants-chlorofluorocarbons (CFCs). Since the passage of the Montreal Protocol in 1987 and subsequent phaseout of CFCs, attention has turned to the environmental impact of the halogenated CFC replacements (hydrochlorofluorocarbons [HCFCs] and hydrofluorocarbons [HFCs]). These include the energy efficiency of products using refrigerants as a working fluid (indirect global warming potential [GWP]) as well as their direct impact when released into the atmosphere (direct GWP). With the negotiation of the Kigali Amendment to the Montreal Protocol in 2016, countries are formally agreeing to take action to reduce the aggregate GWP of the global refrigerant industry. The U.S. Department of Energy has developed a roadmap for research and development (R\&D) activities related to refrigerants, which highlights the potential for impactful research (Goetzler et al. 2014) as well as developing a detailed outlook for certain refrigerant markets, such as air conditioning (Goetzler et al. 2016). That roadmap focused on technical initiatives and priorities for refrigerants in vapor compression systems. This report considers many of the other components of the refrigerant market, including non-vapor-compression applications, technoeconomic analysis, the interaction of innovation and regulation, and the perspective of industry stakeholders.

\subsection{Overview}

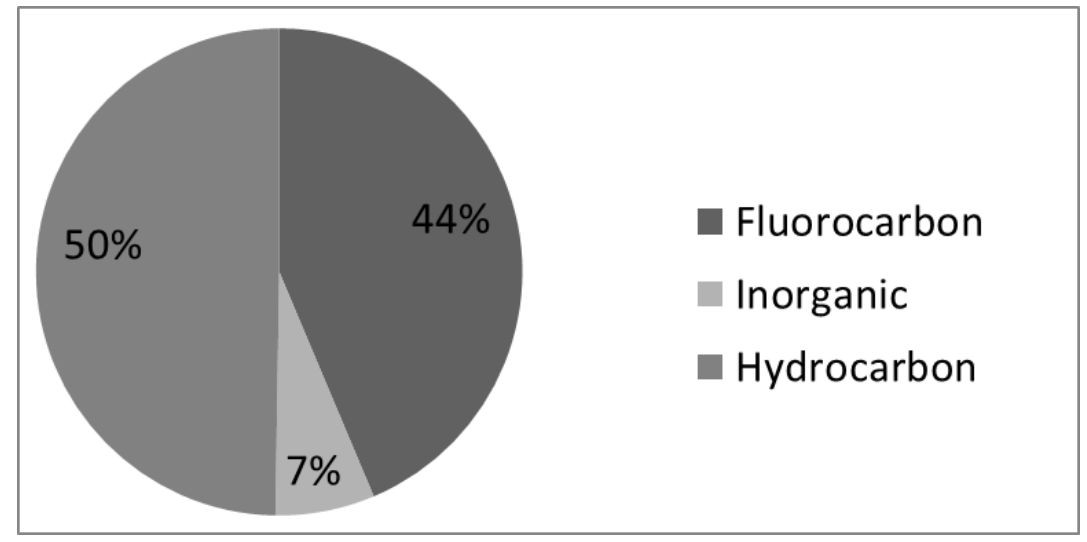

Figure 1. Total global refrigerants market for all classes of refrigerants

Refrigerant chemicals are used in many applications, some of which have nothing to do with refrigeration. Figure 1 shows the percent of the total refrigerant market occupied by the three major classes of refrigerants: fluorocarbons, inorganic, and hydrocarbons. Hydrocarbons and inorganics are often collectively described as "natural" refrigerants, but they are listed 
separately here to highlight that hydrocarbons alone comprise nearly half of the global refrigerant market today. That market share could well grow in the near future due to low cost and favorable performance for many applications. Figure 1 shows the approximate global breakdown of end uses where at least a portion of the market uses fluorinated refrigerants. For example, some of the aerosol and foam blowing markets use fluorinated refrigerants; the markets are included here, even though a substantial portion of those markets use hydrocarbons and inorganics. This distinction bounds the topic such that other end uses of hydrocarbons (e.g., fuel) or inorganics (e.g., fertilizer) are excluded from discussion in this work. Consumption as a chemical precursor (feedstock use) is an important, but sometimes overlooked, use of several refrigerants, primarily HCFC-22, HCFC-142b, and HFC-152a. The use of HFCs and HCFCs as chemical feedstocks is not prohibited by international agreements because the chemicals are never released into the atmosphere. Therefore, substantial production capacity of HFCs and HCFCs for feedstock use will likely continue into the foreseeable future. When only emissive uses of fluorocarbons are considered, vapor compression systems (refrigeration and heating, ventilating, and air conditioning [HVAC]), polymer foam production, fire suppression, aerosols, and chemical solvents are the major end uses.

There are two major refrigerant end uses where hydrocarbons are the dominant refrigerant: foam blowing agents and aerosols, as shown in Figure 2 and Figure 3. The most common foam blowing agents are pentanes, whereas aerosols typically use propane or butane. The importance of hydrocarbons in these areas is likely to increase as regulations reduce the availability of existing fluorocarbons for these applications. In regions such as Europe, where HCFC blowing agents have already been phased out, foam manufacturers may be less likely to transition to newly developed fluorocarbon blowing agents (such as hydrofluoroolefin [HFO]$1234 z e$ or HFO-1233zd) due to cost. However, in regions that still use HFC blowing agents, such as Japan and the United States, HFO blowing agents may gain market acceptance as HFCs are phased out. The choice between hydrocarbons and HFOs could be influenced by many factors, including material compatibility and insulating value (UNEP 2015). For example, some HFOs have better insulating properties than hydrocarbons (McMenamin et al. 2009; Loh et al. 2010). However, if costs are the most important consideration, hydrocarbons are the more appropriate choice. Unlike vapor compression applications, where concerns persist about flammability, safety issues have largely been identified and overcome in the foam blowing sector. Instead, the challenges impeding adoption of HFC substitutes include transition cost, material compatibility, and thermal performance (Desjarlais 2017; Walters-Terronini 2017). 


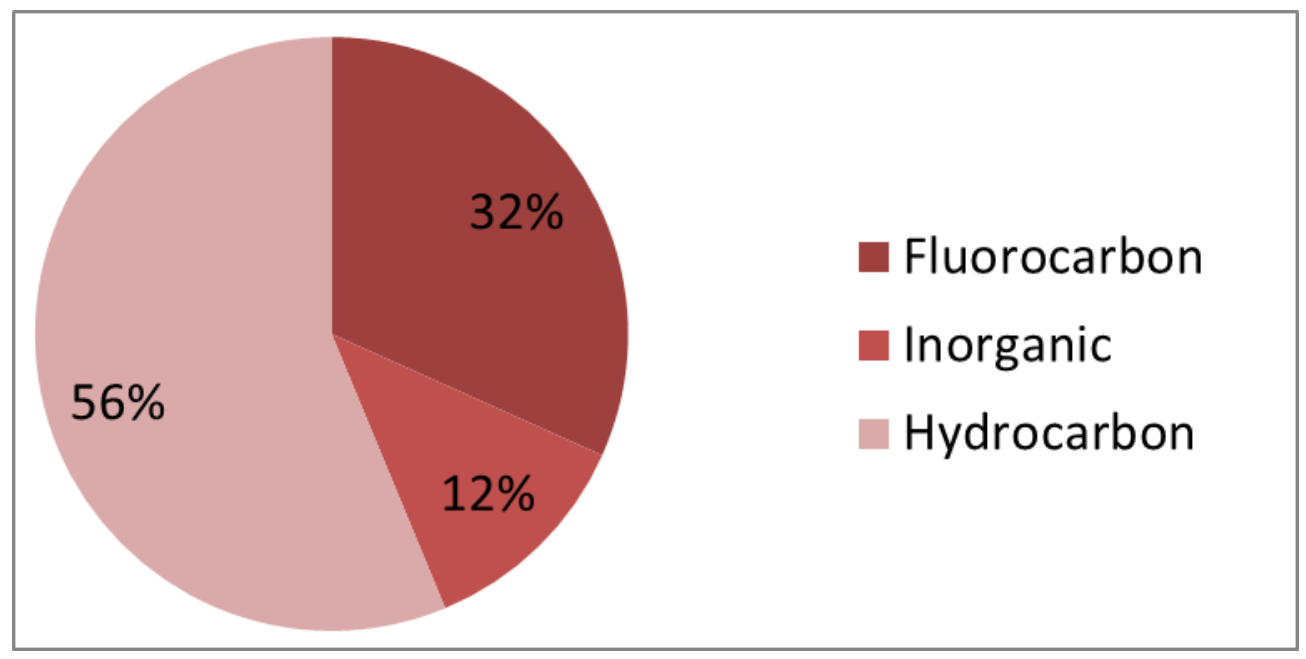

Figure 2. Foam blowing agent use by refrigerant type. As existing fluorocarbon refrigerants are phased out, many of those uses will transition to hydrocarbons, while others may transition to newer fluorocarbons (HFOs).

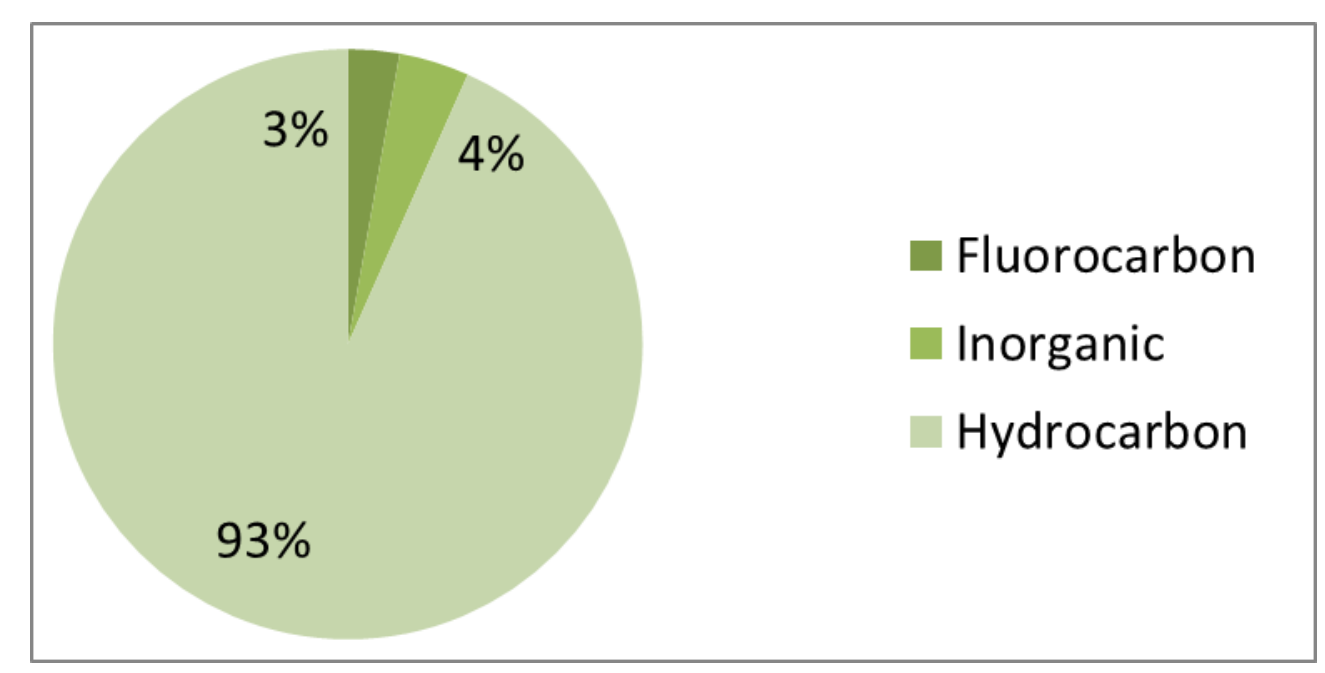

Figure 3. Aerosol use by refrigerant type. The dominance of hydrocarbons in this market is not likely to change substantially with the development of new fluorocarbon refrigerants.

Figure 4 shows the end uses of fluorocarbon refrigerants only. In this context, vapor compression systems used for refrigeration and HVAC dominate the end uses. Vapor compression systems are the dominant technology used for residential and commercial air conditioning and refrigeration as well as mobile air conditioning. Figure 5. breaks down vapor compression into three main categories and shows that the stationary HVAC and refrigeration markets are of comparable size and are much larger than the mobile vapor compression market. Figure 5 includes fluorinated as well as inorganic and hydrocarbon refrigerants, although the vast majority ( 95\%) used in vapor compression are fluorinated (Building Services Research and Information Association [BSRIA] 2015b). The nonfluorocarbon refrigerants are 
dominated by ammonia (R-717), which is used almost exclusively for industrial applications; hydrocarbons are a small but growing portion of the market in terms of tons of refrigerant used. Because hydrocarbons are typically used in small quantities, the number of products using them as a refrigerant is large even though the tonnage is relatively small. Figure 6 focuses on refrigeration applications and the relative refrigerant consumption in each of the four main areas: commercial, industrial, transportation, and domestic/other.

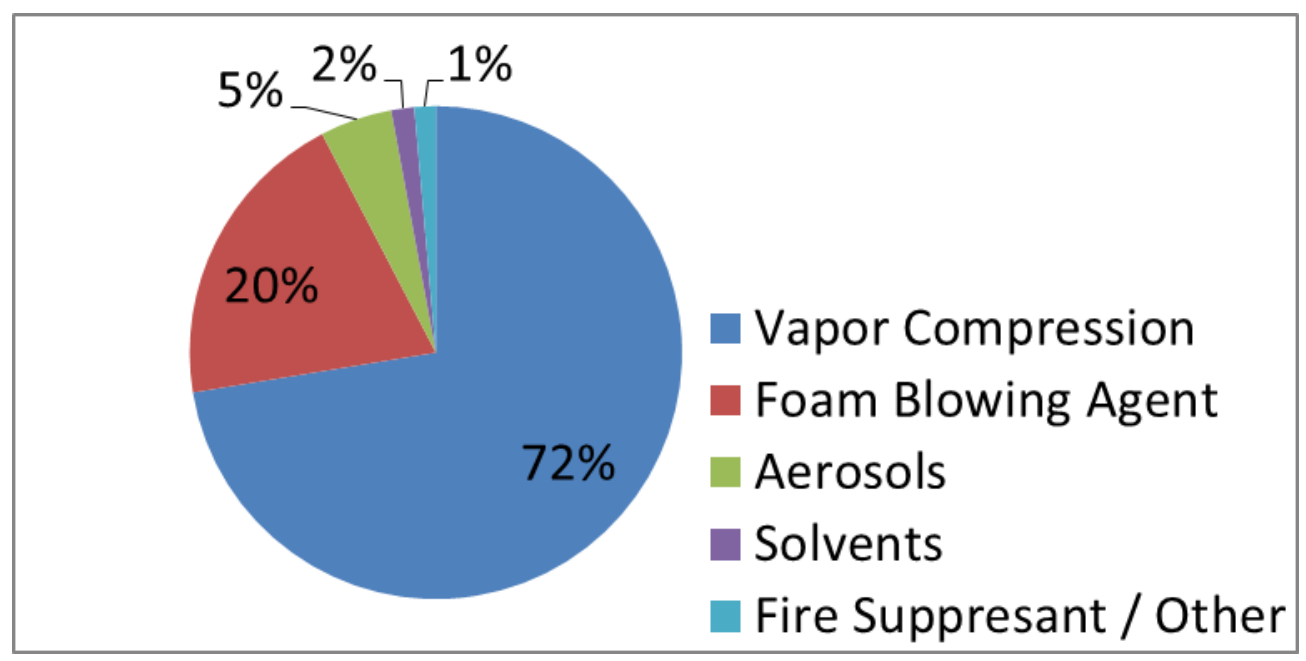

Figure 4. Global end uses of fluorocarbon refrigerants

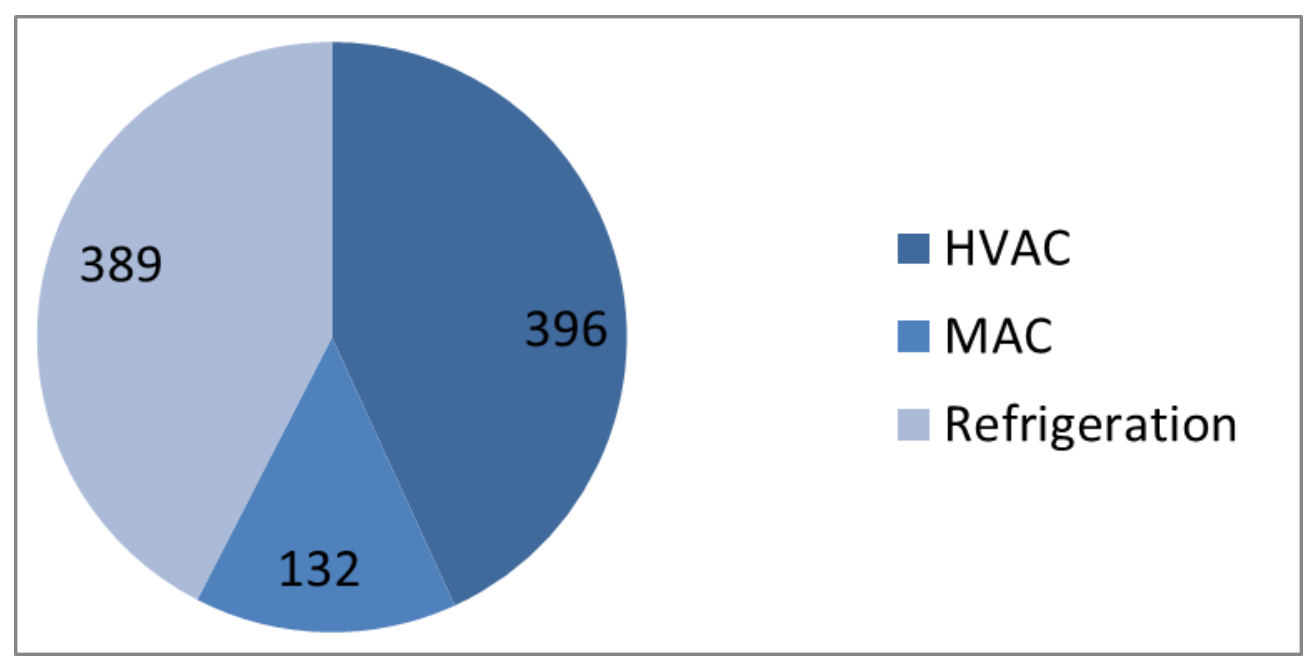

Figure 5. Global vapor compression use of refrigerant, in ktons 


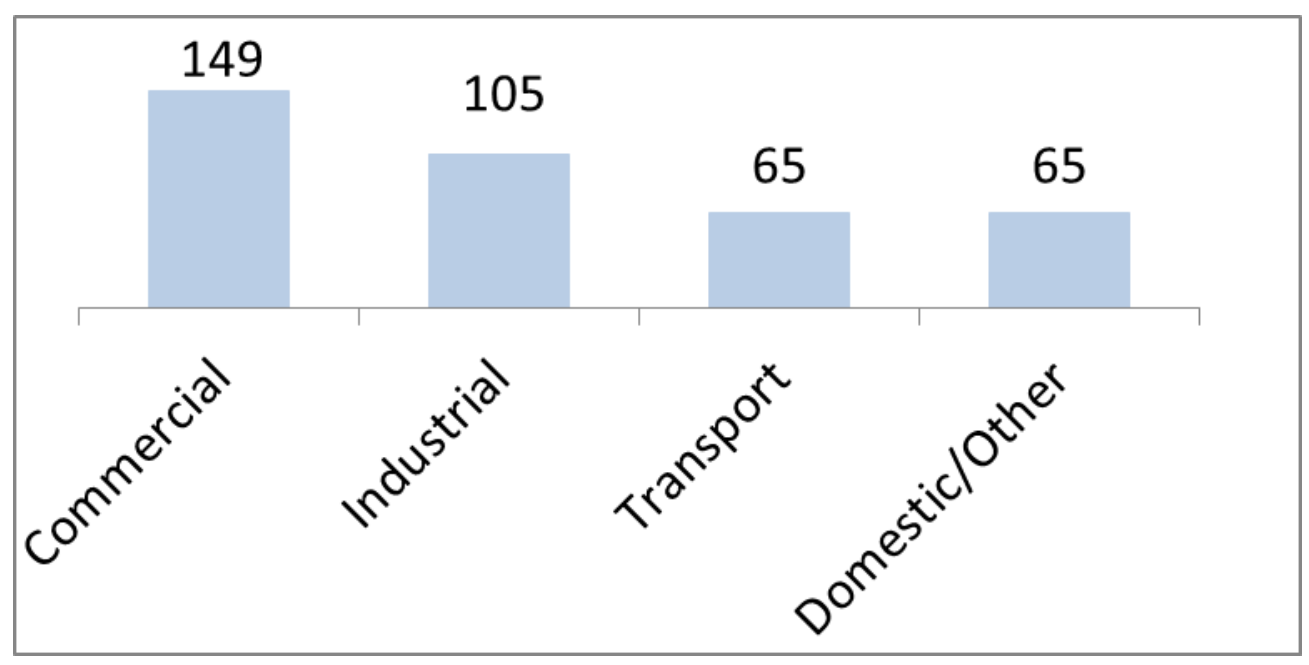

Figure 6. Global refrigerant consumption by refrigeration application (excluding HVAC), in ktons (BSRIA 2015b)

It is also important to understand the volumes of different refrigerants that are used in refrigeration, as shown in Figure 7. This figure does include nonfluorocarbon refrigerants; however, they are used in such small quantities for refrigeration applications that they are combined with the "other" category. Refrigerant volumes are in metric tons, not unit sales. This is an important distinction because the global domestic refrigerator market is approximately $50 \%$ isobutane ( $\mathrm{R}-600 \mathrm{a}$ ) by unit sales, but the low charge quantities per unit mean that the total amount of R-600a used is 6 ktons, less than $3 \%$ of global refrigerant volume (Clodic et al. 2006; BSRIA 2015b).

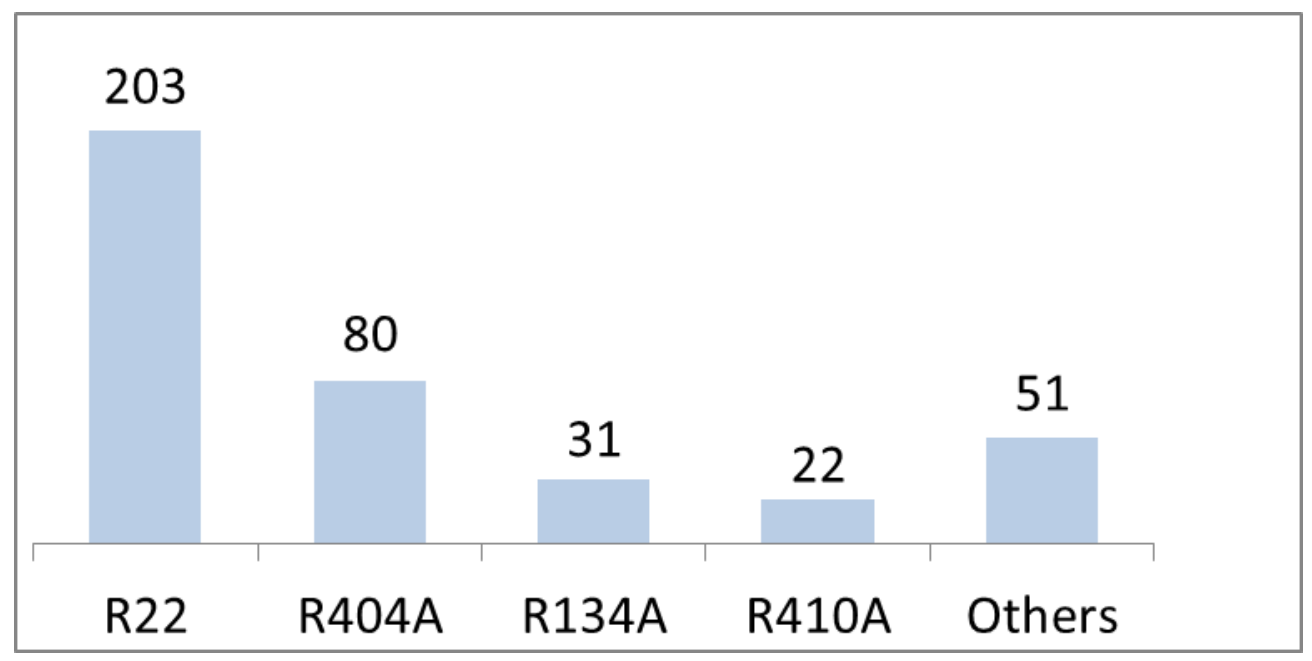

Figure 7. Major refrigerants used globally for refrigeration (excluding HVAC), in ktons (BSRIA 2015b) 


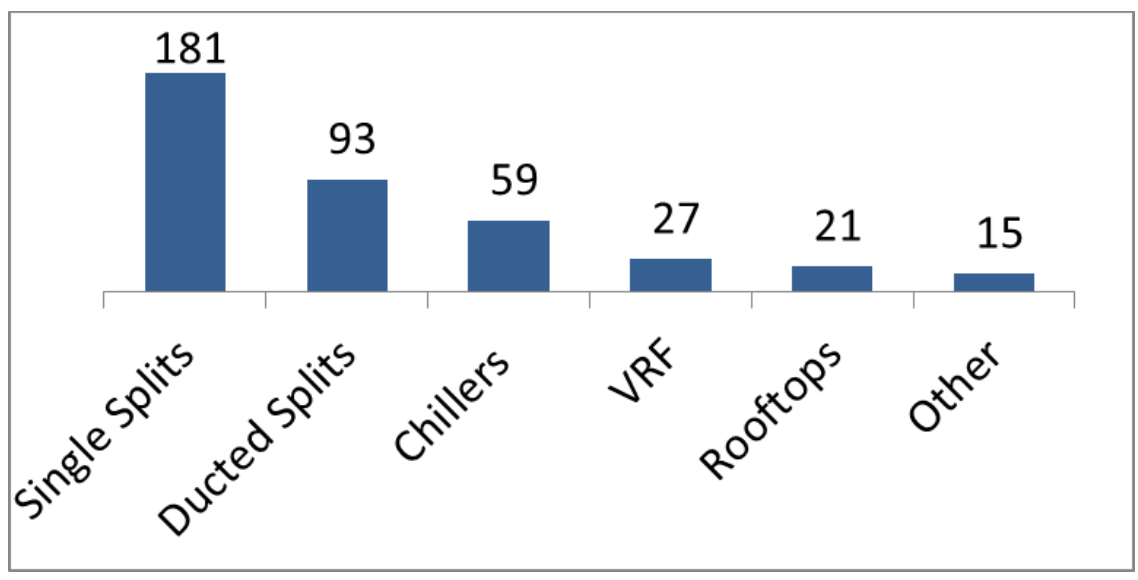

Figure 8. Global refrigerants used in HVAC (excluding refrigeration) applications, in ktons (BSRIA 2015a; BSRIA 2015b)

Sales of refrigerants for HVAC end uses are given in Figure 8, similar to the end-use splits for refrigeration given in Figure 6 . Single splits are another term for ductless or minisplit air conditioners or heat pumps, which are by far the largest end use of refrigerants for HVAC globally. The ducted splits are primarily sold in the United States ( $73 \%$ of total unit sales) with the balance going to markets in Asia (BSRIA 2015b). The ducted split market, while much smaller than that of single splits on a per-unit basis, is the second largest use of refrigerant due to the larger refrigerant charge per unit.

Figure 9 shows the major refrigerants (including blends) that are used in HVAC applications; hydrocarbons and other natural refrigerants are included but account for less than $1 \%$ of the total volume. Even with international agreements and the phaseout of HCFCs and HFCs, R-22 is still the second most commonly used refrigerant in HVAC applications. These data account for blended refrigerants separately from pure refrigerants. For example, pure R-32 accounts for $\sim 3 \%$ of the total; however, R-410A consists of $50 \%$ R-32 by mass.

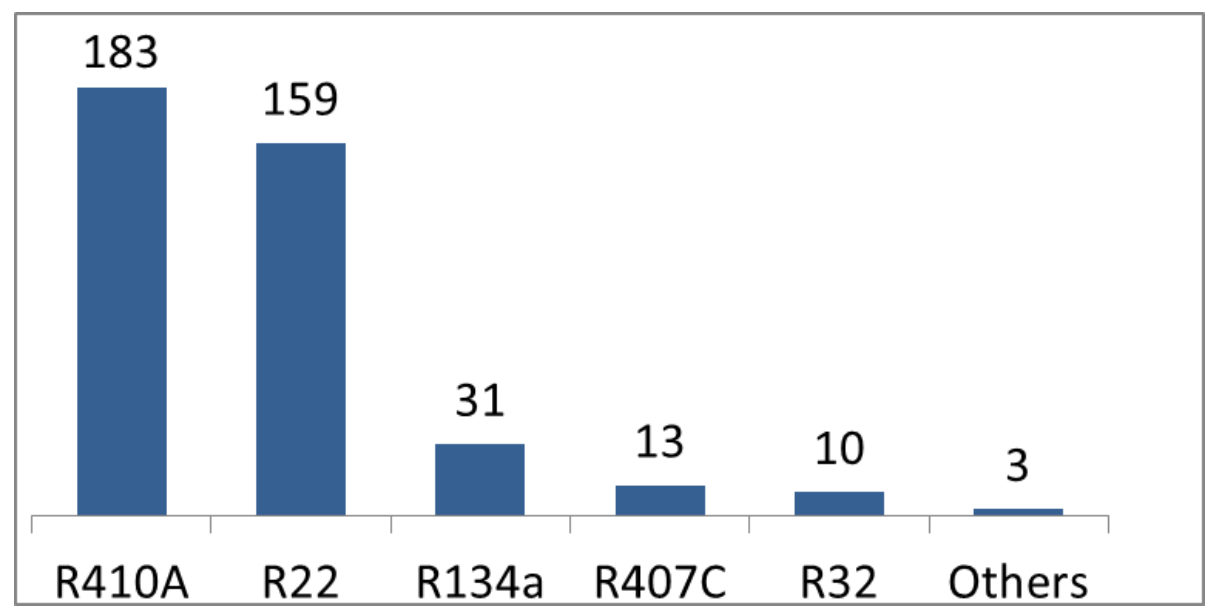

Figure 9. Major refrigerants used in HVAC (excluding refrigeration) applications globally, in ktons (BSRIA 2015b) 
Within each end-use category, many different fluorocarbons are used. Table 1 provides quantitative use estimates for the most common refrigerants, disaggregated by end-use category. This does not consider uses in blends. Although HCFC-22 is being phased out in developed countries, it is still the most produced fluorocarbon globally. Approximately half of HCFC-22 production is for nonemissive uses in chemical production, most notably as a feedstock for polytetrafluoroethylene (PTFE), which is sold under the brand-name Teflon. However, if only emissive uses are considered, HCFC-22 is still the most produced fluorocarbon refrigerant for any application and is used in quantities that are comparable to those of any individual hydrocarbon used in aerosols.

Table 1. Global Annual End Uses of Major Refrigerants in ktons ${ }^{a}$.

This excludes blends, in North America, European Union, China and Japan. Other refrigerants are also used in these applications; however, they are in much lower quantities.

\begin{tabular}{|c|c|c|c|c|c|c|}
\hline Refrigerant & $\begin{array}{l}\text { Polymer } \\
\text { Precursor }\end{array}$ & $\begin{array}{l}\text { Refrigeration } \\
\& \text { A/C }\end{array}$ & $\begin{array}{l}\text { Foam Blowing } \\
\text { Agents }\end{array}$ & Aerosols & Solvents & $\begin{array}{l}\text { Fire } \\
\text { Suppression }\end{array}$ \\
\hline HCFC-22 & 360 & $248-400$ & 34 & - & - & - \\
\hline HCFC-141b & - & - & 60 & - & 5 & - \\
\hline HCFC-142b & 106 & 6 & 11 & - & - & - \\
\hline HFC-32 & - & 10 & - & - & - & - \\
\hline HFC-125 & - & 83 & - & - & - & 0.4 \\
\hline HFC-134a & - & $190-240$ & 70 & - & - & - \\
\hline HFC-152a & 50 & 17 & 16 & 38 & - & - \\
\hline HFC-245fa & - & - & $28-62$ & - & - & - \\
\hline HFC-143a & - & 29 & - & - & - & - \\
\hline HFC-365mfc & - & 1 & 8 & - & - & - \\
\hline HFC-227ea & - & - & - & - & - & 0.6 \\
\hline HFO-1234yf & - & $15-30$ & - & - & - & - \\
\hline HFO-1234ze & - & $<1$ & $1-4.5$ & Unk & - & - \\
\hline HFO-1233zdEk & - & $<1$ & 4 & - & - & - \\
\hline HFO-1336mzz' & - & $\mathrm{Neg}$ & Neg & - & - & - \\
\hline Pentane (R-601c) & - & - & 355 & - & - & - \\
\hline $\mathrm{CO}_{2}(\mathrm{R}-744)$ & - & $70-80$ & $15^{d}$ & 52 & - & - \\
\hline Propane (R-290) & - & $37-46$ & - & 420 & - & - \\
\hline Ammonia (R-717) & - & $9-26$ & - & - & - & - \\
\hline Isobutane (R-600a) & - & $6-11$ & - & 420 & - & - \\
\hline n-butane (R-600) & - & - & - & 420 & - & - \\
\hline Total $\left.\right|^{b}$ & 522 & $749-949$ & $610-649$ & 1510 & 14 & 13 \\
\hline
\end{tabular}

a Greenpeace 2012, True Manufacturing 2017, Clodic et al. 2006, IHS 2014, BSRIA 2015b, Building Green 2010, Business Wire 2016 Transparency Market Research 2016, Grand View Research 2016, CNCIC Consulting 2015, Shecco 2012, 2013, 2015, 2016, Hella 2011, Chemours 2016b, EJARN 2015a, EJARN 2015b, Godwin et al. 2014, Eurostat 2017, U.S. Environmental Protection Agency (EPA) 2016a

${ }^{\mathrm{b}}$ Includes minor refrigerants not listed here; rows may not sum to the total. 
There are regional differences in refrigerant use, as shown in Table 2. This table includes all refrigerants currently used for stationary HVAC and refrigeration applications but does not include mobile applications. Note that this table represents the installed base of refrigerants, not new equipment sales. This is an important distinction because there are some refrigerant applications, such as R-123 in chillers, where sales of new equipment will soon be phased out while servicing use continues for existing equipment. Similarities in refrigerant selection can be seen across regions, with some important exceptions. R-600a is a substantial portion of domestic refrigeration markets outside of the United States which uses R-134a almost exclusively in this end use. Other major differences can be traced to developing versus. developed countries and the use of R-22 in direct expansion air conditioning or chillers.

Table 3 lists common refrigerant blends for vapor compression applications. These include HFC blends as well as HFC/HFO blends. Note that there are a few component refrigerants that are present in most of these blends, including upcoming and newly developed HFC/HFO blends. R$32, \mathrm{R}-125, \mathrm{R}-134 \mathrm{a}$, and R-1234yf appear in most blended refrigerants, with the differences being in the percent composition of the components or the addition of other components such as $\mathrm{R}-1234 z e(E)$. This relatively large selection of new blends is aimed at replacing just a few current refrigerants/blends, so there may be multiple options available to replace an existing refrigerant depending on the particular end use.

Table 2. Dominant Installed Refrigerants for Vapor Compression Applications (BSRIA 2015a). Other refrigerants may be used in these applications but in smaller quantities.

\begin{tabular}{|c|c|c|c|c|c|}
\hline Application & $\begin{array}{l}\text { United } \\
\text { States }\end{array}$ & $\begin{array}{l}\text { Rest of } \\
\text { Americas }\end{array}$ & Europe & Asia & $\begin{array}{l}\text { Middle } \\
\text { East/Africa }\end{array}$ \\
\hline Domestic Refrigeration & $\mathrm{R}-134 \mathrm{a}$ & $\begin{array}{l}R-134 a \\
R-600 a\end{array}$ & $\mathrm{R}-600 \mathrm{a}$ & $\begin{array}{l}\text { R-600a } \\
\text { R-134a }\end{array}$ & $\begin{array}{l}\text { R-600a } \\
\text { R-134a }\end{array}$ \\
\hline Commercial Refrigeration & $\begin{array}{l}R-404 A \\
R-134 a\end{array}$ & $\begin{array}{l}\mathrm{R}-404 \mathrm{~A} \\
\mathrm{R}-134 a\end{array}$ & $\begin{array}{l}\text { R-404A } \\
\text { R-134a } \\
\text { Hydrocarbons } \\
\text { R-744 }\end{array}$ & $\begin{array}{l}\text { R-404A } \\
\text { R-134a } \\
\text { R-22 }\end{array}$ & $\begin{array}{l}R-404 A \\
R-134 a \\
R-22\end{array}$ \\
\hline Industrial Refrigeration & $\begin{array}{l}\mathrm{R}-717 \\
\mathrm{R}-22\end{array}$ & $\begin{array}{l}\mathrm{R}-717 \\
\mathrm{R}-22\end{array}$ & $\begin{array}{l}\text { R-717 } \\
\text { R-744 }\end{array}$ & $\begin{array}{l}\text { R-717 } \\
\text { R-22 } \\
\text { R-744 }\end{array}$ & $\begin{array}{l}\mathrm{R}-717 \\
\mathrm{R}-22\end{array}$ \\
\hline $\begin{array}{l}\text { Direct Expansion Air } \\
\text { Conditioning }\end{array}$ & $\mathrm{R}-410 \mathrm{~A}$ & $\begin{array}{l}\mathrm{R}-410 \mathrm{~A} \\
\mathrm{R}-22\end{array}$ & $\mathrm{R}-410 \mathrm{~A}$ & $\begin{array}{l}\text { R-410A } \\
\text { R-22 } \\
\text { R-32 }\end{array}$ & $\begin{array}{l}R-22 \\
R-410 A\end{array}$ \\
\hline Chillers & $\begin{array}{l}R-134 a \\
R-410 A \\
R-123\end{array}$ & $\begin{array}{l}R-134 a \\
R-410 A \\
R-22 \\
R-123\end{array}$ & $\begin{array}{l}R-410 A \\
R-134 a \\
R-407 A \\
R-407 C\end{array}$ & $\begin{array}{l}R-134 a \\
R-410 A \\
R-407 C \\
R-22 \\
R-123\end{array}$ & $\begin{array}{l}R-410 A \\
R-22 \\
R-134 a \\
R-123\end{array}$ \\
\hline
\end{tabular}


Table 3. Typical End Uses of Refrigerant HFC and HFC/HFO Blends and What Refrigerant(s) They Replace. Most refrigerants used for non-vapor-compression applications are not blended (Abdelaziz et al. 2016; Wang and Amrane 2016; Kujak 2017; Goetzler 2016; Honeywell 2015a; Chemours 2017a; Chemours 2017b).

\begin{tabular}{|c|c|c|c|c|c|}
\hline & Refrigerant & Producer(s) & Components & Replaces & Typical End Uses \\
\hline \multirow{3}{*}{$\begin{array}{l}\text { Current } \\
\text { HFC } \\
\text { Blends }\end{array}$} & $R-404 A$ & (many) & $\mathrm{R}-125 / 143 a / 134 a$ & $\begin{array}{l}\text { R-22, R- } \\
502\end{array}$ & $\begin{array}{l}\text { Commercial } \\
\text { refrigeration }\end{array}$ \\
\hline & R-407C & (many) & $\mathrm{R}-32 / 125 / 134 a$ & $\mathrm{R}-22$ & $\begin{array}{l}\text { Commercial AC, } \\
\text { positive } \\
\text { displacement } \\
\text { refrigeration }\end{array}$ \\
\hline & R-410A & (many) & $\mathrm{R}-32 / 125$ & $\mathrm{R}-22$ & $\begin{array}{l}\text { Residential, small } \\
\text { commercial } \\
\text { stationary AC } \\
\text { systems }\end{array}$ \\
\hline \multirow{9}{*}{$\begin{array}{l}\text { Upcoming } \\
\text { HFO/HFC } \\
\text { Blends }\end{array}$} & R-444B & Honeywell & R-32/152a/1234ze(E) & $\begin{array}{l}\text { R-404A, } \\
\text { R-407C, } \\
\text { R-22 }\end{array}$ & $\begin{array}{l}\text { Low- and medium- } \\
\text { temperature } \\
\text { refrigeration }\end{array}$ \\
\hline & R-447A & Honeywell & $\mathrm{R}-32 / 125 / 1234 z e(E)$ & $\mathrm{R}-410 \mathrm{~A}$ & $\begin{array}{l}\text { Residential, small } \\
\text { commercial } \\
\text { stationary AC } \\
\text { systems }\end{array}$ \\
\hline & R-447B & $\begin{array}{l}\text { Honeywell } \\
\text { (not in } \\
\text { production) }\end{array}$ & $\mathrm{R}-32 / 125 / 1234 z e(E)$ & $\mathrm{R}-410 \mathrm{~A}$ & $\begin{array}{l}\text { Residential, small } \\
\text { commercial } \\
\text { stationary AC } \\
\text { systems }\end{array}$ \\
\hline & R-448A & Honeywell & $\begin{array}{l}\text { R- } \\
32 / 125 / 1234 y f / 134 a / 1234 z e(E)\end{array}$ & $\begin{array}{l}\text { R-22, R- } \\
404 A\end{array}$ & $\begin{array}{l}\text { Low- and medium- } \\
\text { temperature } \\
\text { refrigeration }\end{array}$ \\
\hline & $R-449 A$ & Chemours & $R-32 / 125 / 1234 y f / 134 a$ & $\begin{array}{l}\text { R-22, R- } \\
\text { 404A/R- } \\
\text { 507, R- } \\
\text { 407A/F }\end{array}$ & $\begin{array}{l}\text { Low- and medium- } \\
\text { temperature } \\
\text { refrigeration }\end{array}$ \\
\hline & $\begin{array}{l}\text { R-452B } \\
\text { (DR-55) }\end{array}$ & $\begin{array}{l}\text { Chemours, } \\
\text { Honeywella }\end{array}$ & $\mathrm{R}-32 / 125 / 1234 \mathrm{yf}$ & & $\begin{array}{l}\text { Residential, small } \\
\text { commercial } \\
\text { stationary AC } \\
\text { systems }\end{array}$ \\
\hline & R-454B & Chemours & R-32/1234yf & $\mathrm{R}-410 \mathrm{~A}$ & $\begin{array}{l}\text { Residential, small } \\
\text { commercial } \\
\text { stationary AC } \\
\text { systems }\end{array}$ \\
\hline & R-513A & Chemours & $R-1234 y f / 134 a$ & $R-134 a$ & $\begin{array}{l}\text { Centrifugal, screw } \\
\text { chillers }\end{array}$ \\
\hline & R-514A & Chemours & R-1336mzz(Z)/R-1130(E) & $\mathrm{R}-123$ & Centrifugal chillers \\
\hline
\end{tabular}

a Trane owns patent rights for use in HVAC equipment but has made its patents available on a royalty-free basis (Ingersoll-Rand 2016). 


\section{Existing Refrigerant Landscape}

This section provides details on the current refrigerant landscape with additional background, production, and historical information for the most common individual refrigerants currently in use globally.

\subsection{Individual Refrigerant Market Overviews}

\subsubsection{Chlorofluorocarbons (CFCs)}

By 1996 and 2010, all CFCs had been phased out in developed and developing countries, respectively, in accordance with the Montreal Protocol (UNEP 2016a). The focus of this report is on the classes of chemicals that replaced CFCs in this industry: HCFCs, HFCs, HFOs, and nonfluorinated refrigerants.

\subsubsection{Hydrochlorofluorocarbons (HCFCs)}

\subsubsection{Chlorodifluoromethane (HCFC-22)}

\section{Production}

China, the United States, and Europe account for the majority of HCFC-22 production. China produced 418 ktons of HCFC-22 in 2016 (ChinalOL 2017). The United States reportedly produced 135 ktons in 2011 (EPA 2016a). No more than 56 ktons of U.S. production may be produced for emissive uses through 2019, pursuant to the EPA's HCFC Phaseout Schedule (EPA 2014). Currently, China consumes about $70 \%$ of the HCFC-22 it produces, and of that fraction, about $60 \%$ goes to emissive uses (e.g., refrigeration), while the remaining $40 \%$ is used as a feedstock (e.g., in the production of PTFE). As shown in Figure 10, approximately $40 \%$ of the HCFC-22 produced in the United States is used for emissive applications. The remaining $60 \%$ is used as a feedstock. Although aggregate European production of HCFC-22 is not directly available from public sources for confidentiality reasons, an idea of the size of this market can be estimated from aggregate HCFC production quantities. The European Union produced 120 ktons of HCFCs in 2015 (EEA 2015a), the vast majority of which was HCFC-22 to be used as a feedstock. ${ }^{2}$ Several other countries, such as Japan, India, and Argentina, also produce HCFC-22 in lesser amounts (IHS 2014).

\footnotetext{
${ }^{2}$ In 2016, three ktons of HCFC-22 were also exported to Japan (Trade Map) for ultimate use as a feedstock.
} 


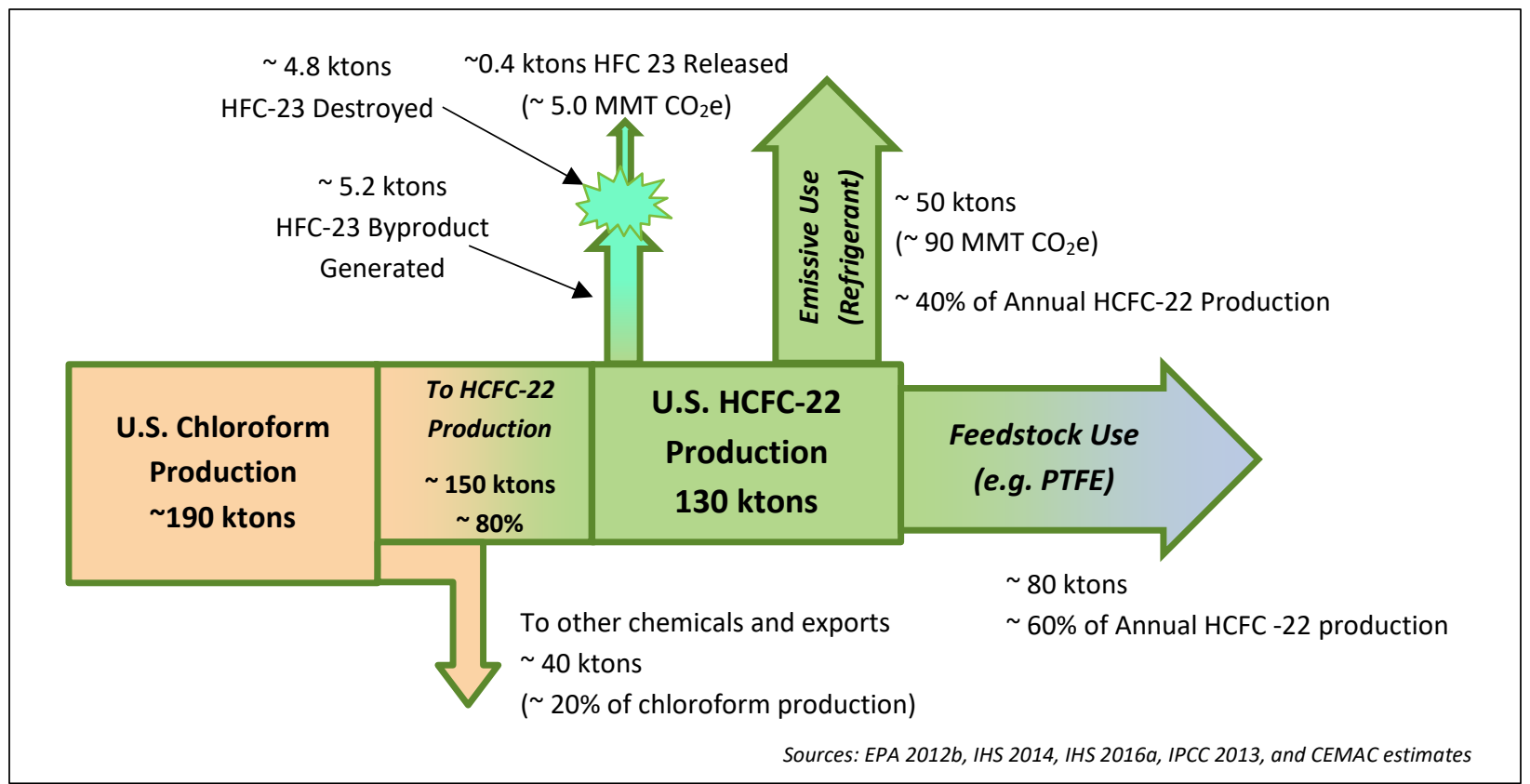

Figure 10. Simplified flow diagram of U.S. HCFC-22 supply chain, as of 2014. HFC-23 is a byproduct of HCFC-22 production, and most HFC-23 is now intentionally destroyed to avoid emitting it to the atmosphere, because it has a high global warming potential (GWP) of 12,400 (IPCC 2013).

\section{Distribution}

China accounted for 112 ktons (73\%) of the 150 ktons of HCFC-22 exported globally in 2016, followed by India with 20 ktons (13\%) and the Netherlands with 6 ktons (4\%) (Trade Map). Chinese HCFC-22 exports were distributed to many countries, with the highest fraction (23\%) going to Japan. ${ }^{3}$ Globally, Japan accounted for $16 \%$ of HCFC-22 imports in 2016, the highest of any country. Japan was followed by Germany with $12 \%$ of imports and Brazil with $8 \%$ (Trade Map). Being an Article 5 country subject to the longer Montreal Protocol phaseout schedule, Brazil still imports HCFC-22 for refrigeration purposes, whereas Germany, like Japan and the other non-Article 5 countries, now consumes HCFC-22 nearly exclusively for nonemissive feedstock applications.

\section{Regulatory Factors}

HCFC-22 is an ozone depleting substance (ODS) subject to phaseout under the Montreal Protocol, which mandates stepwise reductions in consumption leading up to a complete phaseout of all HCFCs in non-Article 5 parties by 2030 and in Article 5 parties by 2040. In addition, several parties have introduced stricter measures to reduce HCFC-22 consumption.

\footnotetext{
${ }^{3}$ Like the United States, Japan banned the use of HCFC-22 in new refrigeration systems as of 2010 (UNEP 2003), so nearly all Japanese imports of HCFC-22 are for feedstock uses, aside from a small "use or servicing tail" for existing refrigeration equipment. HCFC-22 for servicing will be banned in Japan after 2020 (UNEP 2003).
} 
In Europe, the use of virgin (new) HCFC-22 for emissive uses was banned in 2010. From 20102014, only recycled or reclaimed HCFC-22 could be used to service refrigeration equipment. On January 1, 2015, a Europe-wide ban on HCFC use for emissive applications went into effect (Milieu Ltd. 2007).

In the United States, the use of HCFC-22 in new equipment was banned in 2010; it may only be used to service equipment manufactured prior to 2010. By 2020, in accordance with the Montreal Protocol, HCFC-22 production for emissive uses will be banned entirely, and only recycled or reclaimed HCFC-22 will be able to be used to service equipment. By 2030, servicing and any other emissive use HCFCs, including HCFC-22, will be prohibited in the United States (and in all developed countries, pursuant to the Montreal Protocol).

\section{Intellectual Property}

Manufacture of HCFC-22 was first described in the patent literature by Thomas Midgley Jr., Albert L. Henne, and their colleagues at General Motors Corp with the landmark CFC patents filed in the 1930s (Henne 1934; Midgley et al. 1934; Henne 1935). Patents for the large-scale, commercial manufacture of HCFC-22 have long since expired-HCFC-22 is considered "offpatent" (no longer subject to patent restrictions).

\section{Summary}

- China leads the world in HCFC-22 production, followed by the United States and Europe.

- A significant fraction of HCFC-22 is used as a feedstock to make other chemicals. This use is not impacted by Montreal Protocol or other regulations, except to the extent that the emission of HFC-23, a byproduct of HCFC-22 production, is regulated.

- The Montreal Protocol calls for a phaseout of HCFC-22 in all developed countries by 2020 and in all developing countries by 2040.

- Europe has already banned all HCFCs, including HCFC-22, for emissive use.

\subsubsection{2,2-Dichloro-1,1,1-trifluoroethane (HCFC-123)}

\section{Production}

China, the United States, and Canada account for the majority of HCFC-123 production. China had a production quota of 2.8 ktons of HCFC-123 in 2016, which was issued to a single company-Zhejiang Lantian Environmental Protection Hi-Tech Co., Ltd. (CCM 2016b). The United States produced between 0.5 and 5.0 ktons of HCFC-123 in 2015 (EPA 2016a). Canada produced approximately 2.0 ktons of HCFC-123 in 2016 (UNEP Ozone Secretariat 2017).

\section{Distribution}

China accounted for $44 \%$ of global HCFC-123 exports in 2016, followed by Canada with 38\% and the United States with 15\% (Trade Map). Chinese HCFC-123 exports were mainly to Germany 
(72\%). Globally, Germany accounted for 2.3 ktons (33\%) of HCFC-123 imports in 2016, the highest of any country. It was followed by the United States with $30 \%$ of imports (98\% of which came from Canada) and South Korea with 8\% (Trade Map). All of HCFC-123 imported into Germany is intended for feedstock use (EEA 2015a), whereas some of the HCFC-123 imported into the United States can still be used in new centrifugal chillers until 2020.

\section{Regulatory Factors}

HCFC-123 is an ODS subject to regulation under the Montreal Protocol, which mandates stepwise reductions in consumption leading up to a complete phaseout of all HCFCs in nonArticle 5 parties by 2030 and in Article 5 parties by 2040. In addition, several parties have introduced stricter measures to reduce HCFC-123 consumption.

In Europe, the use of virgin (new) HCFC-123 was banned in 2010. From 2010-2014, only recycled or reclaimed HCFC-123 could be used to service refrigeration equipment. On January 1, 2015, a Europe-wide ban on HCFC use for emissive applications went into effect (Milieu Ltd. 2007).

In the United States, the use of HCFC-123 in new equipment is allowed until 2020, after which it may only be produced or imported for servicing existing equipment. U.S. production of HCFC123 for emissive uses will cease by 2030, pursuant to the Montreal Protocol. (See Section 3.1.3 "Other HFOs" for more information on potential replacements for HCFC-123 in commercial chillers).

\section{Intellectual Property}

Patents covering the production of HCFC-123 can be traced back to the original 1930s CFC patents assigned to General Motors after the discovery of CFCs by Thomas Midgley and others. However, modern commercial-scale patents specifically focusing on HCFC-123 production are concentrated in the late 1980s, with patents filed largely by DuPont (Manzer and Rao 1988; Gumprecht et al. 1989). These patents expired in the early 2000s, and HCFC-123 is now considered off-patent.

\section{Summary}

- Global production of HCFC-123 is small compared to that of HCFC-22 and is relatively evenly distributed between China, the United States, and Canada.

- Germany imports HCFC-123 but only for feedstock use (emissive use of HCFCs has been banned in Europe since 2015).

- The Montreal Protocol calls for a phaseout of HCFC-123 production for use in all developed countries by 2030 and in all developing countries by 2040 . 


\subsubsection{Other HCFCs}

The only other HCFCs used commercially are HCFC-124, HCFC-141b, and HCFC-142b. HCFC-124 is used as a refrigerant and fire suppressant but is only produced in negligible quantities. HCFC$141 \mathrm{~b}$ is still used as a blowing agent for polyurethane production in developing countries (especially China). HCFC-142b is mainly consumed as a feedstock but does have some refrigerant applications. As the amounts produced for refrigeration purposes are rather small, these HCFCs will be discussed only briefly.

China produces about 0.3 ktons of HCFC-124 annually and is likely the only significant producer globally, although Canada may also be a producer (Vithoontien 2016). China also produces about 90 ktons of HCFC-141b annually and exports 40\% of it to other Article 5 countries (Vithoontien 2016). China produces 80 ktons of HCFC-142b annually (Vithoontien 2016; ChinalOL 2017), but only about 17 ktons of that is for emissive uses (the remaining 64 ktons is consumed as a feedstock). China exports about 5 ktons of HCFC-142b annually to other Article 5 countries (Vithoontien 2016). The United States also produces HCFC-142b, but production is almost exclusively for feedstock uses as required by the phaseout schedule established by the EPA's HCFC production allowance system (EPA 2014). The production or import for nonfeedstock uses will be prohibited in the United States (and all developed countries) starting in 2020, pursuant to the Montreal Protocol. 


\subsubsection{Hydrofluorocarbons (HFCs)}

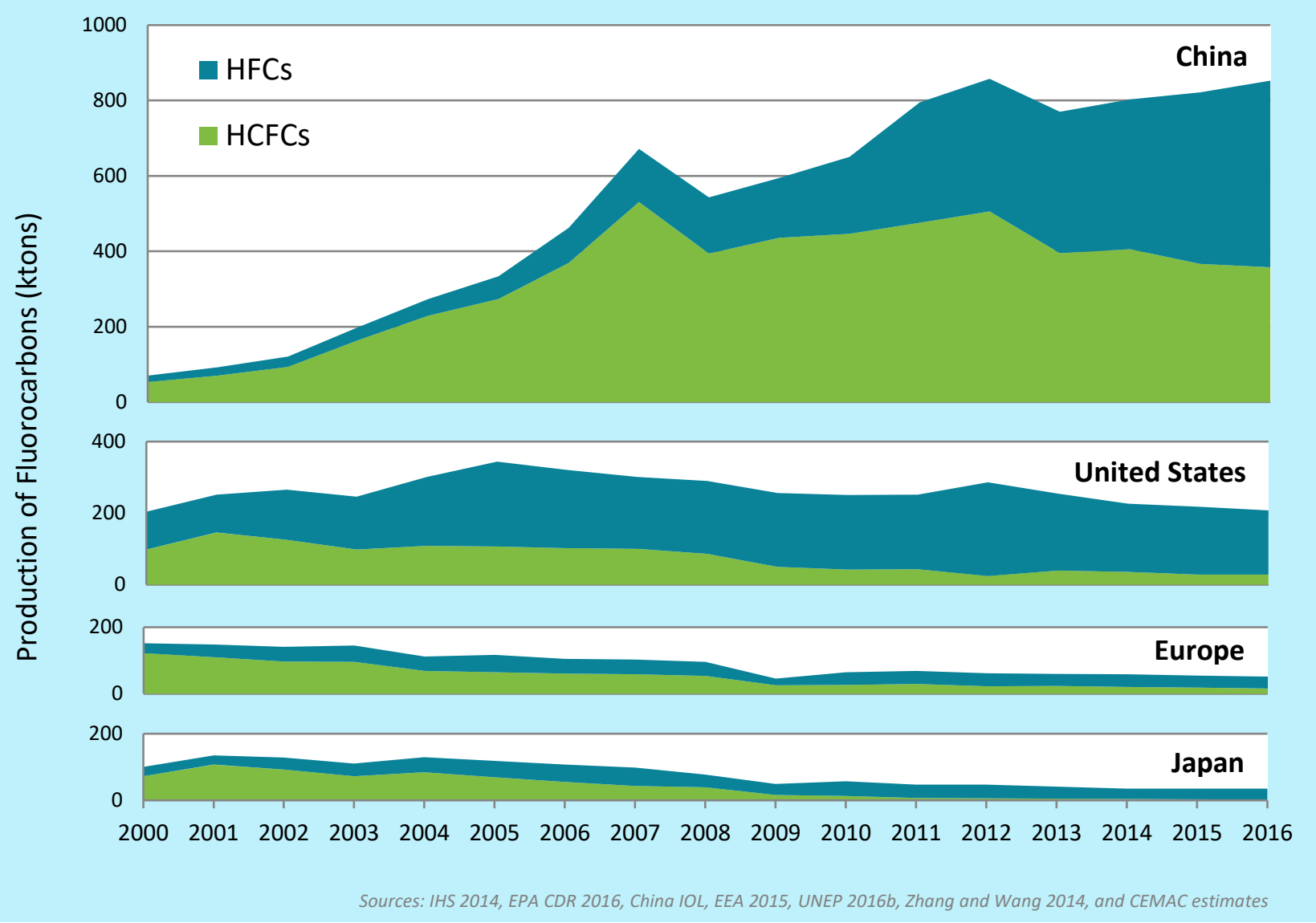

Figure 11. Metric tons of annual HCFC and HFC production for emissive use, by region (20002016). China is now the world's largest producer of both HCFCs and HFCs.

\subsubsection{1,1,1,2-Tetrafluoroethane (HFC-134a)}

\section{Production}

China and the United States are the major producers of HFC-134a. Chinese companies produced 150 ktons of HFC-134a in 2016 (ChinalOL 2017); the United States produces roughly 100 ktons of HFC-134a annually (EPA 2016a; IHS 2014). Lesser amounts are produced in the European Union, Japan, and India (EEA 2015b; IHS 2014; Rao 2016).

\section{Distribution}

China accounted for approximately $60 \%$ of global HFC-134a exports in 2016 , followed by the United States with approximately 30\% (Trade Map and CEMAC estimates). Chinese HFC-134a exports were mainly to the United States and EU, while U.S. exports were mainly to the European Union (Trade Map). 
There have been two separate antidumping lawsuits brought by U.S. HFC-134a manufacturers against their Chinese competitors. In the first, a 2013 suit filed by Mexichem, the U.S.

International Trade Commission (U.S. ITC) determined that the U.S. refrigerant manufacturing industry was not materially injured (U.S. ITC 2014) because of insufficient evidence that the increase in Chinese imports was responsible for the decrease in HFC-134a selling prices. However, in a more recent 2017 ruling, the causal link between Chinese HFC-134a imports and less than fair value prices was found to be more substantiated. The U.S. ITC ruled that Chinese imports were being imported for sale at less than fair value and imposed antidumping duties (U.S. ITC 2017). The approximate inverse relationship between HFC-134a unit value and quantity of Chinese imports is exhibited in Figure 12.

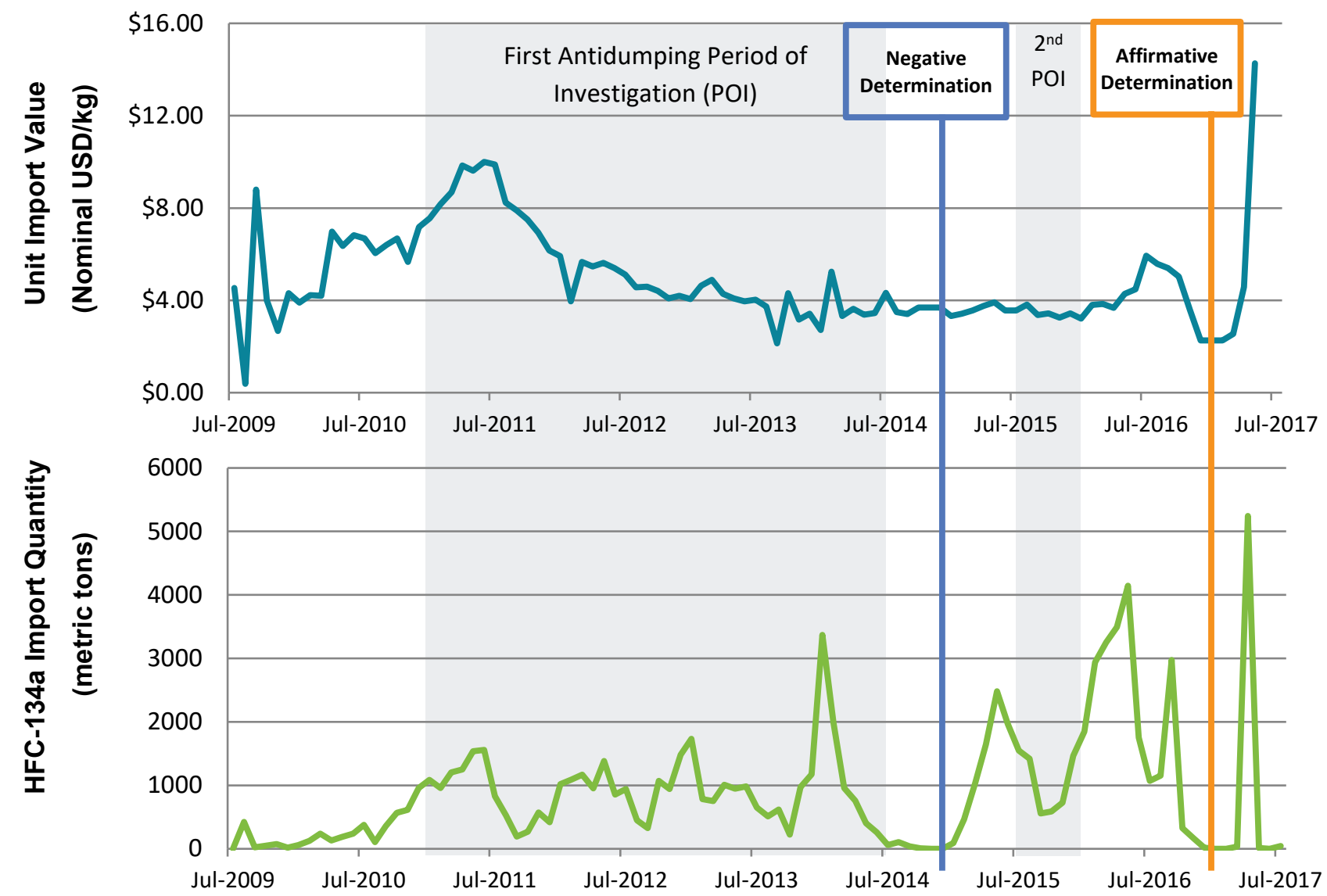

Figure 12. Unit values and quantities for U.S. imports of HFC-134a from China, July 2009-July 2017. The vertical lines represent the dates of final decisions issued by the U.S. International Trade Commission (U.S. ITC) in the two antidumping lawsuits concerning HFC-134a imports from China. The recent spike in unit values is indicative of the antidumping duties going into effect. 


\section{Regulatory Factors}

HFC-134a is not an ODS, but its GWP is 1,300 (see IPCC 2013 for full list of chemicals and their GWPs). For this reason, HFC-134a production and consumption, like that of most HFCs, will be phased down under the Kigali Amendment to the Montreal Protocol. Some developed countries have already implemented regulations aimed at reducing HFC-134a consumption, as described briefly below.

The EU F-gas Mobile Air Conditioning (MAC) Directive prohibits the use of any refrigerant with a GWP higher than 150, including HFC-134a, in all new vehicles as of 2017 (European Parliament Council Directive 2006).

In SNAP Rule 20 (finalized July 20, 2015), EPA determined that HFC-134a will be unacceptable for use in new U.S. automobiles beginning in 2021 (EPA 2015a). This SNAP Rule, however, would not impact the use of HFC-134a to service vehicles manufactured prior to 2021. On August 8, 2017, a federal appeals court ruled in favor of Mexichem in determining that the EPA did not have authority under the Clean Air Act to regulate HFC-134a via SNAP Rule 20 (Chemical \& Engineering News 2017). The EPA has yet to respond, and the ultimate fate of SNAP Rule 20 is unclear at this time.

Japan has enacted regulations that will phaseout the use of HFC-134a in light-duty vehicles by 2023 (MOE 2016).

\section{Intellectual Property}

The earliest HFC-134a manufacturing techniques were patented by Imperial Chemical Industries (ICI) in the late 1970s (Bell 1978; Potter 1979). DuPont was granted a patent for an HFC-134a manufacturing process in 1982 (Gumprecht 1982). By the time that the Montreal Protocol was agreed to in the late 1980s, significant research attention had been given to HFC-134a as a replacement for CFCs, and the patents followed-roughly half of all patents referencing HFC134a were granted between 1990 and 1999 (see Figure 21 in Section 3.1.1). The initial production patents filed in the early 1980s expired in the early 2000s, after which an increase in off-patent HFC-134a manufacturing was observed in Article 5 countries, especially China.

\section{Summary}

- China and the United States will continue to be the dominant producers of HFC-134a.

- Imports of HFC-134a from China to the United States are now subject to antidumping tariffs.

- Europe, the United States, and Japan all have regulations in place to reduce the use of HFC-134a in automotive air-conditioning systems. Phaseout dates for HFC-134a in new vehicles manufactured for these regions are 2017, 2021, and 2023, respectively. However, due to a recent court ruling, the U.S. regulation may be in jeopardy. 


\subsubsection{Blend Components}

\section{Production}

China and the United States are the largest producers of the following three HFCs, which are principally used as components in refrigerant blends: HFC-125, HFC-32, ${ }^{4}$ and HFC-143a. Lesser amounts are produced in the European Union and Japan (IHS 2014). Combined annual production of these blend components in China totaled 205 ktons in 2016 (ChinalOL 2017). Annual U.S. production is approximately 30-60 ktons of blend components (EPA 2016a; Vithoontien 2016). HFC-125 and HFC-32 account for the majority of global blend component production $-\mathrm{R}-410 \mathrm{~A}$, the most widely used HFC refrigerant blend, is composed $50 \% / 50 \%$ (by weight) of HFC-125 and HFC-32.

\section{Distribution}

China is by far the largest exporter of HFC blends and HFC blend components, at 110 ktons and 22 ktons in 2016, respectively (Trade Map). These amounts are each approximately 80\% of their respective global totals. Roughly half of Chinese blend component exports are shipped to the United States, with the balance split between Japan and the European Union. Refrigerants blended in China, on the other hand, are distributed to many countries, with the highest amounts going to Europe and Thailand (10\% each), followed by the United States (9\%) (Trade Map).

\section{Regulatory Factors}

HFC blend components are not ODS, but they do have significant GWPs (see IPCC 2013). Therefore, HFC blends and their components will be subject to phasedown under the Kigali Amendment to the Montreal Protocol.

In a 2016 antidumping lawsuit brought by U.S. refrigerant manufacturers against importers of Chinese HFC blends and blend components, the U.S. ITC found that the U.S. refrigerant industry was materially injured by Chinese imports, but only by the import of blends themselves. HFC blends imported from China are now subject to antidumping duties ranging from $101.82 \%$ to 216.37\% (U.S. ITC 2016). In that same decision, however, import of Chinese blend components was found not to be in violation of U.S. antidumping laws. U.S. refrigerant manufacturers argue that this decision creates a loophole, allowing the duty-free import of Chinese blend components and subsequent blending once those imports clear U.S. Customs (American HFC Coalition 2016). For this reason, the American HFC Coalition filed an appeal of the decision in late 2016, which is still pending (American HFC Coalition 2016).

\footnotetext{
${ }^{4} \mathrm{HFC}-32$ is also used on its own as a refrigerant. Production for this purpose is included in the totals for blend components since HFC-32 production is only reported in aggregate.
} 


\section{Intellectual Property}

The blend of HFC-125, HFC-134a, and HFC-143a now known as R-404A was first patented by DuPont in 1987 (Bivens and Connon 1989). The blend of HFC-125 and HFC-143a now known as R-507A was patented by Allied Signal (now Honeywell) in 1989 (Shankland et al. 1993). The blends of HFC-125, HFC-134a, and HFC-32 now known as R-407A and R-407C were first patented by DuPont in 1990 (Shiflett 1993). The blend of HFC-32 and HFC-125 now known as R410A was patented by Allied Signal (now Honeywell) in 1991 (Bivens et al. 1994).

Given the similar timeframe for the patenting of these major refrigerant blends, it is not surprising that these blend patents all expired around the same time, between 2009 and 2011. Because the blend compositions are no longer under patent protection, any company may now choose to produce or purchase the blend components and combine them to create the HFC refrigerant blends for resale. The degree to which this practice of off-patent blending, on its own, would have lowered blend and component prices (i.e., in the absence of increasing quantities of cheaper Chinese imports) became a central point of contention in the 2016 U.S. antidumping case (see the previous "Regulatory Factors" section).

\section{Summary}

- China is by far the largest producer of HFC blend components, followed by the United States.

- The widely used $\mathrm{R}-410 \mathrm{~A}$ refrigerant blend is a key driver in this market-any regulations targeting the use of R-410A will significantly affect the HFC component market.

- U.S. imports of Chinese HFC blends, but not their constituent blend components, are subject to antidumping tariffs. This may create a loophole for domestic refrigerant blending operations, and an appeal of the decision is pending.

\subsubsection{Other HFCs}

\subsection{HFC-152a}

HFC-152a is primarily used as an aerosol propellant, but does have refrigeration applications. Volumes produced for refrigerant applications remain relatively small; adoption has been minor at least in part due to flammability concerns. The following is a brief market summary and overview of major HFC-152a developments.

China and the United States are the largest producers of HFC-152a. China produced 64 ktons in 2016 (ChinalOL 2017), and the United States produced 23-45 ktons in 2015 (EPA 2016a). The specific amount of U.S. production is likely near the lower end of this range, given the estimated 20 ktons of HFC-152a capacity (Vithoontien 2016). Lesser amounts are produced in the European Union (5 ktons capacity) (Vithoontien 2016). IHS estimates that in 2012, about $54 \%$ of the HFC-152a consumed in the North American market went to aerosol applications, with about $20 \%$ used as a blowing agent, and $17 \%$ as a feedstock. Just $8 \%$ of the HFC-152a consumed in the North American market was for refrigerant uses. Approximately one-third of 
the 2012 European HFC-152a consumption went to refrigeration applications, but overall consumption of HFC-152a in this region was less than 10 ktons.

A Chinese venture to commercialize refrigerators using HFC-152a for the domestic market, with financial support from the Multilateral Fund, proved to be unprofitable (Andersen et al. 2012). Attention has since turned to the possibility of using HFC-152a in MAC. HFC-152a is being trialed as a refrigerant within a secondary loop system in India as part of a collaborative project headed by the Institute for Governance and Sustainable Development (IGSD) (IGSD 2017).

\subsection{HFC-245fa, HFC-365mfc, and HFC-227ea}

These three HFCs are used almost exclusively as foam blowing or fire suppression agents, so they will not be covered in detail in this report. However, restrictions on their production and use could increase the adoption of HFO-1233zd(E) and HFO-1336mzz(Z) (see "Other HFOs" section).

The United States produced between 4.5 and 22.7 ktons of HFC-245fa in 2015 (EPA 2016a). The most recent exact production data from Honeywell's Geismar, Louisiana, plant-the only major U.S. production location-was 21 ktons in 2011 (EPA 2016a). This is consistent with current estimates of installed U.S. HFC-245fa capacity ( 20 ktons) (Vithoontien 2016). The only other major producer, China, is estimated to have approximately 15 ktons per year of HFC-245fa capacity (Vithoontien 2016).

The European Union is currently the only region that produces HFC-365mfc, with 15 ktons per year of capacity at a single Solvay plant in Tavaux, France (the actual production tonnage range for HFC-365mfc is listed as confidential within the European Chemical Agency's [ECHA] Registration, Evaluation, Authorization and Restriction of Chemicals [REACH] database) (UNEP 2002; ECHA 2012a). China is the only region with HFC-227ea capacity, at around 9 ktons per year (Vithoontien 2016).

\subsection{Supply Chain Considerations: Fluorspar and Hydrofluoric Acid}

Essentially all major commercial manufacturing routes used in the production of HCFCs, HFCs, and HFOs start with a chemical reaction involving a chlorine-containing hydrocarbon with hydrofluoric acid (HF) (IHS 2014). HF is produced by reacting the mineral fluorspar with sulfuric acid. Even with the global phaseout of HCFCs and phasedown of HFCs, fluorspar and HF will remain in demand (if not more so) as HFO production increases to meet demand. Reliance on the mineral fluorspar could be reduced by obtaining fluorine from other natural resources, such as phosphate rock. Global reserves of phosphate rock are extensive, but current fluorine yields from this source are not economical when compared to the high fluorine content and relatively low price of acid-grade fluorspar (IHS 2016b). Fluorine extraction from phosphate rock is currently limited to fluosilicic acid byproduct recovery from phosphoric acid fertilizer production, but remains an active area of research (Dahlke et al 2016). 


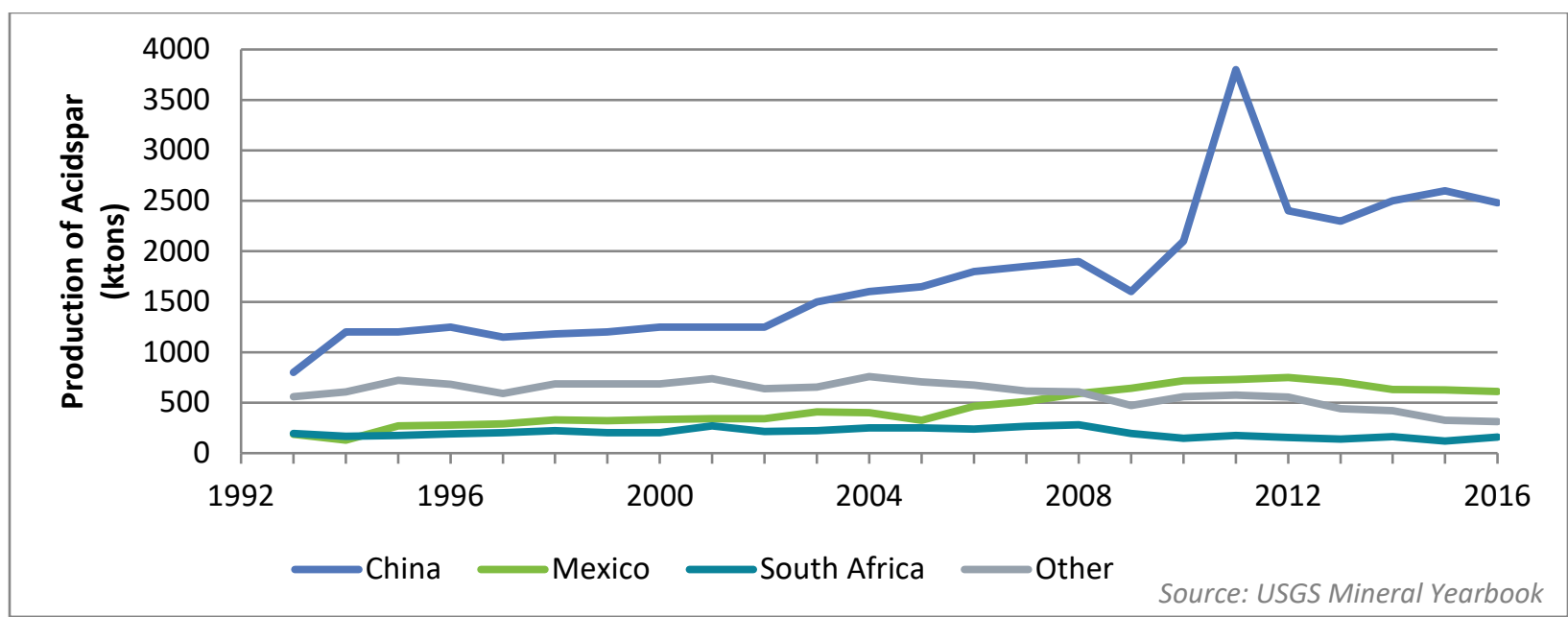

Figure 13. Global mined quantities of acid-grade fluorspar (“acidspar”), 1993-2016

As shown in Figure 13, China mines more acid-grade ${ }^{5}$ fluorspar than any other country in the world, at 2,500 ktons annually (USGS 2017). Mexico is the second-largest producer of acidgrade fluorspar at around 600 ktons annually, followed by South Africa (150 ktons). Contributions from the rest of the world have declined since the mid-2000s, with the remaining balance of acid-grade fluorspar production at about 300 ktons in 2016.

From the mid-1990s to early 2000s, most of the acid-grade fluorspar mined in China was exported to the major refrigerant producing regions (United States, EU, Japan). Starting from around $78 \%$ in 1999, however, the fraction of all mined acid-grade fluorspar in China that was exported has declined substantially. As a result of the dramatic expansion of the Chinese refrigerant manufacturing industry in the 2000s, most acid-grade fluorspar mined in China is now consumed domestically. Just $8 \%$ of the acid-grade fluorspar mined in China in 2016 was exported (Trade Map; USGS 2017). In 2008, Mexico overtook China as the leading exporter of acid-grade fluorspar to the United States and in 2009 became the largest fluorspar exporter globally (Trade Map). In 2016, Mexico supplied about 65\% of the acid-grade fluorspar imported into the United States (see Figure 14).

\footnotetext{
${ }^{5}$ Acid-grade fluorspar (also known as "acidspar") has a higher fluorine content than its metallurgical-grade counterpart ("met-spar"). Acid-grade fluorspar has a $\mathrm{CaF}_{2}$ content of at least $97 \%$ by weight (USGS 2017).
} 


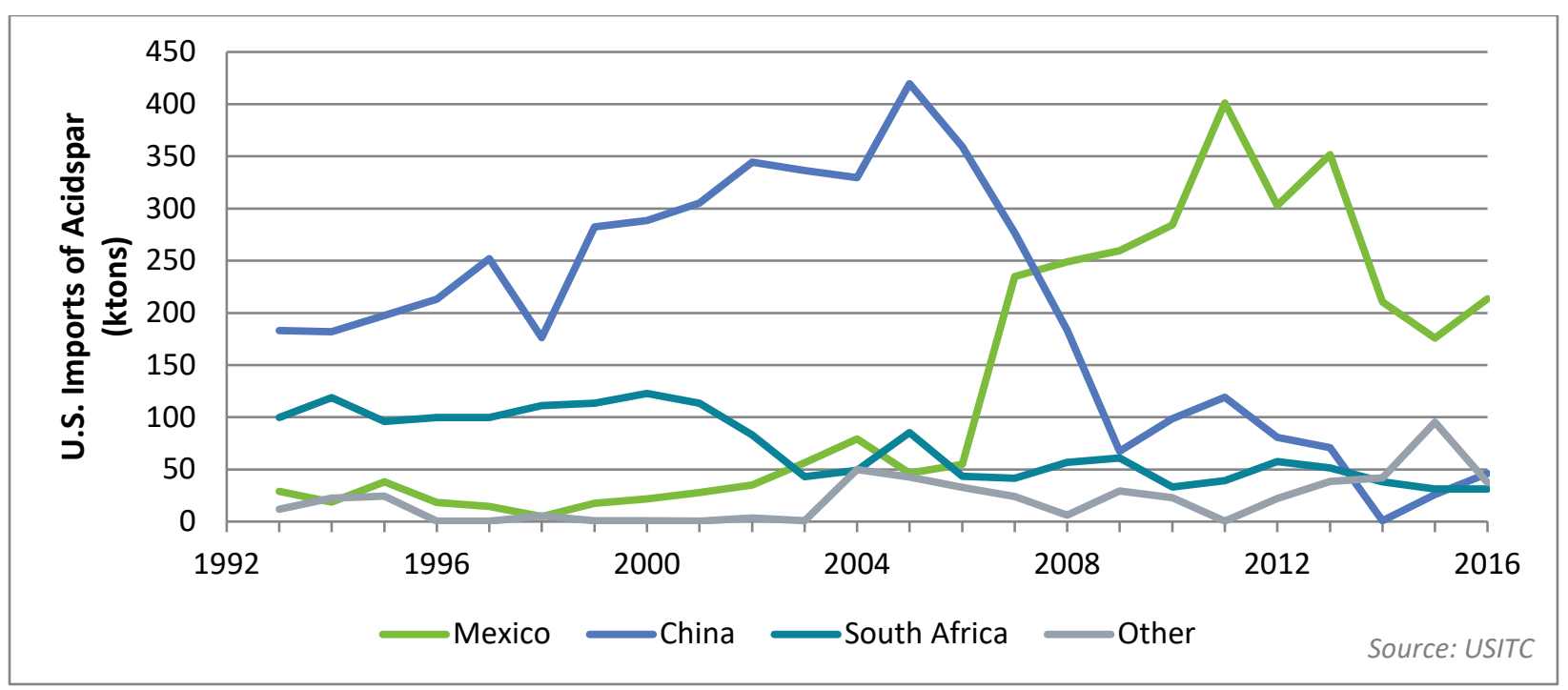

Figure 14. Annual U.S. import quantities of acid-grade fluorspar ("acidspar"), 1993-2016. Mexico, China, and South Africa are the major countries of origin for acidspar. Other countries that have imported significant quantities of fluorspar to the United States include Vietnam, Spain, the United Kingdom, and Mongolia.

The price of fluorspar rose significantly from the early 2000s through 2011 . This was mainly due to a restriction of fluorspar exports from China (BGS 2011; IHS 2014). The Chinese government began implementing export restrictions in January 1999 with the formation of an export quota licensing system (IHS 2014). China then added more controls, including export tariffs, quotas, licenses, and minimum export prices, and fluorspar prices continued to rise through the 2000s (see Figure 15). In 2009, the United States and several other parties, including the European Union and Japan, filed a complaint with the World Trade Organization (WTO) alleging that these export restrictions were inconsistent with China's WTO obligations (WTO 2011). China had argued that such restrictions were enacted for resource conservation and environmental protection purposes (USGS 2012), but the 2011 WTO ruling found Chinese export restrictions to be inconsistent with WTO rules (WTO 2011). After an unsuccessful appeal, China was required to remove export restrictions on fluorspar and the other raw materials covered by the WTO complaint, but Chinese fluorspar export quantities continued to fall after 2011 (see Figure 14).

The subsequent decrease in price level for fluorspar after the WTO ruling had little to do with the lessening of Chinese export restrictions. In the wake of the ruling, the Chinese government took alternative steps to ensure domestic fluorspar supply was consumed internally in the manufacture of higher-valued products (Stewart 2012). The fluorspar price decrease has been attributed more to the reduced demand for raw material feedstocks triggered by the overall lessening of demand for virgin refrigerants themselves, which in turn is due to existing or anticipated phaseouts (Salwan 2015). In other words, the price increase prior to 2011 was driven more by supply constraints, whereas the price decrease after 2011 was caused by lower global demand despite a continued decline in Chinese fluorspar exports. 


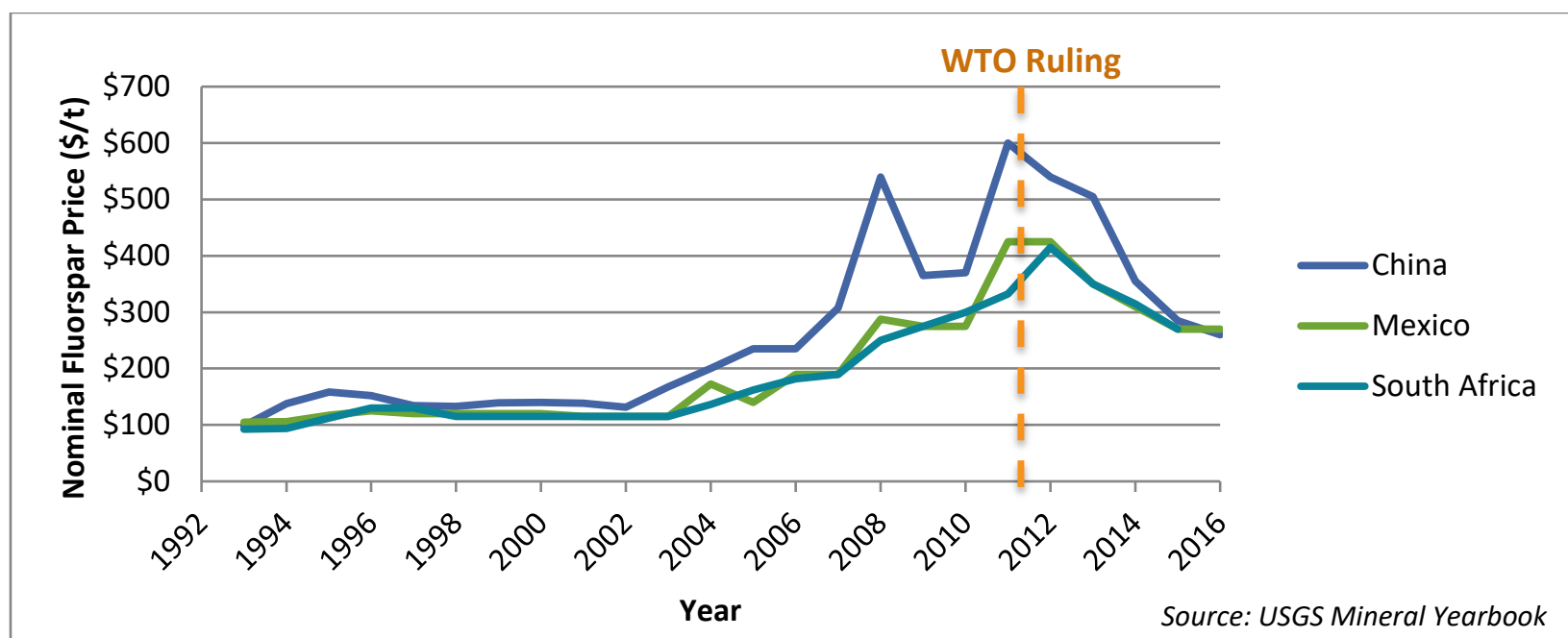

Figure 15. Nominal prices of acid-grade fluorspar ("acidspar") imported into the U.S. market, by country of origin, 1993-2016

HF itself is also traded globally; however, it is both toxic and corrosive (Mexichem 2013), making it difficult to transport great distances. For this reason, exported quantities are substantially lower than those of fluorspar, and HF export is mostly limited to nearby countries. For example, China primarily exports HF to Japan and South Korea, whereas nearly all Mexican HF exports go to the United States (Trade Map). Likewise, most HF imported into the United States comes from Mexico (see Figure 16).

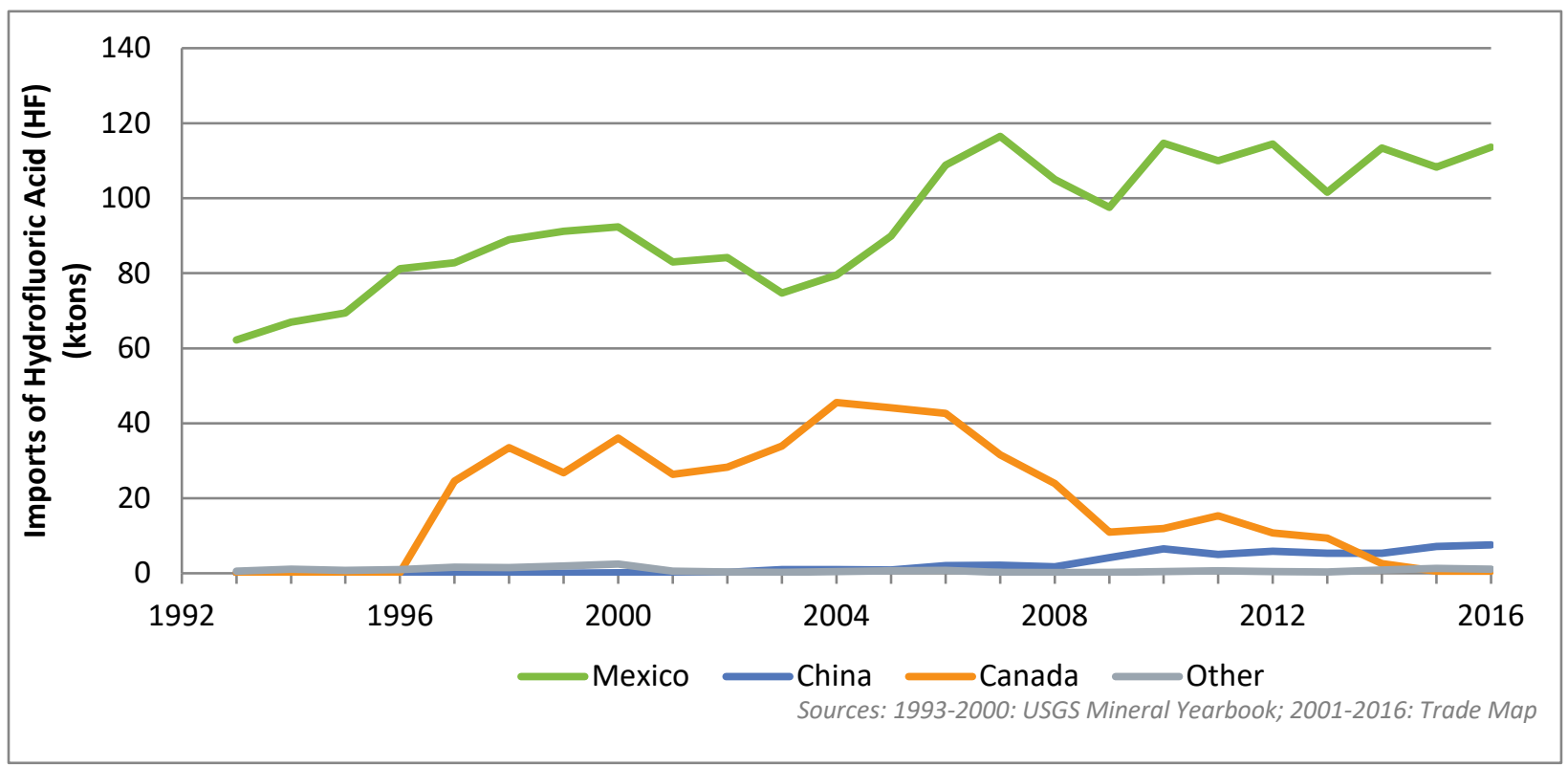

Figure 16. U.S. imports of hydrofluoric acid, 1993-2016 


\subsection{Refrigerant Manufacturing Locations}

At the time CFCs were phased out in the mid-1990s, refrigerant manufacturers were already beginning to produce commercial quantities of the HFCs that would eventually replace the HCFC "transitional substances." DuPont, for example, already had 50 ktons of global HFC-134a capacity by January 1993, with plants located in the United States and Japan (Roberts 1993). $\mathrm{ICl}^{6}$ had an HFC-32 plant in the United Kingdom as well as HFC-134a plants in both the United States and Japan (Roberts 1993). Indeed, refrigerant manufacturing during this period tended to be located in the regions with major end-use markets for the refrigerants: the United States, European Union, and Japan.

More recently, China has become a major refrigerant manufacturer and now accounts for the majority of annual fluorocarbon production. Figure 17 and Figure 18 show the locations of HCFC and HFC capacity as of 2016, respectively. Inexpensive feedstocks derived from China's extensive fluorspar mining operations (see Section 2.2), cheaper labor and processing energy, and the formation of Chinese chemical manufacturing "centers of excellence" all facilitated this growth (Seidel et al. 2015). Furthermore, the rise of Chinese bulk refrigerant manufacturing paralleled an increase in Chinese refrigeration and air-conditioning equipment production, ${ }^{7}$ and this was cited as a key driver for a 2004 joint venture between DuPont and Chinese company Zhonghao New Materials (now known as Shanghai 3F New Materials Co., Ltd.) to manufacture HFC blends (Sheridan 2004). Partnerships between major Western chemical companies and Chinese producers are now common in the refrigerant industry and have continued with the transition to HFO production. In 2010, Shanghai 3F and DuPont formed another partnership, this time to manufacture HFO-1234yf at a jointly operated plant in Changshu, China (CCM 2012).

Nevertheless, the United States has been and continues to be a major producer of HFCs and now HFOs. In 1949, the Pennsylvania Salt Manufacturing Company (now known as Arkema) constructed an HF plant in Calvert City, Kentucky, utilizing the fluorspar from nearby mines as feedstock (Arkema 2017). Although fluorspar has not been mined in Kentucky since 1992 due to lower import prices (Walker 2010), the Calvert City plant still remains and has undergone several expansions - it now produces HFC-134a and HFC-32. The HFC-32 expansion was announced in 2007 and precipitated the 2014 closure of Arkema's aging HFC-32 and HFC-143a plant in Zaramillo, Spain. The Spanish plant was closed due to the "competitiveness gap with China and the United States," as well as the significant capital expenditures that would have been required to bring the plant into compliance with EU regulations (Arkema 2014).

\footnotetext{
${ }^{6} \mathrm{ICl}$ was acquired by AkzoNobel in 2008 (Akzo Nobel 2008).

${ }^{7}$ Air-conditioner production alone was growing at about 10\% per year in China in 2004 (ICIS 2004).
} 


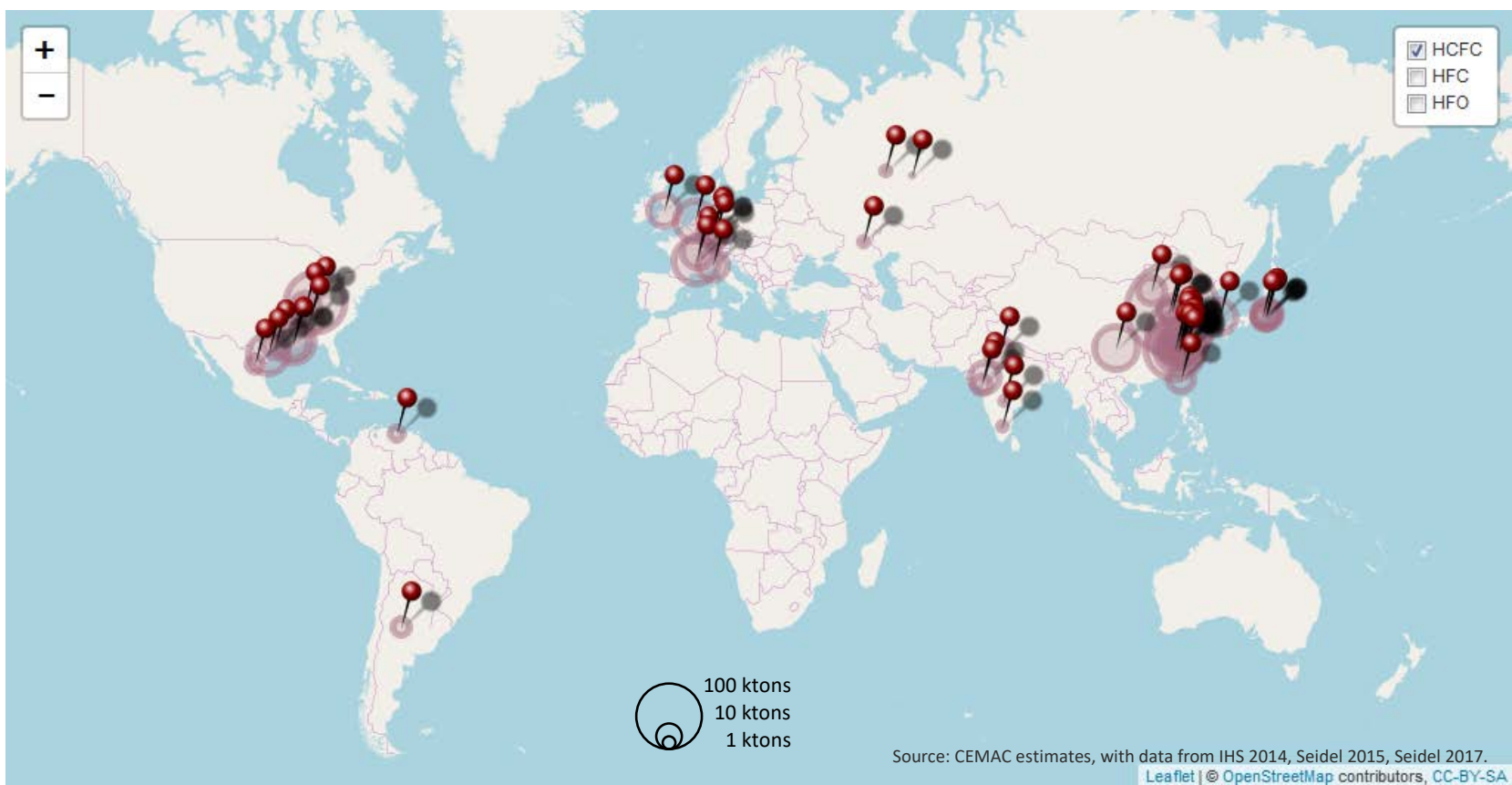

Figure 17. Locations and estimated capacities of HCFC manufacturing plants as of 2016. HCFC capacity is concentrated in China, with significant additional capacity in the United States,

Europe, and Japan. Lesser capacities are scattered across various other countries.

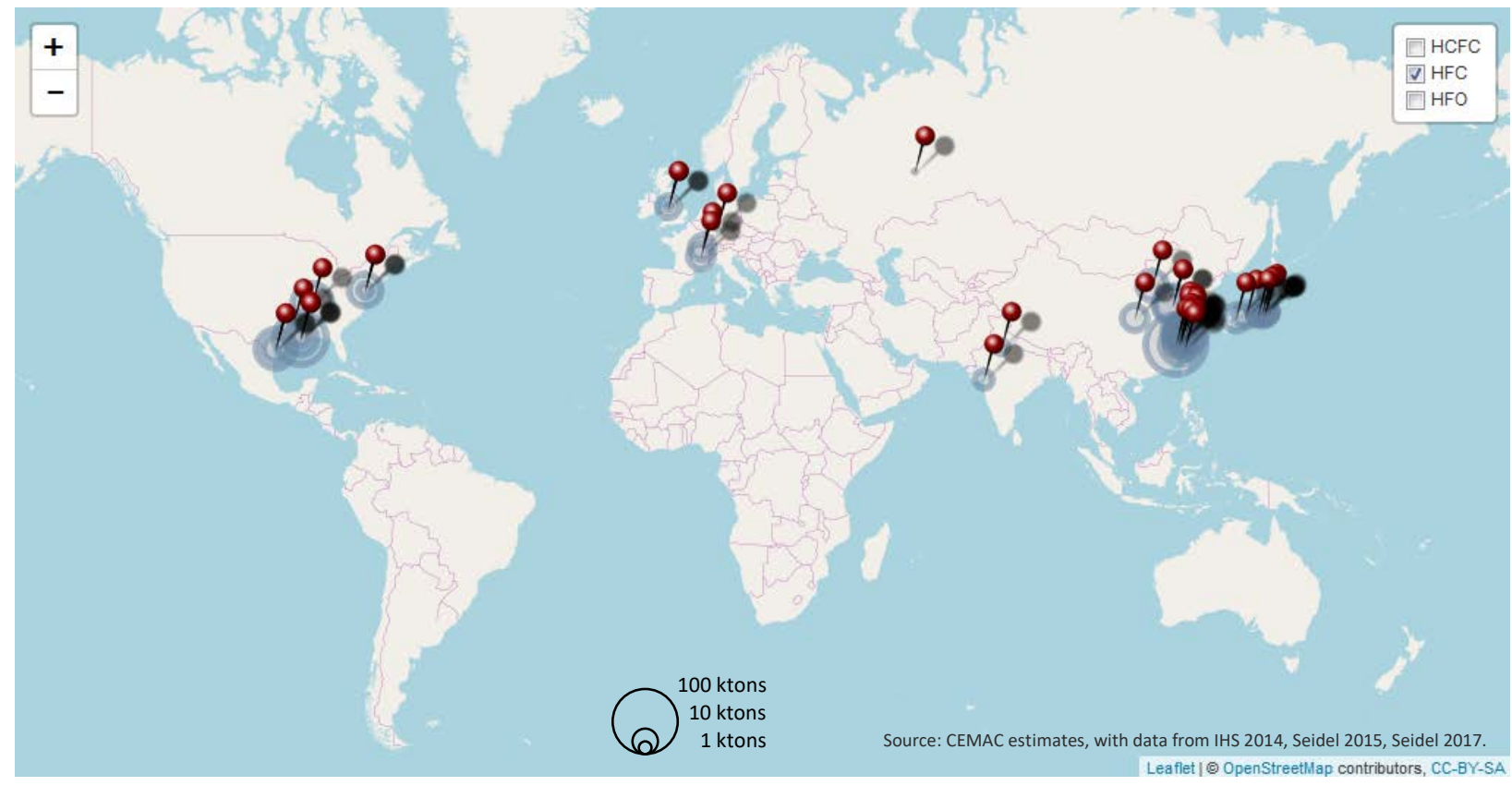

Figure 18. Locations and estimated capacities of HFC manufacturing plants as of 2016. HFC capacity is concentrated in China, with significant additional capacity in the United States and Japan. Lesser capacities are scattered across various other countries. 


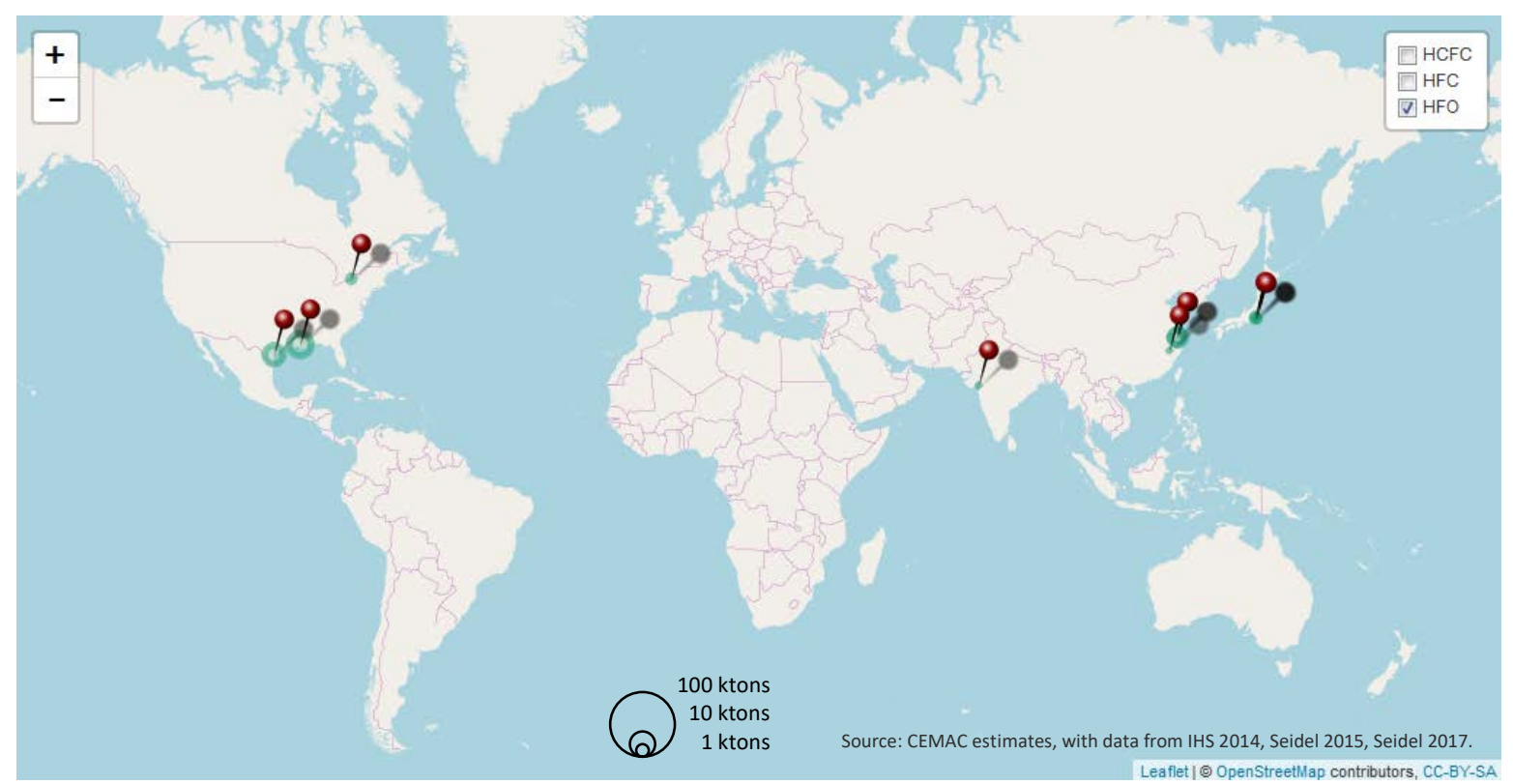

Figure 19. Locations and estimated capacities of HFO manufacturing plants, projected for 2018. By 2018, the major HFO capacity is expected to be relatively evenly spread between the United States and China, followed by Japan and India. Note: capacities for HFO plants are not typically disclosed and may vary widely from the estimates shown here.

In 1991, DuPont began constructing an HFC-134a plant in Corpus Christi, Texas (ICIS 1991). This location was chosen by DuPont at least in part because of the plant's existing capital; HFC-134a production was to utilize the same equipment and feedstock that had been used previously to make CFCs and HCFCs. Still, the HFC-134a production process itself would be "substantially different, both in terms of engineering and process operating parameters" (ICIS 1991). In 1995, DuPont added capacity for HFC-152a at Corpus Christi in order to meet U.S. demand for volatile organic compound-exempted aerosol propellant (ICIS 1995; CARB 1997) ${ }^{8}$.

Honeywell invested over $\$ 200$ million to build HFC-245fa and HFC-125 plants at Geismar, Louisiana in the early 2000s. By constructing them simultaneously, the company was able to reduce overall plant construction costs (Powell 2003). This was the preferred location of the plants due to Honeywell's existing HFC and HCFC capacity at Geismar-the company was able to take advantage of "an experienced workforce and a proven supply chain" (Powell 2003). Honeywell had negotiated a contract with Vulcan Materials Company, which was building a hydrochlorocarbon plant in Geismar, Louisiana to obtain a necessary feedstock chemical for HFC-245fa production (Kamalick 2000). Most recently, Honeywell built an HFO-1234yf facility at

\footnotetext{
${ }^{8}$ Although not directly related to the refrigerant market, this example is worth mentioning because of the parallels to the refrigerant manufacturing industry with regard to pricing disparity. Original equipment manufacturers voiced concern about HFC-152a supply shortage and thus higher prices-quoted prices at the time were \$1.95/lb for HFC-152a compared to $\$ 0.20 / \mathrm{lb}$ for original (hydrocarbon) propellant (CARB 1997). That said, prices were already decreasing in November 1996: $\$ 1.95$ to $\$ 1.85 / \mathrm{lb}$.
} 
Geismar, which began production in 2017. When the plant was announced in 2013, Honeywell cited incentives from the Louisiana Economic Development authority as a key driver in choosing Geismar for additional HFO capacity. The project was estimated to create 1,363 construction jobs as well as 55 permanent jobs (LED 2017). Projections for HFO manufacturing locations and capacities are shown in Figure 19 and indicate that by 2018, HFO production will be relatively evenly distributed between the United States, China, and Japan.

In summary, refrigerant manufacturing plants historically have been constructed in locations with one or more of the following characteristics (roughly in order of chronological relevance):

1. Proximity to fluorspar, HF, or other chemical feedstock

2. Within a country with strong refrigerant demand

3. Proximity to refrigeration and/or HVAC equipment manufacturers

4. Near a port city to facilitate import of raw material and/or export of finished product

5. Existing refrigerant manufacturing capital and experienced labor force

6. Availability of cheap energy and labor

7. Financial incentives from local governments or development authorities. 


\section{Alternative Refrigerants}

\subsection{Overview of Types and Applications}

The term "alternative refrigerants" generally refers to any refrigerant outside the major fluorocarbons currently in use. This designation includes ammonia, carbon dioxide $\left(\mathrm{CO}_{2}\right)$, and propane, which have all been used to some extent for decades as refrigerants, as well as newly developed, man-made fluorocarbons such as HFOs (including HFO-1234yf) or blends of HFOs with other substances (typically HFCs). They are frequently classified into three categories, as shown in Table 4. Recent research and development in this area has focused on $\mathrm{CO}_{2}$-based systems and in HFO commercialization. Data on costs, prices, trading patterns, and production are often not available for these materials. This is partly due to the nascent and dynamic market for these products, but also because these data are typically business sensitive and/or proprietary. However, market trends and other qualitative information are available as well as some quantitative data, which are presented here.

Ammonia is a toxic refrigerant that is widely used in industrial refrigeration. Due to toxicity there is limited opportunity for expanding applications beyond this large but somewhat niche market.

Table 4. Common Alternative Refrigerants (EFCTC 2017)

\begin{tabular}{|c|c|c|}
\hline Category & Common Refrigerants & Typical Applications \\
\hline \multirow{2}{*}{$\begin{array}{l}\text { Inorganic } \\
\text { (Natural) }\end{array}$} & Ammonia (R-717) & Industrial refrigeration \\
\hline & $\mathrm{CO}_{2}(\mathrm{R}-744)$ & $\begin{array}{l}\text { Commercial refrigeration, } \\
\text { foam blowing agent, heat } \\
\text { pump water heaters, combo } \\
\text { (space conditioning and } \\
\text { water heating) systems }\end{array}$ \\
\hline \multirow[t]{4}{*}{$\begin{array}{l}\text { Hydrocarbon } \\
\text { (Natural) }\end{array}$} & Propane (R-290) & $\begin{array}{l}\text { Small self-contained } \\
\text { commercial refrigeration, } \\
\text { small stationary heat pumps, } \\
\text { aerosol }\end{array}$ \\
\hline & Isobutane (R-600a) & $\begin{array}{l}\text { Residential/small commercial } \\
\text { refrigerators, aerosol }\end{array}$ \\
\hline & n-butane (R-600) & Aerosol \\
\hline & Cyclopentane (R-601c) & Foam blowing agent \\
\hline \multirow[t]{4}{*}{$\begin{array}{l}\text { Hydrofluoroolefin } \\
\text { (HFO) }\end{array}$} & R-1234yf & $\begin{array}{l}\text { Mobile, stationary HVAC, } \\
\text { refrigeration }\end{array}$ \\
\hline & $R-1234 z e(E)$ & $\begin{array}{l}\text { Refrigeration, HVAC, aerosol, } \\
\text { blowing agent }\end{array}$ \\
\hline & $R-1233 z d(E)$ & $\begin{array}{l}\text { Chillers, blowing agent, } \\
\text { solvent, waste heat recovery } \\
\text { (organic Rankine cycles) }\end{array}$ \\
\hline & $\mathrm{R}-1336 \mathrm{mzz}(\mathrm{Z})$ & Chillers, blowing agent \\
\hline
\end{tabular}


$\mathrm{CO}_{2}$ has seen a surge in popularity in recent years for cascade systems, where it has been shown to be an efficient and promising system in supermarket refrigeration (Fricke and Sharma 2016). However, in direct expansion systems such as beverage vending machines, initial momentum in using $\mathrm{CO}_{2}$ has been tempered largely due to the high system cost and low reliability that result from the high operating pressures in these systems (Hon 2017; VTech 2017).

Hydrocarbon refrigerants (also referred to as "natural" along with ammonia and $\mathrm{CO}_{2}$ ) have gained traction in vapor compression systems in many areas of the world outside the United States (BSRIA 2015a). Small, self-contained systems, such as those used for household refrigeration, commonly use isobutane with more than 600 million units in operation globally and annual sales of 35-40 million units (Greenpeace 2012). Propane is gaining popularity for use in smaller stationary air-conditioning and small commercial refrigeration systems such as vending machines. Safety limitations (due to flammability) are currently limiting use to smaller systems with less than $150 \mathrm{~g}$ of propane per refrigerant loop in many countries, although there is momentum building for increasing that charge, potentially up to 500g (Hydrocarbons21 2017) and a kilogram or more for some commercial and industrial uses (Kandi 2015). Asian countries are adopting propane devices in large numbers (BSRIA 2015b), with major manufacturers such as Gree developing ductless heat pumps that operate on propane (Hasse 2009). These devices have not made it to the U.S. market as of yet, although they are allowed under the EPA's SNAP program for certain applications (EPA 2017).

The major HFO refrigerants are listed in Table 4; more detail is provided on these HFOs in Goetzler et al. (2014). HFOs are often used in blends with HFCs for vapor compression systems. These blends are not listed here because there are a very large number of them. For a detailed list of refrigerants, including HFO blends, see ASHRAE Standard 34-2016 (ASHRAE 2016). However, the most common compounds in HFO blends are the HFOs listed in the table, plus the HFCs R-32, R-134a, R-125, and R-152a.

Although blending of HFOs is common, the largest application of HFOs currently is R-1234yf for mobile applications, where it is replacing R-134a. R-1234yf is by far the most common HFO in production ( $\sim 3 x$ the production of all other HFOs combined [BSRIA 2015]) and is being adopted globally by the automotive industry.

Prices for HFOs are sometimes a concern; most of the available cost information is for HFO$1234 y f$. Sherry et al. (2017) provide a detailed analysis of different production methods for HFO-1234yf and determine that although costs in the short term are 10x that for HFC-134a, long-term costs are likely to be $2-3 x$ that cost. An example cost comparison between HFC-134a and a hypothetical HFC/HFO blend is presented in Section 3.1.1.

HFO-1234ze(E) is the second-most-developed HFO in terms of production capacity; there could actually be temporary excess capacity in preparation for major equipment shifting to HFOs and blends (Walters-Terronini 2017). It can be used as an aerosol propellant (Rivoira 2014). It is also 
marketed by Honeywell under the name Solstice Gas Blowing Agent. It is a component in many blends such as HFO-444A, $-444 \mathrm{~B},-445 \mathrm{~A},-447 \mathrm{~A}$, and $-447 \mathrm{~B}$ and is suitable for use in low- and medium-temperature refrigeration and stationary air-conditioning/heat pump applications as listed in Table 3. It is SNAP listed in the United States for use in chillers and certain foam blowing agent applications (EPA 2017; Goetzler et al. 2014).

HFO-1233zd(E) is marketed by Honeywell as Solstice LBA liquid blowing agent (EJARN 2016). It is a substitute for HFC-245fa with commercial applications in domestic appliances (EJARN 2015b). It is also used as a replacement for R-123 in centrifugal chillers (EJARN 2015b; EJARN 2016) and is SNAP listed for both of those applications (EPA 2017). This refrigerant is designated "A1," meaning it is nonflammable as well as nontoxic (Goetzler et al. 2014), which is a distinct advantage in terms of regulatory approval and consumer acceptance over many other HFOs.

HFO-1336mzz(Z) has been branded by Chemours as Opteon 1100 (formerly Formacel 1100) and marketed for use as a blowing agent. It has $\sim 5 \%$ better R-value for polyurethane foams than if produced using HFC-245fa (McMenamin et al. 2009). It is also SNAP listed for use in chillers, is nonflammable, and can potentially be used for high temperature heat pumps and organic Rankine cycles (EJARN 2015b; Konstantinos 2014).

Other emerging applications for HFOs, primarily in blends, are for chillers, stationary air conditioners and heat pumps, refrigeration, and as blowing agents. Table 3 and Table 4 provide more detail about which new refrigerant or blend is used in each application.

The following sections provide more in-depth market statistics for the four HFOs that have been commercialized to date: HFO-1234yf, HFO-1234ze(E), HFO-1233zd(Z), and HFO$1336 \mathrm{mzz}(\mathrm{Z})$.

\subsubsection{HFO-1234yf}

\section{Production}

2,3,3,3-Tetrafluoropropene, better known as HFO-1234yf, is the highest volume HFO refrigerant worldwide. The United States, China, and Japan are the leading producers of HFO$1234 y f$. Specific plant capacities for this relatively new refrigerant are confidential in some cases, so it is difficult to estimate production quantities. Honeywell began operation at its newly constructed HFO-1234yf plant in Geismar, Louisiana, in May 2017 (Honeywell 2017). That plant has an estimated annual capacity of 10-15 ktons (Sherry et al. 2017). Chemours has announced plans to triple its HFO-1234yf capacity by constructing a plant in Corpus Christi, Texas, to be operational by the end of 2018 (Allgood 2017). China has at least 6 ktons/year of HFO-1234yf capacity from the Shanghai 3F/Chemours jointly operated plant, and this total does not include the additional 7 kton capacity from an Arkema plant not yet operational and an undisclosed additional capacity from an agreement between Honeywell and Juhua Corp. (PRLog 2012; ACHR NEWS 2016). Two Japanese plants produce smaller quantities of HFO-1234yf, estimated at less than 1 kton capacity each (Sherry et al. 2017). 


\section{Distribution}

Europe has been the focal point of international trade in HFO-1234yf because it was the first region to legislate a phaseout of HFC-134a in mobile air conditioning (see "Regulatory Factors," below). In 2016, more than 4 ktons of HFO-1234yf was imported by Europe, mainly from China and Japan (see Figure 20) (Eurostat 2017). HFO-1234ze(E) is registered in the highest tonnage band ( $>1$ ktons annually) under ECHA's REACH program, meaning there are would be no limitation on further increases in imports of HFO-1234yf into the European Union (Achaichia 2014; ECHA 2010). Exact Chinese and Japanese imports to the United States are uncertain, but the quantities are assumed to be sufficient to meet growing demand for the manufacture of vehicles in the United States by companies such as GM, Ford, Fiat Chrysler, and Tesla. These companies and others are adopting HFO-1234yf in some of the newer model years of American-made and imported cars and trucks (Chemours 2017c). The United States is expected to take over a broader share of the export market from 2017 onward as domestic HFO-1234yf production has begun at the Honeywell's Baton Rouge plant in 2017 and is expected to begin at the Chemours plant in Corpus Christi, Texas, in 2018.

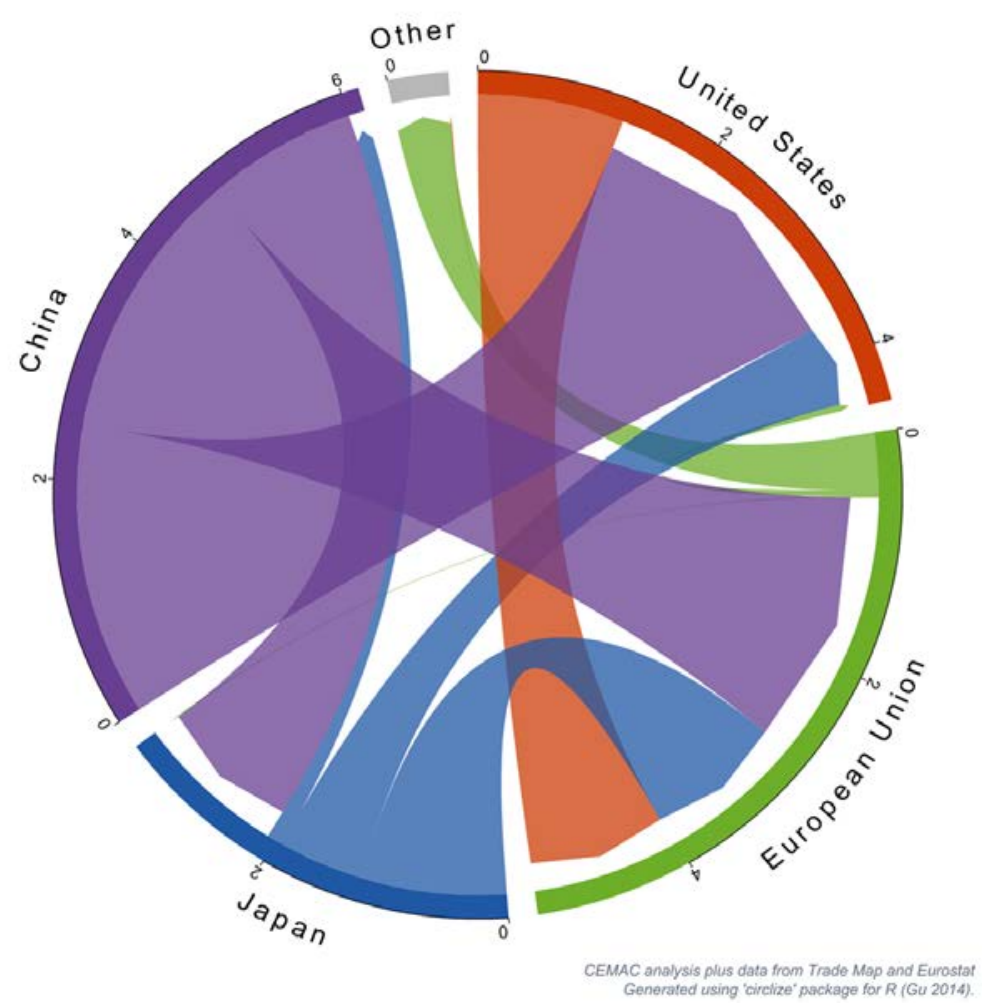

Figure 20. 2016 trade flows of HFO-1234yf in ktons. Trade flows not involving the European Union, which reports import and export data specifically for HFO-1234yf, should only be viewed as rough estimates. The "Other" category includes all other countries listed as receiving HFO-1234yf imports from Europe, most notably Turkey and South Africa. It is anticipated that U.S. production (and exports) will increase significantly in 2017 with the opening of Honeywell's Louisiana plant, and this growth in U.S. market share will continue when the Chemours plant in Texas begins operation in 2018. 


\section{Regulatory Factors}

The EU F-gas MAC Directive prohibits the use of any refrigerant with a GWP higher than 150, including HFC-134a, in all new vehicles as of 2017 (European Parliament Council Directive 2006). Most automakers have decided on HFO-1234yf as the replacement of choice, so most new EU vehicles now use HFO-1234yf in their mobile air-conditioning systems.

In SNAP Rule 20 (finalized July 20, 2015), the EPA determined that HFC-134a is unacceptable for use in new U.S. automobiles beginning in 2021 (EPA 2015a). Following Europe's lead, several U.S. automakers have already begun transitioning MAC systems to HFO-1234yf (see "Distribution," above), with adoption in the remaining U.S. vehicles expected by 2021.

As of July 16, 2015, the EPA has determined that R-513A, a blend of HFO-1234yf and HFC-134a, is acceptable for use in centrifugal chillers in the United States (EPA 2015b). Trane has offered chillers using R-513A since this SNAP ruling was published (Trane 2015). Johnson Controls has offered R-513A chillers since 2016 (Johnson Controls 2016). More recently, Dunham-Bush announced the use of R-513A in chillers marketed for the Asia Pacific region (Cooling Post 2017).

In Notice of Acceptability 31, published on May 23, 2016, the EPA lists R-513A as an acceptable substitute in retail food refrigeration systems (EPA 2016b).

\section{Intellectual Property}

HFO-1234yf production is still a relatively young industry, so most information on the manufacture of this chemical is still considered proprietary and confidential. Much of the relevant HFO-1234yf intellectual property has been disclosed in patents filed by the major refrigerant producers. As shown in Figure 21, the number of granted patents involving HFO1234 yf has risen sharply since 2010 . The rate that patents are now being granted for inventions related to HFO-1234yf-more than 100 per year as of 2016-is now close to double the rate that HFC-134a-related patents were being granted at their peak in the late 1990s and early 2000s. Honeywell and Chemours have the largest shares of HFO-1234yf-related patents, as shown in Figure 22.

A notable subset of HFO-1234yf-related patents is the so-called "use" or "application" patents first issued to Honeywell starting in 2003 (Singh et al. 2009; Wilson et al. 2012). Instead of describing the invention of a method of manufacture, these patents describe the use of HFO$1234 y f$ in automobile air-conditioning systems and have been the subject of several legal disputes concerning their validity as "novel" inventions (Seidel 2015. Companies outside the Honeywell-Chemours HFO-1234yf development partnership, most notably Arkema, have challenged these patents and, in most cases, succeeded in having them revoked. However, there is an extensive appeals process, and Honeywell has appealed each of the patent-revoking decisions. While most of the challenges await a ruling on an appeal, the application patents remain in effect. 


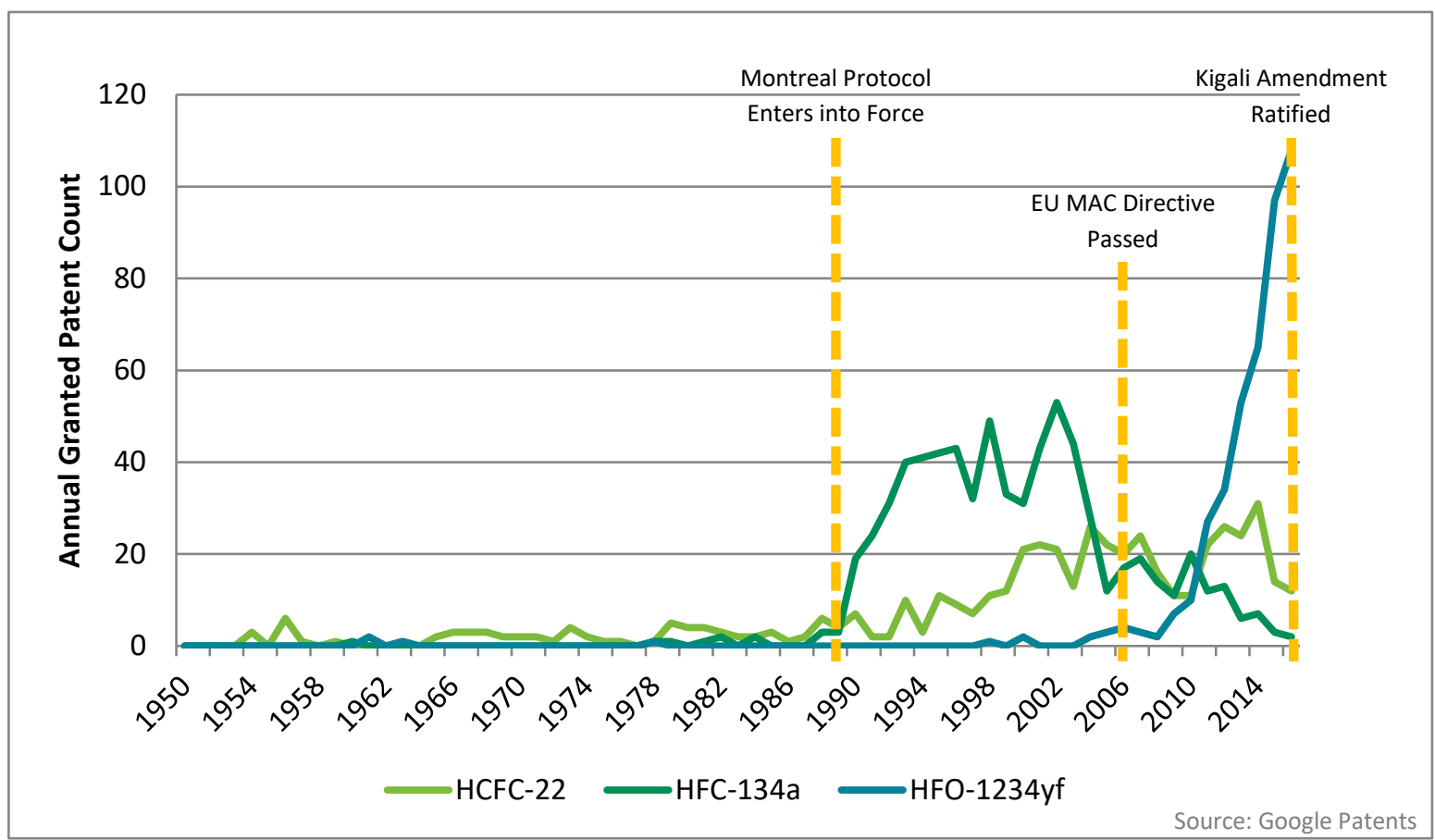

Figure 21. Fluorocarbon-related patents, by grant year. On an annual basis, the rate patents are being granted for technologies and applications relating to HFO-1234yf is unprecedented in the history of the fluorocarbon industry.

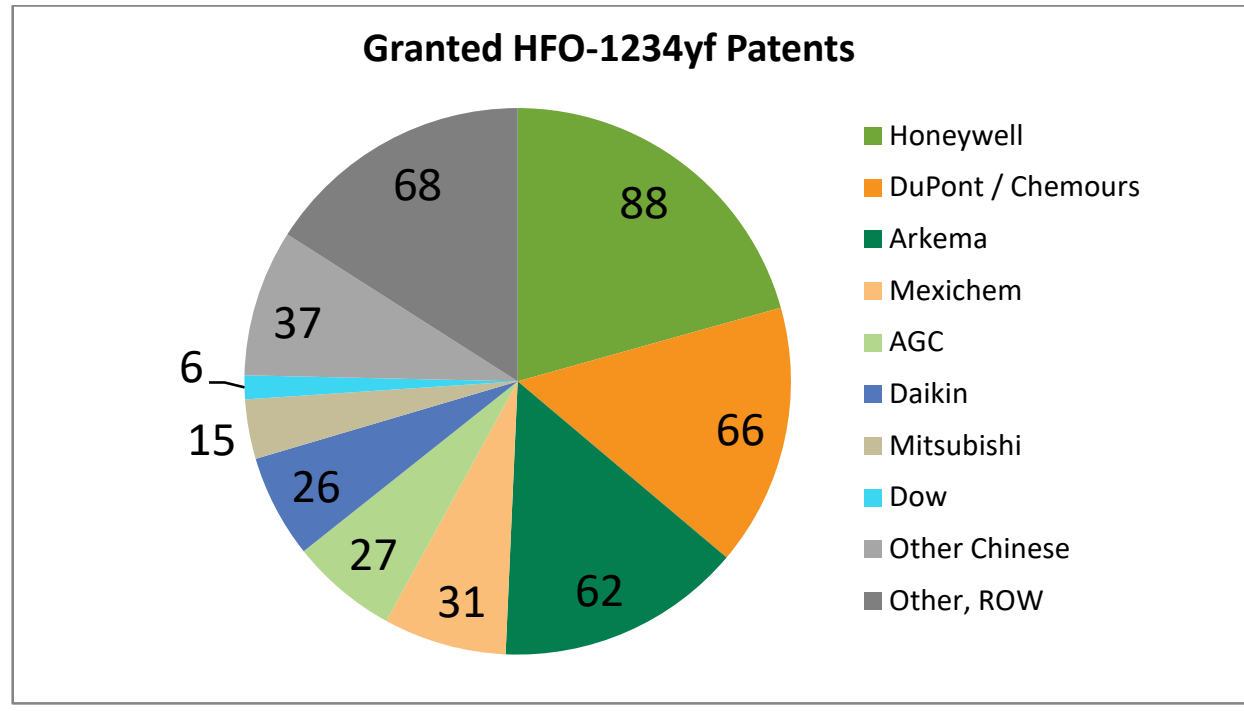

Figure 22. Granted HFO-1234yf patent count, by company. Of the many companies involved in refrigerant research and development, U.S. companies Honeywell and DuPont/Chemours have been granted the highest and second-highest number of patents related to HFO-1234yf, respectively.

To complicate matters further, additional HFO-1234yf patents (known as "continuing applications") have been granted to Honeywell in the time since the original legal challenges began, and these continuing applications would require separate legal challenges if a 
competitor wishes to contest them. Some industry experts expect that this cycle of legal challenges, appeals, and filing of continuing applications will continue until the original application patents expire between 2023 and 2025 (Seidel 2015, Seidel 2017).

\section{Summary}

- Continued demand in the EU automotive sector and growing demand in the U.S. automotive sector ahead of the SNAP Rule 20 going into effect mean HFO-1234yf manufacturing is expected to increase significantly.

- The United States will join China as a principle manufacturer now that the Honeywell plant has been completed and the Chemours plant is under construction.

- Legal challenges to the validity of Honeywell's HFO-1234yf application patents have been launched by competitors, and most of the disputes are now in the appeal phase.

- Some experts expect that litigation involving HFO-1234yf application patents will continue until the hard expiration deadline established by the priority date of the original application patents (2023-2025).

\subsubsection{HFO-1234ze(E)}

\section{Production}

The chemical trans-1,3,3,3-tetrafluoroprop-1-ene, better known as HFO-1234ze(E) and simply referred to as HFO-1234ze in this report from now on, is exclusively manufactured by Honeywell at two locations: Honeywell's Buffalo, New York, research lab, which tripled its capacity in 2011, and at a Baton Rouge, Louisiana, plant, which came online in early 2015 (Honeywell 2015b). The EPA reports that production of HFO-1234ze has been between 0.4 and 4 ktons annually since 2011 (EPA 2016a). Specific capacities at the Honeywell plants have not been disclosed.

\section{Distribution}

The biggest market for HFO-1234ze is currently in Europe, supplied almost entirely by the United States. 0.9 ktons of HFO-1234ze were shipped from the United States to the European Union in 2016 (Eurostat 2017). A small amount of 2016 EU HFO-1234ze imports were reported to come from India (0.03 ktons) and Japan (0.02 ktons) (Eurostat 2017). Presumably, these small quantities are a combination of re-exports of U.S.-produced bulk HFO-1234ze and quantities contained in imported products. U.S.-based Trane, along with Mitsubishi Heavy Industries in Japan and Kirloskar in India, have all announced the adoption of HFO-1234ze in new chiller product lines (Trane 2017; Mitsubishi 2017; Honeywell 2017). HFO-1234ze is registered in the highest tonnage band ( $>1$ ktons annually) under ECHA's REACH program, meaning there would be no limitation on further increases in imports of HFO-1234ze to the European market (Achaichia 2014; ECHA 2012b). 


\section{Regulatory Factors}

As of June 16, 2010, when the EPA issued Notice of Acceptability 25, HFO-1234ze has been an acceptable substitute in refrigeration applications in the United States (EPA 2010). By 2024, HFC-134a will not be permitted in new commercial chillers in the United States, with the exception of some military and spacecraft applications (EPA 2016c). HFOs, including HFO1234ze, are expected to capture a significant share of the U.S. chiller market in the years leading up to the HFC-134a phaseout (BSRIA 2015a).

EU F-gas Regulation 517/2014 mandates automatic leak detection systems to be used in stationary air-conditioning systems charged with more than 500 metric tons $\mathrm{CO}_{2}$ equivalent $\left(\mathrm{MTCO}_{2} \mathrm{e}\right.$ ) of refrigerant (European Parliament 2014). This would apply to large commercial chillers charged with more than $350 \mathrm{~kg}$ of HFC-134a (GWP $=1,300)$. In addition, leak checks must be performed every three months ${ }^{9}$ for systems with more than $500 \mathrm{MTCO}_{2} \mathrm{e}$. Another EU regulation, known as Ecodesign, mandates minimum seasonal space cooling energy efficiency standards for commercial "comfort cooling" chillers, which will go into effect starting in 2018 (European Commission 2016). These two regulations were cited by Carrier Corporation as reasons for introducing HFO-1234ze in its newest fleet of chillers (Gaved 2016). HFO-1234ze has a sufficiently low GWP to reduce the frequency of leak checks for large chiller systems while also having a sufficiently high seasonal cooling energy efficiency to meet the Ecodesign standards.

Extruded polystyrene (XPS) is a frequently used insulation foam for building applications, especially in Europe and North America (IHS 2014b). XPS foam production often uses HFC-134a as a blowing agent (Gluckman Consulting 2015), but EU Regulation 517/2014 calls for XPS foam blowing agents with a GWP above 150 to be phased out by 2020. Because HFC-134a has a GWP above that threshold (1,300), it will no longer be acceptable for use as an XPS blowing agent in Europe starting in 2020.

Similarly, in accordance with EPA SNAP Rule 20, HFC-134a will not be permitted as a foam blowing agent for XPS boardstock in the United States starting in 2021. HFO-1234ze has been listed as acceptable for XPS foam blowing applications in the United States since Sept. 30, 2009, when the EPA issued Notice of Acceptability 24 (EPA 2009).

HFO-1234ze has already gained traction as a substitute for HFC-134a in the European XPS foam market, and this trend is likely to follow in the U.S. XPS market.

\section{Intellectual Property}

The earliest mention of HFO-1234ze in the patent literature is in several patents granted between 1998 and 2002 on the manufacture of HFC-245fa, where HFO-1234ze may be created as a byproduct (Tung 1998; Sakyu et al. 2000; Yates and Gaita 2002; Yamamoto et al. 2002).

\footnotetext{
${ }^{9}$ This frequency drops to every six months if an automatic leak detection system is installed.
} 
However, the first on-purpose production patents for HFO-1234ze were filed by Honeywell in 2003-2004 and granted as early as 2007 (Mukhopadhyay et al. 2007; Merkel et al. 2007; Tung et al. 2009). Honeywell was then granted several application patents involving HFO-1234ze, beginning in 2009 (Singh, Pham, et al. 2009; Singh, Wilson, et al. 2009). Honeywell, Central Glass Company (Japan), and DuPont/Chemours hold the largest portfolios of HFO-1234zerelated patents, as shown in Figure 23.

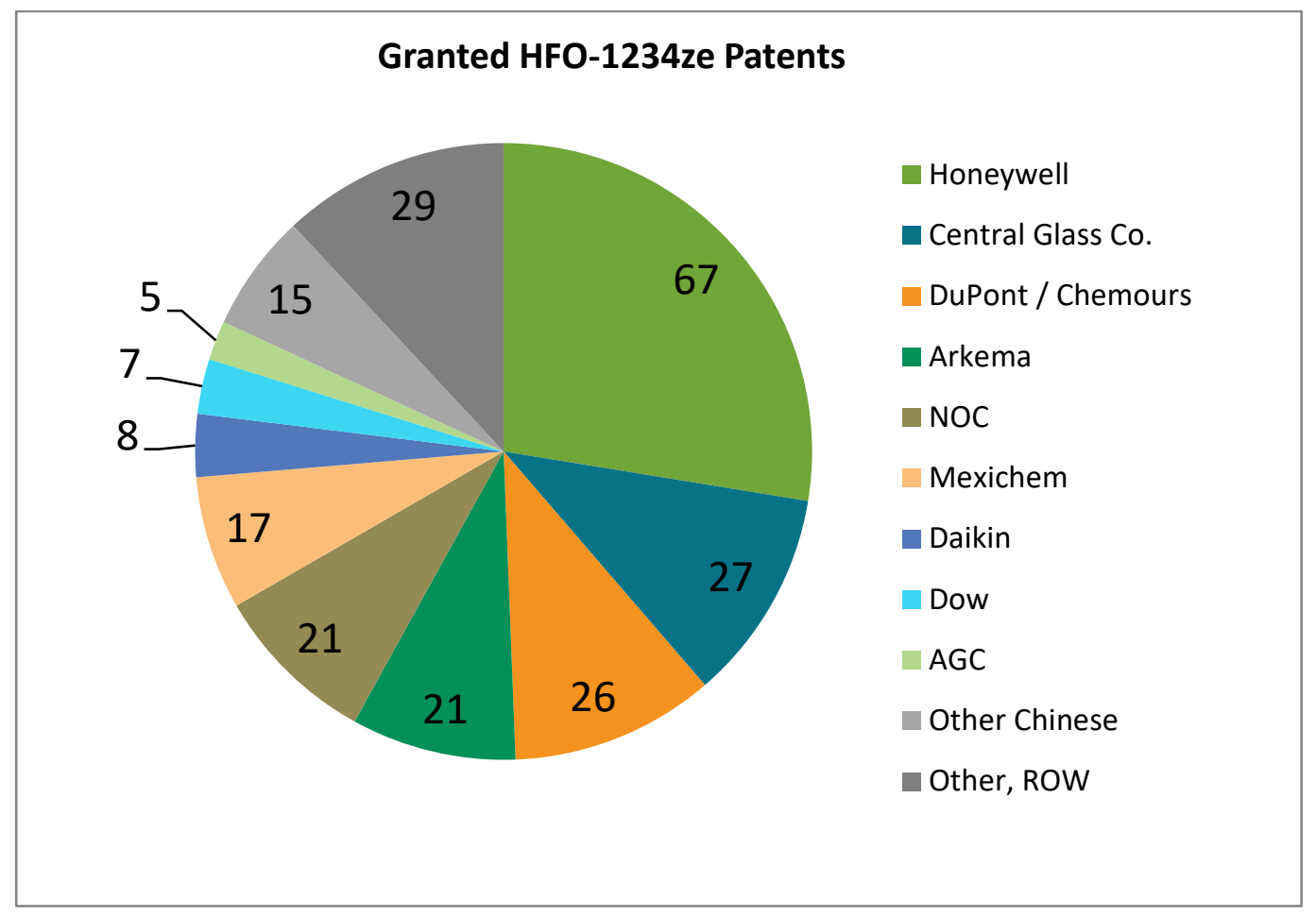

Figure 23. Granted HFO-1234ze patent count, by company. U.S.-based Honeywell holds the highest number of patents related to HFO-1234ze, followed by Japanese company Central Glass Co., U.S.-based Chemours, and the French company Arkema.

\section{Summary}

- U.S. company Honeywell holds the most HFO-1234ze-related patents and is currently the only commercial producer worldwide.

- The biggest market for HFO-1234ze is currently in Europe, where it is used both as a refrigerant and as a foam blowing agent in polystyrene manufacturing.

- HFO-1234ze demand in the United States for stationary cooling (commercial chiller) applications is expected to rise in the lead up to a 2024 phase out of HFC-134a in new equipment. 


\subsubsection{Other HFOs}

\section{Production}

The chemicals trans-1-chloro-3,3,3-trifluoropropene and cis-1,1,1,4,4,4-hexafluoro-2-butene, better known as HFO-1233zd(E) and $\mathrm{HFO}-1336 \mathrm{mzz}(\mathrm{Z})$ and referred to simply as HFO-1233zd and HFO-1336mzz, respectively, in this report from now on, are the two other HFOs with ongoing or planned commercialized manufacture in 2017. HFO-1233zd is targeted both as a replacement for HFCs in foam blowing applications and as a single-component substitute for HCFC-123 in commercial chillers. Central Glass Company (Japan) was the first company to begin manufacturing HFO-1233zd when it started production at its Kawasaki plant in 2012 under a purchase agreement with Honeywell. Central Glass has since formed a new partnership with Arkema to manufacture HFO-1233zd for the Japanese market and opened an additional plant in Ube, Japan in early 2017 (CGC 2017). Capacities for the Central Glass plants have not been disclosed. Honeywell began production of HFO-1233zd at its Baton Rouge facility in 2014 and now produces 4+ ktons annually (EPA 2016a).

$\mathrm{HFO}-1336 \mathrm{mzz}$ is currently marketed as a foam blowing agent and as a component in refrigerant blends like R-514A designed to be replacements for HCFC-123 in commercial chillers. Chemours will become the first company to commercialize the production of HFO-1336mzz when operation at the Chemours/3F Zhonghao plant in Changshu, China begins during the third quarter of 2017 (Chemours 2015; Chemours 2017d). Capacity at this plant is unknown but is likely to be relatively small, assuming modest initial demand for this newly commercialized HFO.

\section{Distribution}

The major markets for these HFOs are currently in Japan and Europe, with U.S. demand also expected to grow in coming years. European imports are between 0.1 and 1 ktons per year for HFO-1233zd (ECHA 2014) and between 0.01 and 0.1 ktons for HFO-1336mzz (ECHA 2012c). Japanese import quantities of HFO-1233zd are unknown but likely to be small or zero assuming production by Central Glass Co. is sufficient to meet domestic demand. HFO-1336mzz imports to regions besides Europe are unknown but likely negligible at this time since commercial production is only just beginning.

Several major refrigeration equipment manufacturing companies are anticipating growth in HFO use for commercial cooling applications and have started to offer HFOs in some of their newest chiller models. In 2014, Trane was the first company to commercialize the use of HFO1233zd in large-scale, low-pressure chillers; these were offered in the European market (Cooling Post 2014). HCFCs have been banned in all emissive uses in Europe since 2015, but Europe was never a significant adopter of HCFC-123 in the first place due to toxicity concerns (Cooling Post 2013). Most HFO chiller adoption in Europe will be for reasons similar to those mentioned in the HFO-1234ze section-namely, meeting the minimum seasonal cooling energy efficiency standards of the Ecodesign program and reducing leak-checking frequency. 
In 2015, Mitsubishi Heavy Industries (Japan) released an HFO-1233zd chiller model for the Japanese market (Mitsubishi 2015). More recently, Trane has expanded its HFO chiller portfolio, and as of 2017 is offering North American HFO chiller options including smaller models that can use the R-514A refrigerant, which is a blend comprised mostly of HFO-1336 $\mathrm{mzz}^{10}$ (Trane 2016). Carrier introduced an HFO-1233zd chiller for the U.S. market at the start of 2017 (Carrier 2017).

By the time Europe phased out HCFC-141b in foam blowing applications in 2004, EU polyurethane foam producers had switched primarily to pentane and water, and to a lesser extent HFC-365mfc, HFC-227ea, and HFC-245fa (IHS 2016c). Pentane and water are not subject to regulatory phaseout, so further adoption of HFO-1233zd in Europe will be limited to producers using the HFCs or blends thereof. In contrast, a larger share of the Japanese polyurethane market chose the HFC blowing agents over hydrocarbon options following the HCFC-141b phaseout, and this explains the pronounced interest in supplying HFO-1233zd to the Japanese market (IHS 2016c). Rigid polyurethane producers in the United States are expected to more closely follow their Japanese counterparts in transitioning to low-GWP HFO blowing agents since a significant fraction of U.S. polyurethane producers had also adopted HFCs rather than hydrocarbons following the phaseout of HCFC-141b. Once these HFCs themselves are phased out in 2020 (see "Regulatory Factors" section below), it is anticipated that HFO-1233zd and/or HFO-1336mzz could see more widespread and significant adoption in the U.S. for rigid polyurethane manufacturing.

\section{Regulatory Factors}

HCFC-123 has a relatively low ozone-depleting potential and GWP (0.02 and 79, respectively), and there is no EPA SNAP rule which specifically identifies HCFC-123 as being unacceptable for use in chillers. However, pursuant to the Montreal Protocol, developed countries may only use HCFCs (including HCFC-123) for servicing existing equipment, and not for any new equipment, starting in 2020. By 2030, servicing or any other use of all HCFCs will be phased out in developed countries. Therefore, demand for alternatives to HCFC-123 in commercial chillers, such as HFO-1233zd and HFO-1336mzz (or blends thereof), is expected to grow in the U.S. by 2020 for new equipment and by 2030 for all equipment.

Within the U.S. market, HFO-1233zd has been an acceptable substitute for HCFC-123 in chillers and as a foam blowing agent since Aug. 10, 2012, when the EPA released Notice of Acceptability 27 (EPA 2012a). HFO-1336mzz has been listed as acceptable for use as a foam blowing agent, with some restrictions, ${ }^{11}$ since the EPA's Notice of Acceptability 30 on July 16, 2015. HFO$1336 \mathrm{mzz}$ has been approved for use in chillers both on its own and as a component in a

\footnotetext{
${ }^{10} \mathrm{R}-514 \mathrm{~A}$ is $74.7 \%$ HFO-1336mzz and $25.3 \% \mathrm{R}-1130$ (E) (Majurin et al. 2017).

${ }^{11} \mathrm{HFO}-1336 \mathrm{mzz}$ was approved with narrowed use limits as a foam blowing agent under EPA SNAP-it may be used for high pressure, two-part polyurethane foam production.
} 
refrigerant blend (R-514A) since the EPA in Notice of Acceptability 31 on May 23, 2016 (EPA 2016b).

EU F-Gas regulations prohibit the use of HFCs with a GWP over 150 in the production of polyurethane foam starting in 2023. This would include HFC-245fa as well as HFC-365mfc and HFC-227ea (and blends thereof).

With the support of the Japan Urethane Foam Association, Japan has set a goal of reducing the GWP of foam blowing agents to below 100 by 2020 (Honeywell 2016). All of the HFCs currently used in polyurethane manufacturing (HFC-245fa, HFC-365mfc, HFC-227ea, and any blends of these) have a GWP above 100, so HFO adoption for foam blowing applications in Japan is expected to be significant by 2020 .

\section{Intellectual Property}

As shown in Figure 24, HFO-1234yf has been referenced in the greatest number of HFO-related patents to date, followed by HFO-1234ze. HFO-1233zd and HFO-1336mzz are in earlier stages of adoption compared to the more mature HFO-1234yf and HFO-1234ze, but references to these HFOs in granted patents has also grown in recent years.

No lawsuits involving patents related to HFO-1233zd or HFO-1336mzz have been identified to date; all HFO-related patent disputes appear to be focused solely on HFO-1234yf. Nevertheless, intellectual property continues to play a role in the adoption of these newest commercialized HFO chemicals due to patents on production methods.

As shown in Figure 25, Honeywell holds nearly half of all granted patents related to HFO-1233zd as of 2016, followed by Central Glass Co. of Japan. These two companies have undertaken the majority of commercialized production of HFO-1233zd globally as of 2017.

As of 2016, Arkema has been granted the highest number of patents referencing HFO-1336mzz, followed closely by Honeywell and DuPont/Chemours, as shown in Figure 26. Despite this ordering of companies in this approximate patent count, Chemours seems to be the most heavily invested in commercializing HFO-1336mzz. This reinforces the caveat that company patent counts are not perfect indicators of investment or capacity; these counts are best used as a qualitative guide to identify the major players in an industry. 


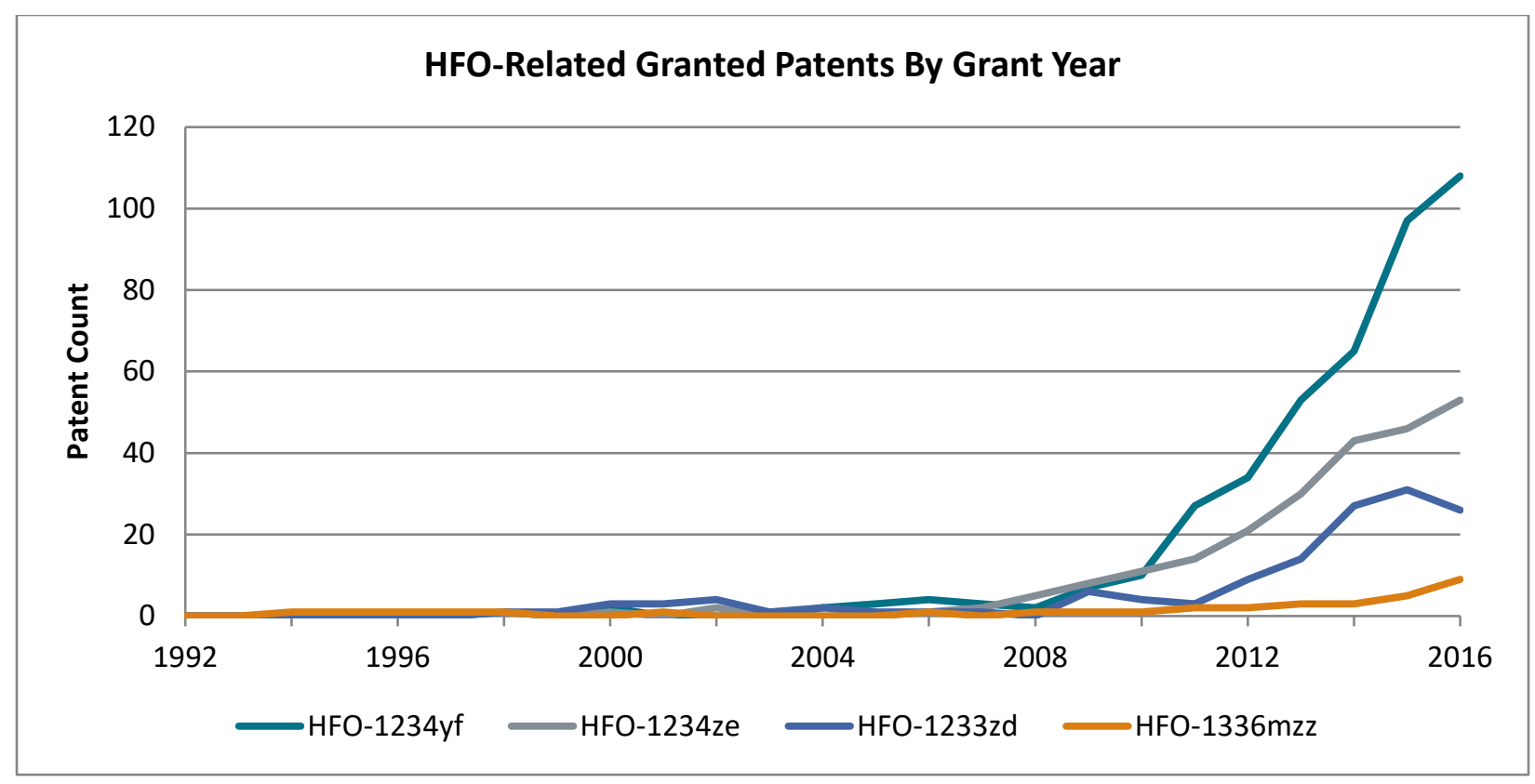

Figure 24. HFO-related granted patents, by grant year, 1992-2016

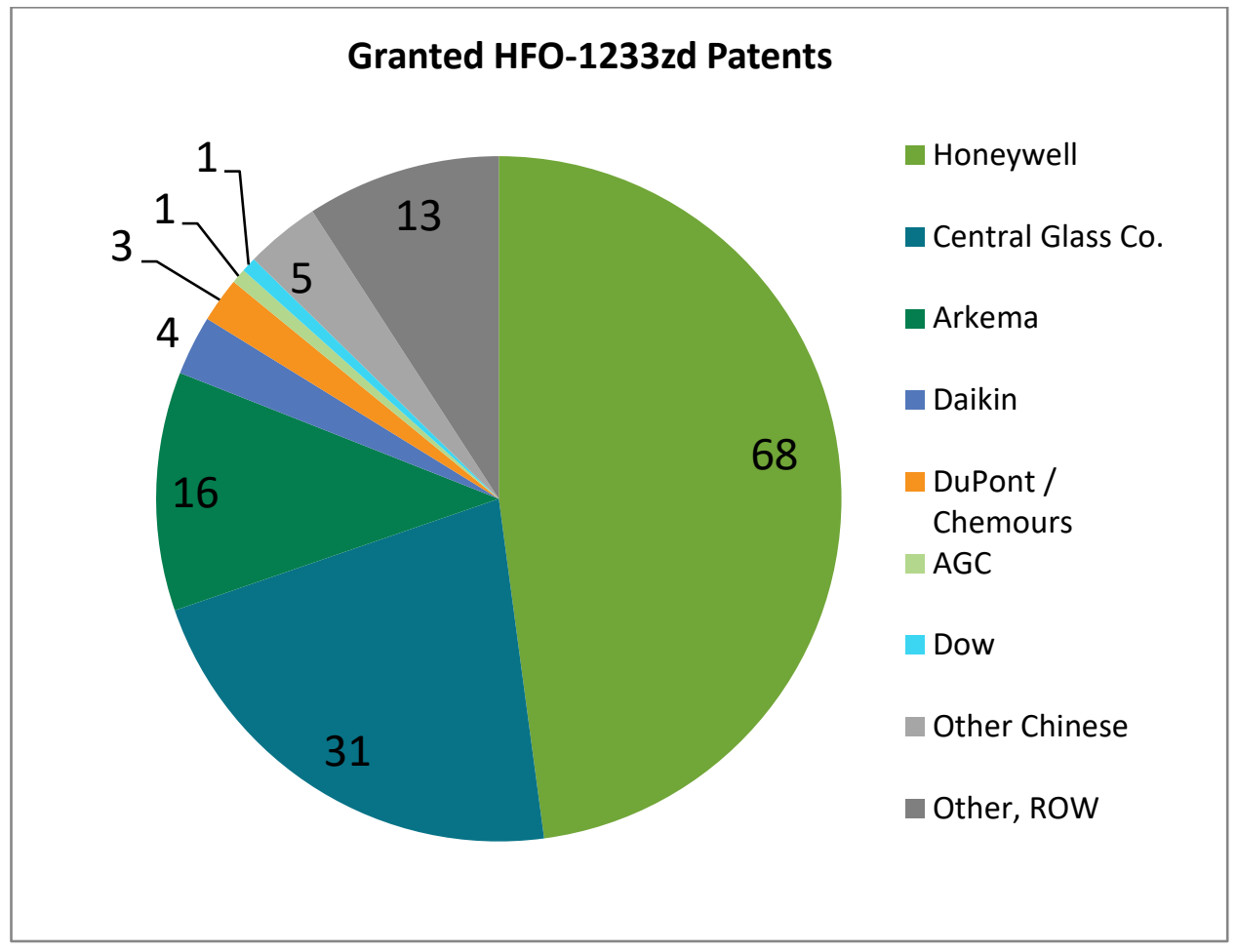

Figure 25. Granted HFO-1233zd patent count, by company, though 2016 


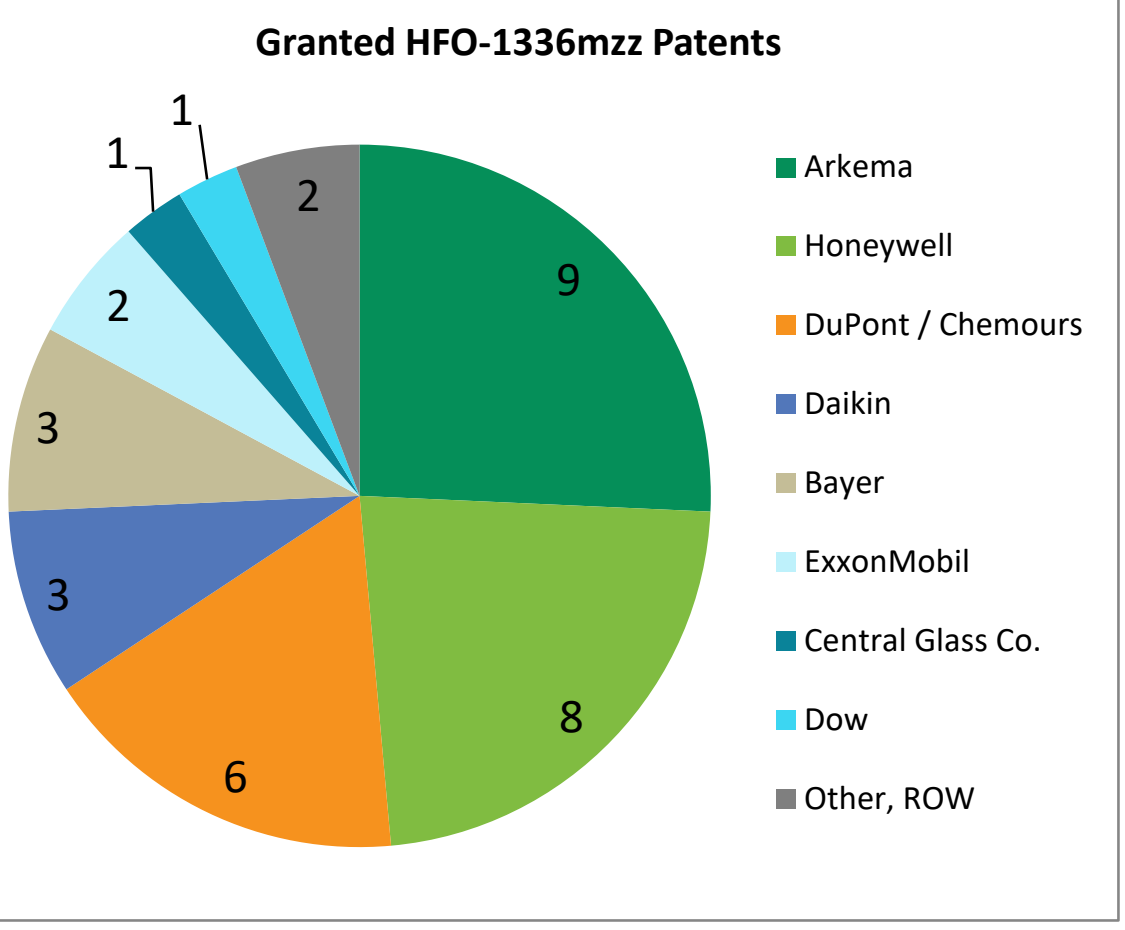

Figure 26. Granted HFO-1336mzz patent count, by company, through 2016

\section{Summary}

- The United States and Japan are the leading producers of HFO-1223zd and HFO$1336 \mathrm{mzz}$, currently supplying the Japanese and European markets for commercial comfort cooling (chillers) and polyurethane foam manufacturing.

- U.S. demand for these HFOs is projected to increase prior to the 2020 ban on HCFC-123 in new chiller equipment.

- Demand for these HFOs as foam blowing agents is expected to increase in Japan by 2020 and, to a lesser extent, in Europe by 2023 due to the respective phaseouts of high-GWP HFCs in the polyurethane manufacturing sector.

\subsection{Limitations}

Existing "alternative" refrigerants have limitations (e.g., toxicity, flammability, efficiency) that have restricted their use until now. Newly formulated and/or developed refrigerants and blends (i.e., HFOs and HFC/HFO blends) generally have drawbacks as well, which are typically around flammability, material compatibility, and cost. Most major refrigerants today have alternatives that are similar in efficiency and capacity, but are inferior in one or more of these other ways. 


\subsubsection{Flammability}

There are different designations for flammability, determined by the test method in ASTM E681 and listed in ASHRAE Standard 34-2016 (ASHRAE 2016). This is the most common, unanswered concern about alternative refrigerants. Some natural refrigerants, such as $\mathrm{CO}_{2}$, are nonflammable, as are some of the most promising HFOs, HFO-1233zd and HFO-1336mzz. However, hydrocarbon refrigerants, ammonia, and most HFC/HFO blends that are considered top candidates for replacing common refrigerants are flammable.

Flammability concerns involve more than whether equipment and buildings catch fire during certain kinds of refrigerant leakage situations. However, this is one of the major concerns and there is active research in understanding this problem (Goetzler et al. 2014; Goetzler et al. 2016; Gandhi et al. 2017). An additional concern is whether the byproducts of combustion are toxic. Fluorocarbon combustion can result in hydrogen fluoride or carbonyl fluoride, which are both extremely toxic (Laboratory News 2014; Ito et al. 2014).

Another concern is about the impact on the supply chain. Dealing with flammable substances as part of the manufacturing process can require higher operating costs through higher insurance and/or bonding costs, additional safety measures, oversight, and compliance with more restrictive regulations, in addition to the engineering and design costs of redesigning components and the added expense of the components themselves. These costs are distributed throughout the entire supply chain and can result in a substantial cost increase (Kujak 2017).

\subsubsection{Cost}

The increase in cost of new refrigerants is often cited as a concern for the industry. Although natural refrigerants (ammonia, $\mathrm{CO}_{2}$, hydrocarbons) are cheap relative to HFCs, next-generation fluorocarbons, HFOs, are currently much more expensive-up to eight times the price of HFCs. In addition, there can be large transition costs associated selecting new refrigerants. These issues have been discussed in many places (Goetzler 2016; Calm 2012; Sherry et al. 2017). Previous refrigerant transitions have shown that upfront costs for new equipment tend to increase, but that life cycle cost increases are often offset by improved product efficiency, production process improvements, and economies of scale.

The cost of HFO refrigerant blends amid the transition to large-scale production is a topic that has not been explored in great depth. Figure 27 shows a hypothetical HFC/HFO blend with an $\mathrm{HFC} / \mathrm{HFO}$ ratio of $75 \% / 25 \%$. This is a representative mix of HFC/HFO for several promising blends: 447A, 447B, 448A, 449A, 452B, and 454B. Costs were estimated assuming the HFC component costs are those of HFC-134a and HFO costs are those of HFO-1234yf because those are common constituents whose costs are well established. Year 1 is assumed to be 2017; where current costs are known and components are commercially available. Current and highvolume HFO costs are approximated from Sherry et al. (2017). This comparison shows that although the cost premium of a blend could be substantial today, $300 \%$, at very high-volume production, the premium is modest, $\sim 25 \%$. This price premium is for the refrigerant only. Refrigerant costs are a small portion of total system costs, typically <1\% (Goetzler et al. 2016; 
Geister 2017), meaning that total system cost increases due to a "drop-in" replacement HFC/HFO blended refrigerant could be $~ 3 \%$ now, but as low as $0.25 \%$ at sufficiently high production volume. Note that this does not account for the costs of any system design or component changes required to use the blended refrigerant.

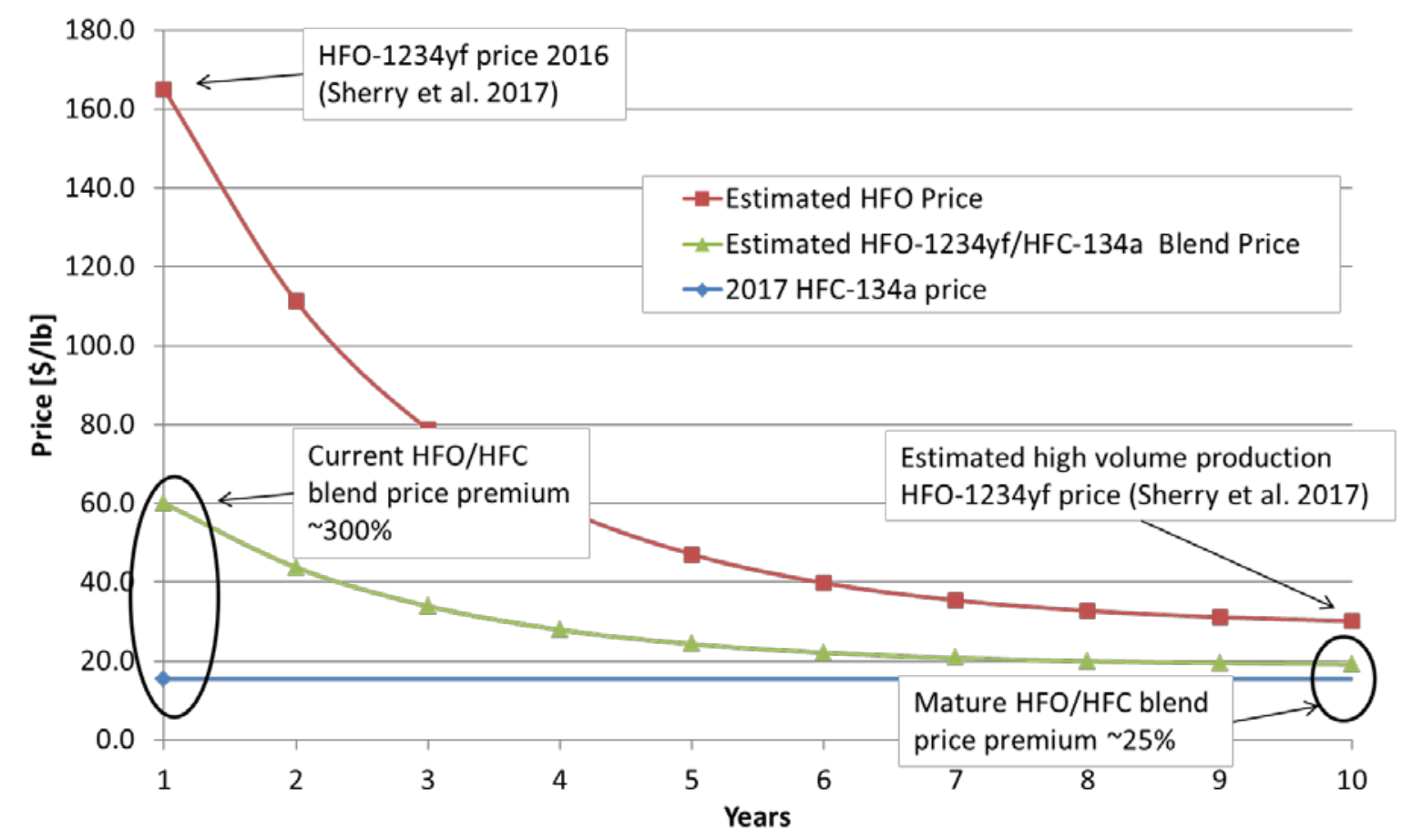

Figure 27. Price estimates for a generic HFC/HFO blended refrigerant with $75 \%$ HFC and $25 \% \mathrm{HFO}$. The current cost premium is high $(-300 \%)$, but not as high as might be expected because most blends are predominantly HFC. Long-term cost premiums are small $(\sim 25 \%)$. Because refrigerant costs are 1\% or less of total system costs for most systems (Goetzler et al 2016; Geister 2017) the high-volume price premium of a system using an HFC/HFO blend will be $\sim 0.25 \%$.

\subsubsection{GWP}

In many applications, HFC-based refrigerants do not meet long-term goals for direct GWP; thus, they are often viewed as interim solutions. This results in hesitation and uncertainty among manufacturers about whether to make a switch to new refrigerants given the potentially high transition costs associated. Many stakeholders prefer a "wait and see" approach.

This dilemma is illustrated in Figure 28, which shows refrigerant solutions for vapor compression systems over a range of applications and direct GWP of the refrigerant. For some applications, such as chillers and MAC, alternative refrigerants currently exist that meet longterm direct GWP goals, such as Europe's GWP threshold of 150. For other systems, such as stationary air conditioning and many refrigeration applications, the long-term options are less clear. Interim options are available that have comparable capacity and efficiency to established refrigerants; however, they have moderate GWPs (150-700) that make their long-term viability questionable. Options that have acceptable, long-term GWPs have other concerns such as 
flammability (hydrocarbons, R-290 and R-600a, HFOs), toxicity ( $\left.\mathrm{NH}_{3}\right)$, or efficiency and equipment cost concerns $\left(\mathrm{CO}_{2}\right)$.

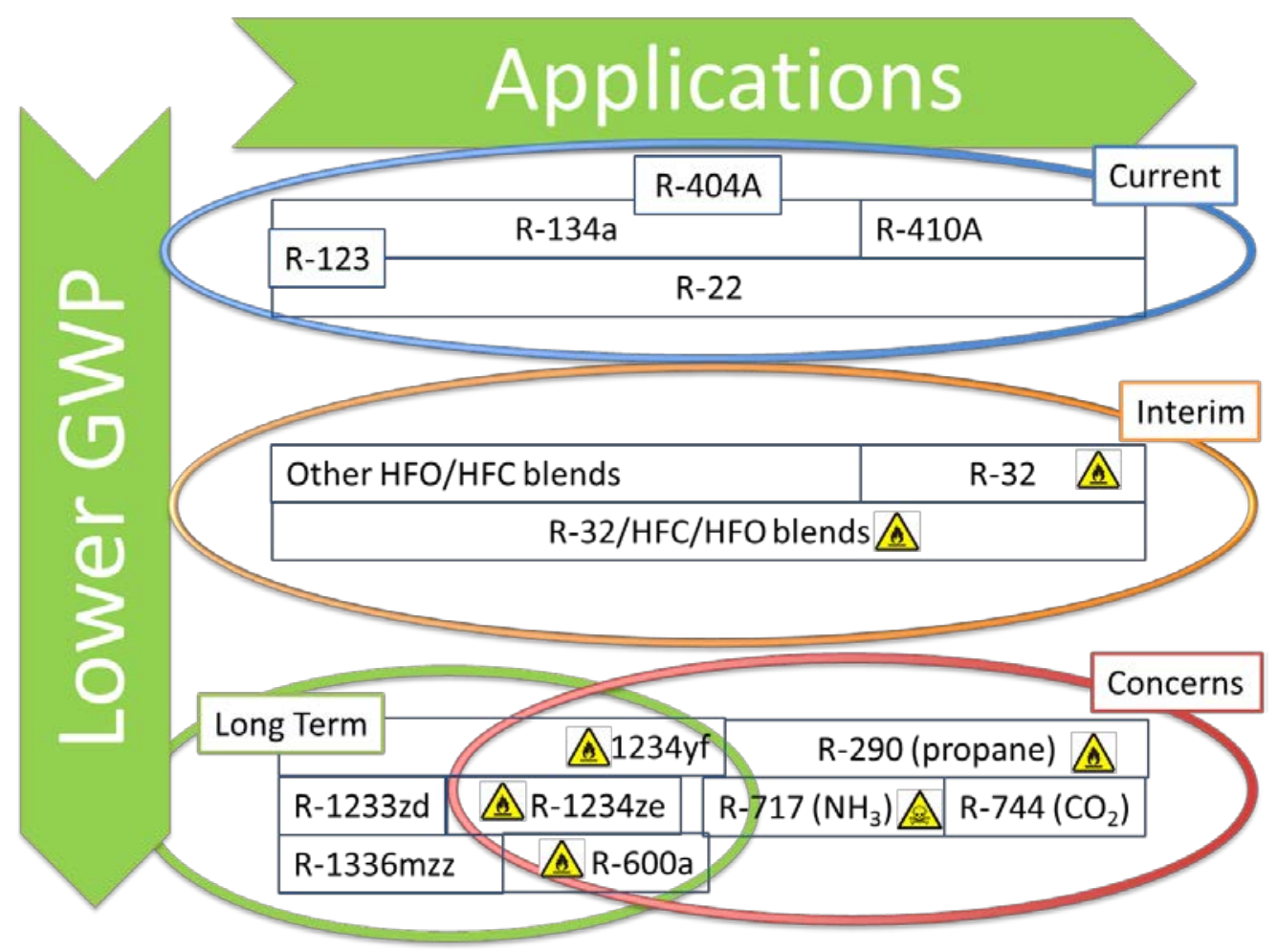

Figure 28. Vapor compression refrigerant applications and direct GWP. Long-term solutions exist for lower operating pressure systems. At higher operating pressures, alternatives are often highly flammable (hydrocarbons), have intermediate GWP (150-700), or have potential efficiency or toxicity constraints $\left(\mathrm{CO}_{2}, \mathrm{NH}_{3}\right)$.

\subsubsection{Regulatory Uncertainty}

The global refrigerant industry has evolved in the context of safety and efficiency regulations; therefore, it is not surprising that stakeholders pay close attention to changes in laws and regulations across multiple markets.

Equipment manufacturers have some hesitation in embracing new refrigerants and technology given the uncertainty in future regulations. The primary uncertainties are associated with flammability and end goals for direct GWP of refrigerants. Currently available solutions meet established criteria in some applications but not others, as shown in Figure 28. Some manufacturers are unsure whether it is worth investing in products and technologies that could prove to be transitional, rather than waiting for longer-term technical solutions or additional clarity on regulatory requirements, not just in the United States but globally. This uncertainty has been highlighted in the United States by a recent court decision striking down EPA regulations requiring the phaseout of R-134a (Chemical \& Engineering News 2017). 


\subsection{Market Trends}

Globally, there is substantial momentum for transition away from HCFCs and HFCs to alternative refrigerants. This is manifest in the Kigali amendment to the Montreal Protocol, the European F-gas Regulations, and the EPA's SNAP Program. Manufacturers have already transitioned substantially away from high-GWP refrigerants for many applications, such as aerosols, whereas the transition is underway for other applications such as MAC, foam blowing agents, and small, self-contained refrigeration systems. Production of alternative refrigerants is growing rapidly on a global scale to match this increasing demand. However, regulation is still an important consideration for companies when selecting new refrigerants or designing new equipment.

Production capacity is difficult to quantify for the newly developed HFO refrigerants. Production plant locations have been quantified in Table 5, which is an updated and expanded version of a similar table in Seidel et al. (2015). Production of these chemicals is global and is becoming concentrated in China, even though many of the producers are U.S.-based companies. All of these facilities have opened within the past several years, reflecting current trends in production location decision-making.

The global nature of HFO production is important because much of the demand for these products is in developed countries (because developing countries are exempt or have delayed implementations of regulations the require the use of these refrigerants). This highlights how the United States does not have a "lock" on production, even for refrigerants that are shipped to other developed countries.

Table 5. HFO Production Locations (adapted from Seidel et al. 2015)

\begin{tabular}{|c|c|c|c|}
\hline Chemical & Producer & Location & Startup Year and Capacity \\
\hline \multirow[t]{8}{*}{ HFO-1234yf } & Arkema Changshu & China & 2016,7 kton $/ \mathrm{yr}^{\mathrm{c}}$ \\
\hline & Chemours & Japan & In production \\
\hline & 3F Zhonghao (Chemours) & China & Up to $6 \mathrm{kton} / \mathrm{yr}^{\mathrm{a}}$ \\
\hline & AGC (Honeywell) & Japan & 2015 , up to $1,000 \mathrm{t} / \mathrm{yr}^{\mathrm{b}}$ \\
\hline & Honeywell & U.S. & $2017,10-15$ kton/yrb \\
\hline & Juhua Corp. (Honeywell) & China & 2016 \\
\hline & Navin Fluorine Int'I Ltd. (Honeywell) & India & 2016 (small-scale) \\
\hline & Chemours & U.S. & 2018 \\
\hline HFO-1234ze & Honeywell & U.S. & 2015 \\
\hline \multirow[t]{2}{*}{ HFO-1233zd } & Central Glass Co. & Japan & 2012 \\
\hline & Honeywell & U.S. & $2014,4+$ ktons/yrd \\
\hline \multirow[t]{2}{*}{ HFO-1336mzz } & Chemours & China & 2016 \\
\hline & Chemours & U.S. & 2017 \\
\hline
\end{tabular}


This point is solidified by looking at HFC trade data from 2000 and 2015, shown in Figure 29. These plots show trade data from 2000 and 2015 (ITC 2016). The clear trend is for reduced exports from the United States and EU and increasing exports from Asia, mostly China. This is a familiar trend that supports the idea that the United States is losing market share in export markets despite having large U.S. companies as major market participants; they think globally about supply chains and logistics and think less about national borders (Seidel 2017).

HFO-1234yf is the dominant HFO refrigerant and has the most quantitative production/consumption information available. It is estimated that by 2017,40 million vehicles will use it (Chemours 2016a), correlating to $15-30$ ktons per year of consumption. This is the most widely produced HFO, with production or planned production in at least eight locations globally, as shown in Table 5. It is estimated that more than 100 million vehicles with HFO1234 yf air-conditioning systems will be sold from 2018 to 2020 (Chemours 2016a). Personal vehicles average $700 \mathrm{~g}$ of R-134a (interpreted from Hella 2011); because the volumetric capacity of R-1234yf is $7 \%$ less than R-134a (Leck 2009), the charge per vehicle with R-1234yf should be $\sim 750 \mathrm{~g}$. This equates to $\sim 24 \mathrm{ktons} /$ year demand, on average, for vehicle applications alone in the near future. Therefore, production is substantial for this industry and is balanced with near-term demand. 

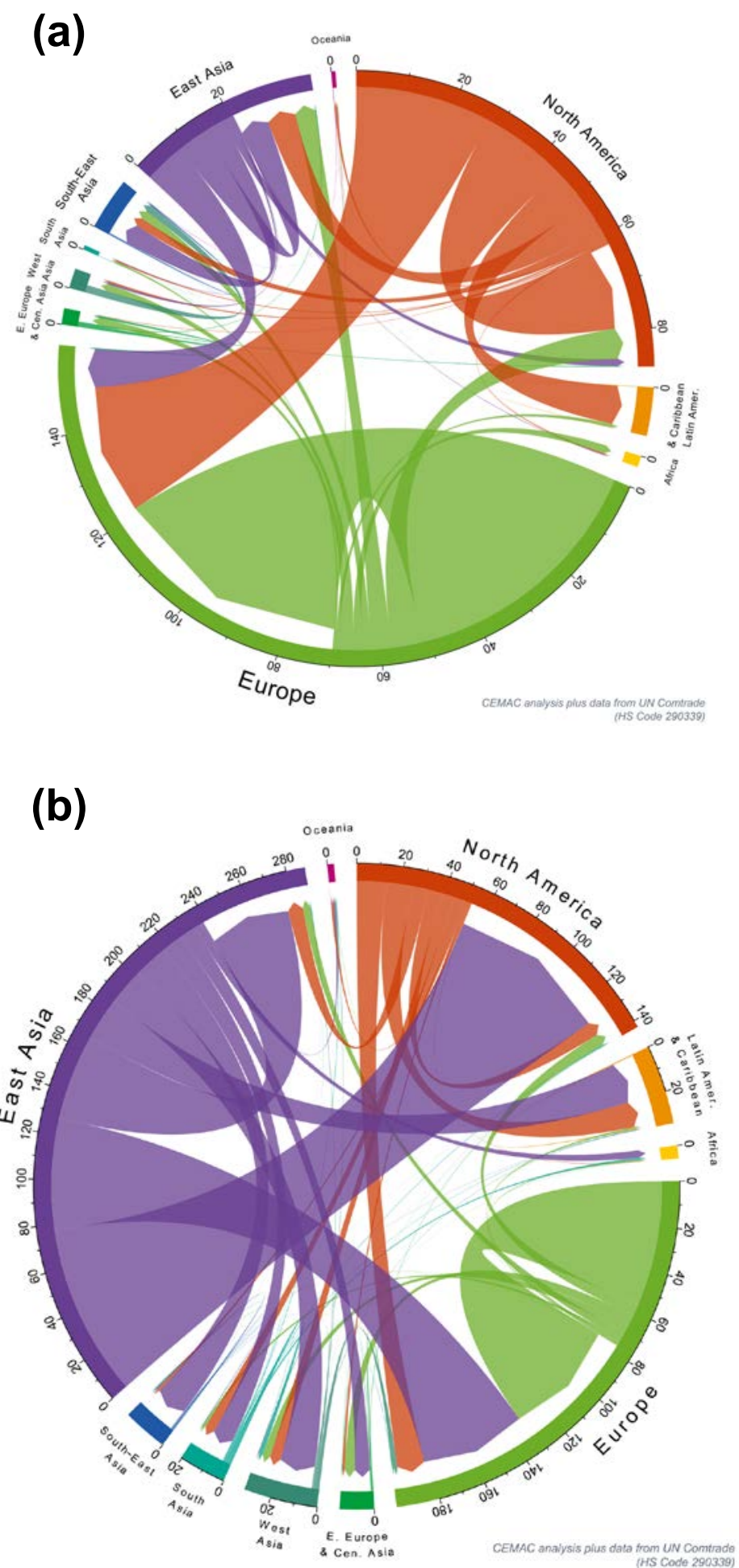

Figure 29. International HFC trade flows in 2000 (a) and 2015 (b), in ktons. There is a clear trend of reduced exports from the United States and EU and increasing exports from Asia, mostly China. 


\section{Conclusions and Insights}

NREL, in partnership with Oak Ridge National Laboratory and under the CEMAC umbrella, assessed the current state of existing and low-GWP refrigerants for major end-use applications, including HVAC and those outside of the HVAC industry. The project incorporated a market overview and supply chain assessment to determine the production, distribution, consumption, costs, and potential operating efficiency impacts of new and alternative refrigerants entering the market. Market trends and ongoing research are also documented. This work supplements other U.S. Department of Energy efforts to support research activities on refrigerants and their applications, including a refrigerant $R \& D$ roadmap and outlook into global air-conditioning markets (Goetzler et al. 2014; Goetzler et al. 2016).

The global refrigerants market is large and is projected to grow rapidly as developing countries in warmer areas of the globe grow, become more affluent, and consume more air conditioning, refrigeration, foam, and aerosol products and services. Innovation in the global refrigerants market is often led by major U.S. companies; however, the markets for their products are global. Understanding this global market landscape is critical to maintaining U.S. leadership in innovation and manufacturing in this strategically important industry.

\section{Key Findings From This Report:}

- Refrigerant markets are global and growing rapidly

- 2010-2050: 4.5x increase in air conditioning for non-OECD countries, and 1.3x increase for OECD countries (IEA 2013).

o Regional, national, and international commitments will create large market opportunities for innovative refrigerants and products that use them.

o U.S.-based companies are currently leaders in innovation and production of advanced refrigerants.

o China is aggressively expanding production of refrigerants for domestic use as well as export.

- Refrigerants are used in large quantities for more than just cooling.

- Foam production, aerosols, fire suppression, and chemical production are important end uses of these materials.

- Vapor compression systems primarily use fluorocarbon refrigerants.

o Vapor compression is the most challenging but also the most impactful area for refrigerant innovation.

- Alternative refrigerants to fluorocarbons are well established.

o They account for more than $50 \%$ of the total market as it exists today. 
o Common natural/hydrocarbon refrigerants: ammonia, pentane, carbon dioxide, propane, and butane.

- Substantially lower GWP than most fluorocarbons.

o Often provide comparable or superior performance to fluorocarbons.

- Advanced fluorocarbon refrigerants are commercially available that can reduce unintended environmental impacts while maintaining or potentially improving performance.

- One size doesn't fit all-some common applications are more difficult to solve than others, therefore there is a need for ongoing R\&D.

o U.S. companies are currently at the forefront of this innovation.

- Refrigerant manufacturing locations are primarily guided by:

o Proximity to fluorspar, hydrofluoric acid, or other chemical feedstock

- Existing refrigerant manufacturing capital and experienced labor force

- Availability of cheap energy and labor

o Financial incentives from local governments or development authorities.

- The United States is positioned to be a major production center for advanced refrigerants, including HFOs and their blends.

o Market share of production likely to be larger if there is a substantial U.S. market for advanced refrigerants

- Fluorspar will remain in demand as manufacturers transition to producing HFOs, and U.S. fluorspar supply is stable. Demand is now supplied mainly by Mexico, whereas historically, China had been the leading importer.

o U.S. companies, such as Honeywell and Chemours, own much of the intellectual property associated with the production and usage of HFOs.

- Antidumping lawsuits regarding Chinese imports have played a major role in shaping this industry. Decisions on HFC imports have generally been in favor of U.S. companies, setting an important precedent for any future HFO-related trade disputes.

o Recently constructed HFO capacity in Louisiana serves as an example of the effect that financial incentives from development authorities can have on manufacturers' plant location decisions. 


\section{References}

Abdelaziz, O., S. Shrestha, B. Shen, A. Elatar, R. Linkous, W. Goetzler, M. Guernsey, and Y. Bargach. 2016. "Alternative Refrigerant Evaluation for High-Ambient-Temperature Environments: R-22 and R-410A Alternatives for Rooftop Air Conditioners." Oak Ridge, TN: ORNL/TM-2016/513.

https://energy.gov/sites/prod/files/2016/09/f33/ORNL\%20High\%20Ambient\%20RTU\%20Testin g\%20Report.pdf.

Achaichia, N. 2014. "Low GWP Chillers Development Update." Presentation at Chillventa 2014. Nuremberg, Germany. October 14-16, 2014. https://www.honeywellrefrigerants.com/europe/wp-content/uploads/2014/11/Honeywell-chillers-update-201410.pdf.

ACHR NEWS. 2016. "Honeywell Partners with Juhua to Produce 1234yf in China." May 2, 2016. http://www.achrnews.com/articles/132395-honeywell-partners-with-juhua-to-produce--yf-inchina.

Akzo Nobel. 2008. “Akzo Nobel Completes ICI Acquisition.” January 2, 2008. https://www.akzonobel.com/for-media/media-releases-and-features/akzo-nobel-completesici-acquisition.

Allgood, C. 2017. "The Future of Refrigerants." Presentation at 2017 HVAC Excellence. Orlando, FL. https://www.chemours.com/Refrigerants/en US/assets/downloads/the-future-ofrefrigerants-hvac-excellance-2017.pdf.

American Hydrofluorocarbon (HFC) Coalition. 2016. "The American HFC Coalition Appeals the International Trade Commission Decision Regarding Chinese Imports of Dumped HFC Components." http://www.prnewswire.com/news-releases/the-american-hfc-coalitionappeals-the-international-trade-commission-decision-regarding-chinese-imports-of-dumpedhfc-components-300368053.html.

Andersen, S. O., K. Madhava Sarma, and K. N. Taddonio. 2012. Technology transfer for the ozone layer: Lessons for climate change. Routledge, 2012. pp.151

ANSI/ASHRAE Standard 34-2016. "Designation and Safety Classification of Refrigerants." 2016.

Arkema. 2014. "Proposed shutdown of fluorogas production in Zaramillo, Spain." http://emea.forane.com/en/forane-foams-solvents-and-aerosols/our-products/newsdetails/Proposed-shutdown-of-fluorogas-production-in-Zaramillo-Spain/?back=true.

Arkema. 2017. "Arkema Inc. history (before 1950)." http://www.arkemaamericas.com/en/arkema-americas/arkema-inc-history/before-1950/. 
ASHRAE. 2016. "Designation and Safety Classification of Refrigerants." ANSI/ASHRAE Standard 34-2016. https://www.ashrae.org/news/2017/2016-versions-of-ashrae-refrigerant-standardspublished.

Bell, S. L. 1978. “Manufacture of Halogenated Compounds.” U.S. Patent 4,129,603, filed February 7, 1978, and issued December 12, 1978.

BGS. 2011. "Fluorspar." British Geological Survey. http://www.bgs.ac.uk/mineralsUK/statistics/mineralProfiles.html.

Bivens, D. B., and H. A. Connon. 1989. "Halocarbon blends for refrigerant use." U.S. Patent 4,810,403 filed February 5, 1988, and issued March 7, 1989.

Bivens, D. B., M. B. Shiflett, and A. Yokozeki. 1994. "Near-azeotropic blends for use as refrigerants." U.S. Patent 5,277,834 filed December 22, 1992, and issued January 11, 1994.

Building Services Research and Information Association (BSRIA). 2015a. "Global Refrigerant Policies and Trends 2015: Outlook to 2035." Report 58445/1.

Building Services Research and Information Association (BSRIA). 2015b. "Global Overview Analysis Refrigerants." Report 58312/1.

Building Green. 2010. "Avoiding the Global Warming Impact of Insulation." https://www.buildinggreen.com/news-article/avoiding-global-warming-impact-insulation.

Business Standard. 2013. "Arkema to invest Euro 200 million in two plants for 1234yf refrigerant gas." http://www.business-standard.com/content/b2b-chemicals/arkema-to-investeuro-200-million-in-two-plants-for-1234yf-refrigerant-gas-113091000163 1.html.

Business Wire. 2016. "High Demand From Emerging Economies to Boost the Global Polyurethane Foam Market Through 2020." http://www.businesswire.com/news/home/20161214005038/en/High-Demand-EmergingEconomies-Boost-Global-Polyurethane.

Calm, J. 2012. "Refrigerant Transitions ... Again." Moving Towards Sustainability, proceedings of the ASHRAE/NIST Conference. Gaithersburg, MD. October 29-30, 2012. http://www.techstreet.com/standards/refrigerant-transitions-again?product id=1845779.

CARB. 1997. "Initial Statement of Reasons for Proposed Rulemaking-Volume II: Technical Support Document." California Air Resources Board. https://www.arb.ca.gov/regact/conspro/midterm/tsd.pdf. 
Carrier. 2017. "Carrier Previews AquaEdge 19DV Centrifugal Chiller with Environmentally Sustainable Refrigerant." Carrier Corporation. Las Vegas, NV.

http://www.carrier.com/carrier/en/us/news/news-

article/carrier previews aquaedge $19 \mathrm{dv}$ centrifugal chiller with environmentally sustainabl e refrigerant.aspx.

CCM. 2012. "China expected to be largest production base of HFO-1234yf worldwide." https://www.prlog.org/12050134-china-expected-to-be-largest-production-base-of-hfo-1234yfworldwide.html.

CCM. 2016a. "Chemours to double HFO-1234yf production capacity in China." CCM Data \& Business Intelligence. http://www.cnchemicals.com/Press/88399-

CCM:\%20Chemours\%20to\%20double\%20HFO 1234yf\%20production\%20capacity\%20in\%20Chi na.html.

CCM. 2016b. "The Chinese government keeps eliminating the HCFC's production." http://eshare.cnchemicals.com/publishing/home/2016/01/20/2042/the-chinese-governmentkeeps-eliminating-the-hcfc\%E2\%80\%99s-production.html.

CGC. 2017. "Notice about Collaboration on HFO-1233zd(E) with Arkema." Central Glass Com., Ltd. http://v4.eir-

parts.net/v4Contents/View.aspx?template=announcement $\&$ sid=37030\&code=4044.

Chemical \& Engineering News. 2017. "Court strikes down U.S. restrictions on HFCs." ISSN 00092347. http://cen.acs.org/articles/95/web/2017/08/Court-strikes-down-US-restrictions-onHFCs.html.

Chemours. 2015. "Chemours Breaks Ground for World's First Full-Scale Production of HFO1336mzz." Wilmington, DE. https://investors.chemours.com/investor-relations/investornews/press-release-details/2015/Chemours-Breaks-Ground-for-Worlds-First-Full-ScaleProduction-of-HFO-1336mzz/default.aspx.

Chemours press release. 2016a. "Chemours to Invest in Expanded Capacity for High Growth Opteon Products." May 2, 2016. http://www.prnewswire.com/news-releases/chemours-toinvest-in-expanded-capacity-for-high-growth-opteon-products-300261094.html.

Chemours press release. 2016b. "Chemours Announces Major Investments in New U.S. HFO1234yf Plant." https://www.chemours.com/Refrigerants/en US/assets/downloads/20160502HFO-1234yf-plant-triple-opteon-product-supply.pdf.

Chemours. 2017a. "Opteon XP40 (R-449A) refrigerant." https://www.chemours.com/Refrigerants/en US/products/Opteon/Stationary Refrigeration/p roducts/Opteon XP40.html. 
Chemours. 2017b. "Opteon XL41 (R-454B) Refrigerant."

https://www.chemours.com/Opteon Stationary/en GB/products/opteon-xl41.html.

Chemours. 2017c. "The Exponential Growth of HFO-1234yf in Automotive Air Conditioning." The Chemours Company.

https://www.chemours.com/Refrigerants/en_US/assets/downloads/opteon-yf-automotivebrochure.pdf.

Chemours. 2017d. "Big Impact, Small Footprint." Foam Expo North America. May 8, 2017. http://www.foam-expo.com/press-room-articles/2017/05/08/big-impact,-small-footprint/.

ChinalOL. 2017. Beijing Zhixindao Sci-Tech Corp., Ltd. Beijing, China. http://data.chinaiol.com/ECData.

Clodic, et al. 2006. "Global inventories of the worldwide fleets of refrigerating and airconditioning equipment in order to determine refrigerant emissions. The 1990 to 2006 updating." Centre Energetique Et Procedes.

CNCIC Consulting. 2015. "The Alternative Process is Irreversible, But FCs Market Remains Growth." http://en.chemconsulting.com.cn/cnt 152.html.

Cooling Post. 2013. "Finally, a replacement for R123?" Cooling Post (London). http://www.coolingpost.com/world-news/finally-a-replacement-for-r123/.

Cooling Post. 2014. "Trane introduces five new chillers." Cooling Post (London). http://www.coolingpost.com/products/trane-introduces-five-new-chillers/.

Cooling Post. 2017. "Dunham-Bush chiller to use R134a replacement." Cooling Post (London). http://www.coolingpost.com/world-news/dunham-bush-chiller-to-use-r134a-replacement/.

European Parliament Council Directive 2006/40/EC. 2006. "Relating to emissions from airconditioning systems in motor vehicles and amending Council Directive 70/156/EEC." http://data.europa.eu/eli/dir/2006/40/oj.

Dahlke, T., O. Ruffiner, and R. Cant. 2016. "Production of HF from $\mathrm{H}_{2} \mathrm{SiF}_{6}$." Procedia Engineering 138 (2016): 231-239.

Desjarlais, A. 2017. Oak Ridge National Laboratory. Personal communication. June 2017.

E\&E News. 2017. "Staying cool makes Earth warmer. There's help for that." July 7, 2017.

ECHA. 2010. "Polyhaloalkene." European Chemicals Agency. Registration, Evaluation, Authorisation and Restriction of Chemicals (REACH) Registration Database. First published March 24, 2010. Last modified September 1, 2017. https://echa.europa.eu/registrationdossier/-/registered-dossier/16012. 
ECHA. 2012a. “1,1,1,3,3-pentafluorobutane." European Chemicals Agency. Registration, Evaluation, Authorisation and Restriction of Chemicals (REACH) Registration Database. First published April 27, 2012. Last modified August 14, 2017. https://echa.europa.eu/registrationdossier/-/registered-dossier/3527.

ECHA. 2012b. “(2Z)-1,1,1,4,4,4-hexafluorobut-2-ene.” European Chemicals Agency. Registration, Evaluation, Authorisation and Restriction of Chemicals (REACH) Registration Database. First published July 14, 2012. Last modified April 26, 2017. https://echa.europa.eu/registration-dossier/-/registered-dossier/10030.

ECHA. 2012c. "HFO-1234ze." European Chemicals Agency. Registration, Evaluation, Authorisation and Restriction of Chemicals (REACH) Registration Database. First published April 27, 2012. Last modified April 18, 2017. https://echa.europa.eu/registration-dossier//registered-dossier/15736.

ECHA. 2014. “(1E)-1-chloro-3,3,3-trifluoroprop-1-ene.” European Chemicals Agency. Registration, Evaluation, Authorisation and Restriction of Chemicals (REACH) Registration Database. First published September 15, 2014. Last modified July 13, 2017. https://echa.europa.eu/registration-dossier/-/registered-dossier/10762.

EEA. 2015a. “Ozone-depleting substances 2015.” EEA Report No 19/2016. https://www.eea.europa.eu/publications/ozone-depleting-substances-2015.

EEA. 2015b. “Fluorinated greenhouse gases 2015." EEA Report No 33/2016. https://www.eea.europa.eu/publications/fluorinated-greenhouse-gases.

EJARN. 2015a. January 6, 2015. "Japanese company to produce 1233zd." https://www.ejarn.com/news.aspx?ID=32859.

EJARN. 2015b. “Afinox picks 1233zd(E) after successful tests." June 17, 2015.

EJARN. 2015c. November 17, 2015. “Chemours to build HFO-1336mzz plant." http://ejarn.com/news.aspx?ID=37144.

EJARN. 2015d. “Chemours to build HFO-1336mzz plant.” November 20, 2015.

EJARN. 2016. "Honeywell Solstice 1233zd \& 1234ze Gaining Attention in Chiller Industry." July 24, 2016. https://www.ejarn.com/news.aspx?ID=40725.

EPA. N.D. "Significant New Alternatives Policy (SNAP) Program." Environmental Protection Agency. https://www.epa.gov/snap.

EPA. 2009. "Protection of Stratospheric Ozone: Notice 24 for Significant New Alternatives Policy Program." Environmental Protection Agency. September 30, 2009. 74 FR 50129. https://www.gpo.gov/fdsys/pkg/FR-2009-09-30/pdf/E9-23470.pdf. 
EPA. 2010. "Protection of Stratospheric Ozone: Notice 25 for Significant New Alternatives Policy Program." Environmental Protection Agency. June 16, 2010. 75 FR 34017. https://www.gpo.gov/fdsys/pkg/FR-2010-06-16/pdf/2010-14510.pdf.

EPA. 2012a. "Protection of Stratospheric Ozone: Determination 27 for Significant New Alternatives Policy Program." Environmental Protection Agency. August 10, 2012. 77 FR 47768. https://www.gpo.gov/fdsys/pkg/FR-2012-08-10/pdf/2012-19688.pdf.

EPA. 2012b. "Direct Emissions from Fluorinated Chemicals (Including HCFC-22) Production." GHGRP Industrial Profiles. https://www.epa.gov/sites/production/files/2016-

11/documents/fluorinated chemicals sector 2012 112516.pdf.

EPA. 2014. "Protection of Stratospheric Ozone: Adjustments to the Allowance System for Controlling HCFC Production, Import and Export, 2015-2019". Environmental Protection Agency. October 28, 2014. 79 FR 64253. https://www.gpo.gov/fdsys/pkg/FR-2014-1028/pdf/2014-25374.pdf.

EPA. 2015a. Protection of Stratospheric Ozone: Change of Listing Status for Certain Substitutes Under the Significant New Alternatives Policy Program. Federal Register, 80(138), 42870. https://www.gpo.gov/fdsys/pkg/FR-2015-07-20/pdf/2015-17066.pdf.

EPA. 2015b. "Protection of Stratospheric Ozone: Determination 30 for Significant New Alternatives Policy Program." Environmental Protection Agency. July 16, 2015. 80 FR 42053. https://www.gpo.gov/fdsys/pkg/FR-2015-07-16/pdf/2015-17469.pdf.

EPA. 2016a. "2016 Chemical Data Reporting Results.” https://www.epa.gov/chemical-datareporting/2016-chemical-data-reporting-results.

EPA. 2016b. "Protection of Stratospheric Ozone: Determination 31 for Significant New Alternatives Policy Program." Environmental Protection Agency. May 23, 2016. 81 FR 32241. https://www.gpo.gov/fdsys/pkg/FR-2016-05-23/pdf/2016-12117.pdf.

EPA. 2016c. "Protection of Stratospheric Ozone: New Listings of Substitutes; Changes of Listing Status; and Reinterpretation of Unacceptability for Closed Cell Foam Products Under the Significant New Alternatives Policy Program; and Revision of Clean Air Act Section 608 Venting Prohibition for Propane." Environmental Protection Agency. December 1, 2016. 81 FR 86778. https://www.gpo.gov/fdsys/pkg/FR-2016-12-01/pdf/2016-25167.pdf.

EPA. 2017. "SNAP Substitutes by Sector." https://www.epa.gov/snap/snap-substitutes-sector. 
European Commission. 2016. “Commission Regulation (EU) 2016/2281 of 30 November 2016 implementing Directive 2009/125/EC of the European Parliament and of the Council establishing a framework for the setting of ecodesign requirements for energy-related products, with regard to ecodesign requirements for air heating products, cooling products, high temperature process chillers and fan coil units."

http://data.europa.eu/eli/reg/2016/2281/oj.

European Parliament. 2014. "Regulation (EU) No 517/2014 of the European Parliament and of the Council of 16 April 2014 on fluorinated greenhouse gases and repealing Regulation (EC) No 842/2006." European Parliament, Council of the European Union. April 16, 2014. http://data.europa.eu/eli/reg/2014/517/oj.

Eurostat. 2017. “International Trade in Goods.” http://ec.europa.eu/eurostat/data/database.

Fricke, B. and V. Sharma. 2016. "High Efficiency, Low Emission Refrigeration System." Oak Ridge, TN: ORNL/TM-2016/363.

https://betterbuildingssolutioncenter.energy.gov/sites/default/files/attachments/Refsystem.pdf.

Gandhi, P., G. Hunter, R. Haseman, and B. Rodgers. 2017. "Benchmarking Risk by Whole Room Scale Leaks and Ignitions Testing of A2L Refrigerants." AHRTI Report No 9007-01. http://www.ahrinet.org/App_Content/ahri/files/RESEARCH/Technical\%20Results/AHRI 9007$\underline{01 \text { Final Report.pdf. }}$

Gaved, A. 2016. "Carrier opts for HFO 1234ze refrigerants for global chiller range." RAC Magazine (London). February 26, 2016. https://www.racplus.com/news/carrier-opts-for-hfo1234ze-refrigerants-for-global-chiller-range/10003440.article.

Geister, W. 2017. “Refrigerant Update: The Next Transition Has Begun.” Trane. http://nccashrae.org/images/meeting/022217/ashrae trane refrigerant presentation feb 2017 v1c.pdf.

Gluckman Consulting. 2015. "EU F-Gas Regulation Guidance-Information Sheet 7: Foam Insulation Products." February 2015. http://www.gluckmanconsulting.com/wpcontent/uploads/2015/02/IS-7-Insulating-Foam-v3.pdf.

Godwin, D., M. Van Pelt, and B. Ferenchiak. 2014. "Modeling Emissions in Fire Extinguishing." June 12, 2014. https://wescohmb.wordpress.com/2014/07/03/modeling-emissions-in-fireextinguishing/.

Goetzler, W., T. Sutherland, M. Rassi, and J. Burgos. 2014. "Research \& Development Roadmap for Next-Generation Low Global Warming Potential Refrigerants." U.S. Department of Energy. DOE/EE-1154. https://energy.gov/sites/prod/files/2014/12/f19/Refrigerants\%20Roadmap\%20Final\%20Report \%202014.pdf. 
Goetzler, W., M. Guernsey, J. Young, J. Fuhrman, and O. Abdelaziz. 2016. "The Future of Air Conditioning for Buildings." DOE/EE-1394. July 2016.

https://www.energy.gov/sites/prod/files/2016/07/f33/The\%20Future\%20of\%20AC\%20Report \%20-\%20Full\%20Report 0.pdf.

Grand View Research. 2016. “Aerosol Propellant Market Analysis By Product (Hydrocarbons, Dimethyl Ether (DME) \& Methyl Ethyl Ether, Nitrous Oxide And Carbon Dioxide), By Application (Personal Care, Household, Automotive \& Industrial, Food, Paints, Medical) And Segment Forecasts, 2014 - 2025." http://www.grandviewresearch.com/industry-analysis/aerosolpropellants-market.

Grand View Research. 2017. "Polyurethane (PU) Market Analysis By Product (Rigid Foam, Flexible Foam, Coatings, Adhesives \& Sealants, Elastomers), By End-Use (Furniture \& Interiors, Construction, Electronics \& Appliances, Automotive, Footwear, Packaging), \& Segment Forecasts, 2014 - 2025." Report ID: 978-1-68038-262-4. http://www.grandviewresearch.com/industry-analysis/polyurethane-pu-market.

Greenpeace. 2012. "Cool Technologies: Working Without HFCs." http://www.ammonia21.com/files/GP report.pdf.

Gumprecht, W. H. 1982. "Process for the Manufacture of 1,1,1,2-Tetrafluoroethane." U.S. Patent 4,311,863, filed June 11, 1980, and issued January 19, 1982.

Gumprecht, W. H., L. E. Manzer, V. N. Mallikarjuna Rao. 1989. "Process for the manufacture of 1,1,1-trifluorodichloroethane and 1,1,1,2-tetrafluorochloroethane." U.S. Patent 4,843,181 filed Octobe 22, 1987, and issued June 27, 1989.

Hasse, V. 2009. "R290 Air Conditioner." Presented on behalf of GREE, Joint West Asia and South Asia Network Meeting. May 10, 2009.

http://hydrocarbons21.com/knowledge/papersView/gree electric r290 air conditioner.

Hella KGaA Hueck \& Co. 2011. "Refrigerant and compressor oil filling quantities 2010/2011." http://www.autototal.ro/dmdocuments/Catalog\%20Behr\%20Hella.pdf.

Henne, A. L. 1934. "Method of manufacturing halofluoro hydrocarbons." U.S. Patent 1,978,840, filed January 30, 1931, and issued October 30, 1934.

Henne, A. L. 1935. "Fluoration in the presence of chlorine as a catalyst." U.S. Patent 1,990,692, filed January 30, 1931, and issued February 12, 1935.

Hon, C. 2017. True Manufacturing. Personal communication. April 2017.

Honeywell. 2015a. "Low GWP Refrigerants for Refrigeration: Solstice HFOs and HFO Blends." May 2015. https://www.honeywell-refrigerants.com/americas/?document=may-20presentation-national-refrigerants\&download=1. 
Honeywell. 2015b. "Honeywell starts full-scale production of low global-warming propellant, insulating agent, and refrigerant." Morris Township, NJ. January 6, 2015.

https://www.honeywell.com/newsroom/pressreleases/2015/01/honeywell-starts-full-scaleproduction-of-low-global-warming-propellant-insulating-agent-and-refrigerant.

Honeywell. 2016. "Foam Insulation Using Honeywell's Ultra-Low Global-Warming-Potential Material Added To Japanese Industrial Standard." Tokyo, Japan. January 27, 2016. https://www.honeywell-Igwp.com/?press release=foam-insulation-using-honeywells-ultralow-global-warming-potential-material-added-to-japanese-inustrial-standard.

Honeywell. 2017. "Kirloskar Adopts Honeywell's Solstice ${ }^{\circledR}$ Ze Refrigerant For Breakthrough Chiller Line In India." New Delhi, India. February 23, 2017. https://www.honeywellrefrigerants.com/europe/?press release=kirloskar-adopts-honeywells-solstice-ze-refrigerantfor-breakthrough-chiller-line-in-india.

Hydrocarbons21. 2017. "NEXT Series: Hydrocarbon charge limits under spotlight in 2017" January 10, 2017.

http://hydrocarbons21.com/articles/7371/next series hydrocarbon charge limits under spot light in 2017.

ICIS. 1991. "Du Pont gives green light to HFC 134a facility." ICIS Chemical Business. September 2, 1991. https://www.icis.com/resources/news/1991/09/02/14355/du-pont-gives-green-light-tohfc-134a-facility/.

ICIS. 1995. "HFC-152a plant for DuPont." ICIS Chemical Business. February 10, 1995. https://www.icis.com/resources/news/1995/02/10/20455/hfc-152a-plant-fordupont/https://www.icis.com/resources/news/1991/09/02/14355/du-pont-gives-green-lightto-hfc-134a-facility/.

IGSD. 2017. "Tata Motors and MAHLE partner together to develop a prototype Secondary Loop Mobile Air Conditioning System on a vehicle." Institute for Governance \& Sustainable Development. July 13, 2017. http://www.igsd.org/tata-motors-and-mahle-partner-together-todevelop-a-prototype-secondary-loop-mobile-air-conditioning-system-on-a-vehicle/.

IHS. 2014a. "Fluorocarbons." IHS Chemical Economics Handbook. February 2014. https://www.ihs.com/products/fluorocarbons-chemical-economics-handbook.html.

IHS. 2014b. "Polystyrene." IHS Chemical Economics Handbook. December 2014. https://www.ihs.com/products/polystyrene-chemical-economics-handbook.html.

IHS. 2016a. "Chlorinated Methanes." IHS Chemical Economics Handbook. December 2016. https://www.ihs.com/products/chlorinatedmethanes-chemical-economics-handbook.html. 
IHS. 2016b. "Fluorspar and Inorganic Fluorine Compounds." IHS Chemical Economics Handbook. January 2016. https://www.ihs.com/products/fluorspar-and-inorganic-fluorine-chemicaleconomics-handbook.html.

IHS. 2016c. "Polyurethane Foams." IHS Chemical Economics Handbook. October 2016. https://www.ihs.com/products/polyurethane-foams-chemical-economics-handbook.html.

Ingersoll-Rand. 2016. “Ingersoll Rand Innovates HVAC Portfolio Using Next Generation, Low Global Warming Refrigerant, R-452B." https://company.ingersollrand.com/content/dam/ircorp/documents/pdf/2016-DR55-Update-Release-FINAL.pdf.

International Energy Agency (IEA). 2013. "Transition to Sustainable Buildings: Strategies and Opportunities to 2050." OECD/IEA.

https://www.iea.org/media/training/presentations/etw2014/publications/Sustainable Building s 2013.pdf.

IPCC. 2013. Myhre, G., D. Shindell, F.-M. Bréon, W. Collins, J. Fuglestvedt, J. Huang, D. Koch, J.-F. Lamarque, D. Lee, B. Mendoza, T. Nakajima, A. Robock, G. Stephens, T. Takemura, and H. Zhang. Anthropogenic and Natural Radiative Forcing. In: Climate Change 2013: The Physical Science Basis. Contribution of Working Group I to the Fifth Assessment Report of the Intergovernmental Panel on Climate Change. [Stocker, T.F., D. Qin, G.-K. Plattner, M. Tignor, S.K. Allen, J. Boschung, A. Nauels, Y. Xia, V. Bex and P.M. Midgley (eds.)]. Cambridge University Press, Cambridge, United Kingdom and New York, NY, USA. http://www.ipcc.ch/pdf/assessment-report/ar5/wg1/WG1AR5 Chapter08 FINAL.pdf.

Ito, M., C. Dang, and E. Hihara. 2014. "Thermal Decomposition of Lower-GWP Refrigerants." Herrick Laboratories. Purdue University. http://docs.lib.purdue.edu/iracc/1538.

Johnson Controls. 2016. "YORK ${ }^{\circledR}$ YVWA and YMC2 chillers offer unique solutions for customers investing in low-GWP refrigerants." Milwaukee, WI. October 11, 2016. http://www.johnsoncontrols.com/media-center/news/press-releases/2016/10/11/r513a.

Kamalick, J. 2000. "Vulcan to build \$50m HCC-240fa plant in Louisiana." ICIS News. April 5, 2000. https://www.icis.com/resources/news/2000/04/05/109570/vulcan-to-build-50m-hcc240fa-plant-in-louisiana/.

Kandi, V. 2015. "Hydrocarbons - A Viable Natural Refrigerant Solution For Medium Temperature Commercial Refrigeration Applications." ATMOsphere. March 16-17, 2015. Brussels, Belgium. http://hydrocarbons21.com/files/1734 venugopal kandi emerson.pdf.

Kontomaris, K. 2014. "HFO-1336mzz-Z: High Temperature Chemical Stability and Use as A Working Fluid in Organic Rankine Cycles." International Refrigeration and Air Conditioning Conference. Paper 1525.

http://docs.lib.purdue.edu/iracc/1525 
Kujak, S. 2017. Trane. Personal communication. February 2017.

Laboratory News. 2014. "Refrigerant replacement highly toxic on combustion." April 17, 2014. https://www.labnews.co.uk/news/refrigerant-replacement-highly-toxic-on-combustion-17-042014/.

Leck, T. 2009. "Evaluation of HFO-1234yf as a Potential Replacement for R-134a in Refrigeration Applications." $3^{\text {rd }}$ IIR Conf. on Thermophysical Properties and Transfer Processes of Refrigerants. Boulder, CO.

http://www.autototal.ro/dmdocuments/Catalog\%20Behr\%20Hella.pdf.

LED. 2017. “Honeywell Dedicates $\$ 300$ Million Mobile Refrigerants Facility In Louisiana." Louisiana Economic Development. May 16, 2017. https://www.opportunitylouisiana.com/lednews/news-releases/news/2017/05/16/honeywell-dedicates-\$300-million-mobile-refrigerantsfacility-in-louisiana.

Loh, G., J. Creazzo, and M. Robin. 2010. "Further Development of FEA-1100: a Low GWP Foam Expansion Agent." Polyurethane 2010 Technical Conference. Houston, TX. https://www.chemours.com/Formacel/en US/assets/downloads/20101011 CPI paper.pdf.

Majurin, Julie, E. Sorenson, D. Steinke, and M. Herried. 2017. "Chemical Stability Assessments of R-514A and R-1233zd(E)." Proceedings of the ASHRAE 2017 Winter Conference. Las Vegas, NV. January 28-February 1, 2017.

https://www.trane.com/content/dam/Trane/Commercial/global/products-systems/educationtraining/industry-articles/ASHRAE012017 Chemical\%20Stability\%20Assessments\%20of\%20R1233zd(E)\%20and\%20R-514A.pdf.

Manzer, L. E., and V. N. Mallikarjuna Rao. 1988. "Gas-phase fluorination process." U.S. Patent 4,766,260 filed July 7, 1987, and issued August 23, 1988.

Markets and Markets. 2017. "Refrigerant Market by Type (HCFC, HFC, HFO, Isobutane, Propane, Ammonia, and CO2), Application (Refrigerators, Large-scale Refrigerators, Chillers, Air Conditioners, and Heat Pumps), Region - Global Forecast to 2022." Report Code: CH 1536, May 2017. http://www.marketsandmarkets.com/Market-Reports/refrigerant-market-1082.html.

McMenamin, J. M. Robin, G. Loh, and J. Creazzo. 2009. "Development of Novel Blowing Agents for Polyurethane Foams." UTECH Europe 2009, Maastricht, Netherlands, March 31-April 2, 2009.

https://www.chemours.com/Formacel/en US/assets/downloads/UTECH presentation 200903 31.pdf.

Merkel, D. C., R. R. Singh, and H. S. Tung. 2007. "Process for producing fluoropropenes." U.S. Patent 7,230,146 filed October 27, 2003, and issued June 12, 2007. 
Mexichem 2013. "Safety Data Sheet - Hydrogen Fluoride (Anhydrous)." March 2013. http://www.mexichemfluor.com/wp-content/uploads/2016/01/ahf-uk-ghs02.pdf.

Midgley, T. Jr., A. L. Henne, and R. R. McNary. 1934. "Heat Transfer and Refrigeration." U.S. Patent 1,968,050, filed November 19, 1931, and issued July 31, 1934.

Milieu Ltd. 2007. "Review of the implementation of Regulation (EC) No 2037/2000 on substances that deplete the ozone layer-Summary Report." December 14, 2007. http://ec.europa.eu/dgs/environment/pdf/summary report.pdf.

Mitsubishi. 2015. "MHI Develops 'ETI-Z Series' of Next-generation Centrifugal Chillers.” Mitsubishi Heavy Industries, Ltd. Tokyo, Japan. June 10, 2015. http://www.mhi.com/news/story/1506101900.html.

Mitsubishi. 2017. "MHI Thermal Systems Develops "GART-ZE/ZEI" Series as Next-Generation Large-Capacity Centrifugal Chillers Adopting Low-GWP Refrigerant." Mitsubishi Heavy Industries, Ltd. Tokyo, Japan. February 16, 2017. http://www.mhi.com/news/story/1702162051.html.

MOE. 2016. "Act on Rational Use and Proper Management of Fluorocarbons JAPAN." Ministry of the Environment, Government of Japan. March 2016.

https://www.env.go.jp/en/earth/ozone/laws/ozone4.pdf.

Mukhopadhyay, S., H. K. Nair, H. Tung, and M. Van Der Puy. 2007. "Processes for synthesis of tetrafluoropropene." U.S. Patent 7,189,884 filed April 29, 2005, and issued March 13, 2007.

Potter, S. E. 1979. "Manufacture of Halogenated Compounds." U.S. Patent 4,158,675, filed February 7, 1978, and issued June 19, 1979.

Powell, P. 2003. “Honeywell's R-125 Plant Comes On Line." ACHRNews. May 23, 2003. http://www.achrnews.com/articles/95037-honeywell-8217-s-r-125-plant-comes-on-line.

PRLog. 2012. "China expected to be largest production base of HFO-1234yf worldwide." December 28, 2012. https://www.prlog.org/12050134-china-expected-to-be-largestproduction-base-of-hfo-1234yf-worldwide.html.

Rao, R. 2016. "SRF to set up pilot plant for next-gen refrigerant gas HFO 1234yf." Business Standard, April 1, 2016. http://www.business-standard.com/content/b2b-chemicals/srf-to-setup-pilot-plant-for-next-gen-refrigerant-gas-hfo-1234yf-116040100307 1.html.

Rivoira. 2014. "Refrigeration \& Air Conditioning” PE-172-UK 09/14.

Roberts, G. 1993. "Carving up the HFC Market." ICIS Chemical Business. January 10, 1993. https://www.icis.com/resources/news/1993/01/10/34782/carving-up-the-hfc-market/. 
Sakyu, F., Y. Hibino, S. Yoshikawa, R.Tamai, and Y. Gotoh. 2000. "Method for producing 1,1,1,3,3,-pentafluoropropane." U.S. Patent 6,111,150 filed December 12, 1996, and issued August 29, 2000.

Salwan, S. 2015. “Fluorspar Price Tracker: February 2015." Industrial Minerals. February 18, 2015. http://www.indmin.com/Article/3429446/Fluorspar-Price-Tracker-February-2015.html.

Seidel, S., J. Ye, and S. O. Andersen. 2015. "Technological Change in the Production Sector Under the Montreal Protocol." Center for Climate and Energy Solutions. October 2015. https://www.c2es.org/publications/technological-change-production-sector-under-montrealprotocol.

Seidel, S. 2017. Personal communication.

Shankland, I. R., T. Atwood, E. A. E. Lund, and H. T. Pham. 1993. "Azeotrope-like compositions of pentafluoroethane and 1,1,1-trifluoroethane." U.S. Patent 5,211,867 filed July 30, 1991, and issued May 18, 1993.

Shecco Publications. 2012. "The GUIDE 2012: Natural Refrigerants - Market Growth for Europe." https://issuu.com/shecco/docs/guide $2012 \mathrm{nr}$ final.

Shecco Publications. 2013. "2013: Natural Refrigerants Market Growth for North America." http://www.zero-c.com/wp-content/uploads/2014/01/the-guide-2013-Natural-RefrigerantsMarket-Growth-for-North-America2.pdf.

Shecco Publications. 2015. "GUIDE to Natural Refrigerants in China-State of the Industry 2015." http://publication.shecco.com/publications/view/2015-guide-china-natural-refrigerants.

Shecco Publications. 2016. "GUIDE to Natural Refrigerants in Japan-State of the Industry 2016." https://issuu.com/shecco/docs/guide japan-2016.

Sheridan, M. 2004. "DuPont, China's Zhonghao New Materials finalise HFC jv." ICIS Chemical Business. March 15, 2004. https://www.icis.com/resources/news/2004/03/15/566205/dupontchina-s-zhonghao-new-materials-finalise-hfc-jv/.

Sherry, D., M. Nolan, S. Seidel, and S. O. Andersen. 2017. "HFO-1234yf: An Examination of Projected Long-Term Costs of Production." Center for Climate and Energy Solutions. April 2017. https://www.c2es.org/docUploads/hfo-1234-yf.pdf.

Shiflett, M. B. 1993. "Constant boiling compositions of pentafluoroethane, difluoromethane, and tetrafluoroethane." U.S. Patent 5,185,094 filed February 1, 1991, and issued February 9 , 1993.

Singh, R. R., D. P. Wilson, I. Shankland, and H. T. Pham. 2009. "Azeotrope-like compositions of tetrafluoropropenes and bromofluoropropenes." U.S. Patent 7,597,818 filed February 27, 2007, and issued October 6, 2009. 
Singh, R. R., H. T. Pham, D. P. Wilson, R. H. Thomas, and I. Shankland. 2009. "Compositions containing fluorine substituted olefins." U.S. Patent 7,534,366 filed October 27, 2003, and issued May 19, 2009.

Singh, R. R., H. T. Pham, G. M. Knopeck, L. E. Herena, and J. N. Diringer. 2009. “Azeotrope-like compositions of tetrafluoropropene and hydrofluorocarbons." U.S. Patent 7,524,805 filed April 29, 2004, and issued April 28, 2009.

Smithers Rapra. 2014. "Polymer Foams Market Expected to Consume 25.3 Million Tonnes by 2019." http://www.smithersrapra.com/news/2014/may/polymer-foam-market-to-consume25-3-million-tonnes.

Stewart, T.P. 2012. "China's Export Restraints on Fluorspar: The WTO Dispute and its Aftermath." From the Proceedings of the Fluorspar 2012 Conference. Vancouver, Canada. October 22-24, 2012.

http://www.indmin.com/events/download.ashx/document/speaker/6558/a0ID000000X0jZAM AZ/Presentation.

Trade Map. International Trade Centre. http://www.trademap.org/.

Trane. 2015. "Trane Sintesis"M Air-Cooled Chillers are Now Available to Help Reduce Greenhouse Gas Emissions." Trane Inc. Davidson, NC. June 15, 2015. http://www.trane.com/commercial/north-america/us/en/about-us/newsroom/pressreleases/trane-sintesis -air-cooled-chillers-are-now-available-to--help-r.html.

Trane. 2016. "Trane Announces Significant Centrifugal Chiller Line Expansion and Services for the United States and Canada." Trane Inc. Davidson, NC. June 15, 2016. http://www.trane.com/commercial/north-america/us/en/about-us/newsroom/pressreleases/centrifugal-chiller-line-expansion.html.

Trane. 2017. "Trane Expands XStream" ${ }^{\mathrm{TM}}$ Portfolio of Water-Cooled Chillers with the Addition of a High-Efficiency and Low-Environmental Impact Model." Trane, Inc. Brussels, Belgium. April 5, 2017. http://www.trane.com/commercial/europe/uk/en/about-us/newsroom1/pressreleases/trane-expends-xstream.html.

Transparency Market Research. 2016. “Aerosol, SPF (Spray Polyurethane Foam) and Aerosol Propellants (CFC, Hydrocarbons, DME and Others) Market for Paints, Coatings, Medical and Household Applications-Global Industry Analysis, Size, Share, Growth, Trends and Forecast, 2013-2019." http://www.transparencymarketresearch.com/aerosol-propellants-market.html.

Tung, H. S. 1998. "Vapor phase process for making 1,1,1,3,3-pentafluoropropane and 1-chloro3,3,3-trifluoropropene." U.S. Patent 5,710,352 filed September 19, 1996, and issued January 20, 1998. 
Tung, H. S., R. C. Johnson, and D. C. Merkel. 2009. "Process for the manufacture of 1,3,3,3tetrafluoropropene." U.S. Patent 7,592,494 filed July 25, 2003, and issued September 22, 2009.

UNEP. 2002. "Report of the Technology and Economic Assessment Panel-Progress Report." Volume I. April 2002. http://www.unep.fr/ozonaction/information/mmcfiles/3924-e.pdf.

UNEP. 2003. "Report of the Technology and Economic Assessment Panel: HCFC Task Force Report." p.86 http://wedocs.unep.org/bitstream/handle/20.500.11822/8112/77.pdf.

UNEP. 2016a. "The Montreal Protocol on Substances that Deplete the Ozone Layer." Section 1.1. http://ozone.unep.org/sites/ozone/files/Publications/Handbooks/Montreal-ProtocolEnglish.pdf.

UNEP. 2016b. "Project Proposals: China." United Nations Environment Programme. 76th Meeting of the Parties. Montreal, Canada. May 9-13, 2016.

http://www.multilateralfund.org/76/English/1/7625.pdf.

UNEP Ozone Secretariat. 2015. "Fact Sheet 13 Insulating Foam." Workshop on HFC management: technical issues. Bangkok, Thailand. April 20-21, 2015. http://conf.montrealprotocol.org/meeting/workshops/hfc management02/presession/English/FS\%2013\%20Insulating\%20Foam\%20final.pdf.

UNEP Ozone Secretariat. 2017. Data Access Centre. http://ozone.unep.org/reporting/. U.S. ITC. 2014. "1,1,1,2--Tetrafluoroethane from China." Pub. 4503. U.S. International Trade Commission. December 2014. https://www.usitc.gov/publications/701 731/pub4503.pdf.

U.S. ITC. 2016. "Hydrofluorocarbon Blends and Components from China." Pub. 4629. U.S. International Trade Commission. August 2016. https://www.usitc.gov/publications/701 731/pub4629.pdf.

U.S. ITC. 2017. "1,1,1,2--Tetrafluoroethane (R-134a) from China." Pub. 4679. U.S. International Trade Commission. April 2017. https://www.usitc.gov/publications/701 731/pub4679.pdf.

USGS. 2012. "Fluorspar [Advance Release]." In 2012 Minerals Yearbook. U.S. Geological Survey. https://minerals.usgs.gov/minerals/pubs/commodity/fluorspar/myb1-2012-fluor.pdf.

USGS. 2017. "Fluorspar." In Mineral Commodity Summaries 2017. U.S. Geological Survey, p. 6263. https://doi.org/10.3133/70180197.

Vithoontien, V. 2016. "Global Supply and Demand of HCFCs and HFCs." Presentation at Workshop on Implementation Progress of HCFC. World Bank, Washington, D.C. April 1, 2016. http://www.ozonediw.org/attach/56/PresentationWorldBank.pdf. 
VTech Process Equipment. 2017. " $\mathrm{CO}_{2}$ : End-user Driven Change in Vending Machines and Other Applications." http://www.vtechonline.com/pdf/News-PDFs/CO2\%20--\%20End-

user\%20Driven\%20Change\%20in\%20Vending\%20Machines\%20and\%200ther\%20Applications.p df.

Walker, J. 2010. "Fluorspar mining makes comeback." Paducah Sun (KY), March 7, 2010. http://www.paducahsun.com/business/fluorspar-mining-makes-comeback/article 9c11537c5a8f-11e7-ae50-10604b9f0f42.html.

Walters-Terronini, H. Chemours. 2017. Personal communication.

Wang, X., and K. Amrane. 2016. "AHRI Low Global Warming Potential Alternative Refrigerants Evaluation Program (Low-GWPAREP) Summary of Phase II Testing Results." International Refrigeration and Air Conditioning Conference. Paper 1586. Purdue University. http://docs.lib.purdue.edu/iracc/1586.

Wilson, D. P., R. R. Singh, R. H. Thomas, and H. T. Pham. 2012. "Compositions containing fluorine substituted olefins." European Patent 7,534,366 filed October 27, 2003, and issued May 2, 2012.

WTO. 2011. "Panel Report, CHINA-Measures Related to the Exportation of Various Raw Materials." World Trade Organization. WT/DS394/R. July 5, 2011.

https://www.wto.org/english/tratop_e/dispu_e/cases_e/ds394_e.htm

Yamamoto, A., N. Shibata, T. Nakada, and T. Shibanuma. 2002. "Process for producing 1,1,1,3,3pentafluoropropane." U.S. Patent 6,472,573 filed February 5, 1999, and issued October 29, 2002.

Yates, S. F. and R. Gaita. 2002. "Purification of 1,1,1,3,3-pentafluoropropane (R-245fa)." European Patent EP0902776B1, filed April 4, 1997, and issued June 19, 2002.

Zhang, J. and C. Wang. 2014. "China's hydrofluorocarbon challenge." Nature Climate Change 4, no. 11 (2014): 943. doi:10.1038/nclimate2377. 